\title{
Vantage Points: Mock Juror Perception of Body-Worn Camera Video Evidence in Cases Involving Police Use of Force
}

by

Holly Ellingwood

A thesis submitted to the Faculty of Graduate and Postdoctoral Affairs in partial fulfillment of the requirements for the degree of

Doctor of Philosophy

in

Psychology

Carleton University
Ottawa, Ontario

(C) 2019

Holly Ellingwood 


\begin{abstract}
Recent shooting events have led to demands that police officers use body-worn video cameras (BWCs) in order to increase police accountability. While preliminary research has found that BWCs have some general benefits (e.g., they may decrease use of force and reduce false allegations of police misconduct), no research to date has examined the impact of BWC evidence on juror decision-making. Study 1 in this thesis involves a survey of community members to examine public perception of BWC use. In addition to other findings, the survey results indicate that the majority of respondents do not accurately comprehend the limitations of visual footage and are likely to attribute dishonest intentions to police officers when their testimony contradicts BWC footage (especially when the discrepancies are central versus peripheral in nature). Study 2 involves a mock juror study designed to assess how the degree of discrepancies between officer testimony and BWC footage (few vs. many), the nature of these discrepancies (peripheral vs. central), and the presence of expert testimony designed to explain these discrepancies impacts juror decision-making in a case involving allegations of excessive force by a police officer. The results of this study suggest expert testimony and perceptions of police legitimacy (PL) have a significant impact on verdict decisionmaking (and other outcome variables) in such cases. The implications of these results, for theory and practice, are discussed.
\end{abstract}

Keywords: body-worn video camera, use of force, juror decision-making, police psychology 


\section{Acknowledgements}

When I was in my undergraduate, my health suddenly changed to include a permanent disability. I was told there was no point finishing my bachelor's degree because I would never be able to use it. That person didn't realize that their comment would make me more determined than ever. I resolved that I would achieve things despite the attitudinal barriers they threw at me and the many such barriers I continue to face. I not only graduated from my bachelor's but also a master's and now a doctorate. I volunteer in my community to promote healthier spaces and enhance inclusiveness. I have held many exciting positions in my field, and am now in a permanent position where I continue to apply my degrees. I have won awards for my work and am a published academic researcher.

I can't say that it has been easy. As a person with a disability, I find the discrimination and barriers against people with disabilities have been the ones I have found in my life to be the most pervasive and the ones that have the greatest impact on my capacities and well-being. As far as society has come in terms of accessibility, it has much further to go, particularly when it comes to ableism, which causes a great deal of harm.

To my fellow people with disabilities, pursuing graduate work, or any goals outside of the boxes society tries to put us in, I can tell you this - the surest road to success I know is persistence on one's path and perseverance against hardship. Keep in mind why you are striving for your goals. You don't have to be the best, be the most determined, be the person who finishes when other people take things for granted. You 
are valuable as you are for who you are, and please don't ever forget it. Persist. Everyone has value, everyone.

My journey was a far longer and harder road than I could have imagined and one I could not have travelled without support from various people.

First and foremost, thank you to my family, especially my mother, Lawanda Willar, and my sister, Wendy Ellingwood, for all their support throughout the years. I could not have done this without you.

Thank you to my supervisor, Dr. Craig Bennell, for his support and insights throughout the years. Thank you also to my Committee members, Dr. Shelley Brown, Dr. Evelyn Maeder, Dr. Tara Burke, and Dr. Diana Majury for their invaluable time. This has been a long road and thanks should also go to Etelle Bourassa for every time she took time out of her incredibly busy schedule to listen to a student's concerns and offer a kind word of encouragement. Thanks to my former lab mates Karla Emeno and Rebecca Mugford for their ongoing friendship and support. Thanks also to Brittany Blaskovits for her help when asked and encouraging words. Thanks also to the following former and current members of Dr. Maeder's lab - Laura McManus, Susan Yamamoto and Logan Ewanation, who provided invaluable insights when I first took on the massive challenge of conducting a juror study. You were a tremendous help. Thanks to the Rebel Alliance Lab - couldn't have gotten here without you Beth Schultheis, Frances Churcher and Heidi O'Hagan with additional thanks to Mitch and the Churchers. Thank you to other Carleton colleagues Emad Talisman, Dr. Maaike Leslie Helmus, Geoff Wilton, Kaitlyn Wardrop, Dr. Emily Pica, Dr. Danay Novoa, Dr. Chantal Bacev-Giles, and Melissa Salmon for friendship, support and unexpected kindnesses. Thanks also to Heather Cross 
of Library Services for her incredible help throughout the years - it has been such a pleasure.

Thanks to the Paul Menton Centre; with specific thanks to Laura Brawn for being a sounding board and to Jason Goveas, tech support extraordinaire. Without your help Jason, I would not have been able to take the courses that required technical accommodations that were needed to complete my degree.

Gratitude goes to the Department of Law and Legal studies at Carleton University. Thank you to Dr. Sheryl Hamilton, Dr. Dawn Moore, and Dr. Dale Spencer for proving your insights and offering your time to share with me your knowledge and suggestions. You helped point me in the right direction and broaden my scope of understanding of visual legal evidence and visual culture and introduce me to visual criminology. Your support has been invaluable to my project and I am deeply grateful to each of you.

Gratitude must also be expressed to the many people who have given me support throughout this challenging period, including: Carole and Tom Fulton and the Crop-aWhile community, my friends at Domenic's Academy of Music for their many kindnesses, Rosie Veliz and Karen Fish for their faith, and my Orleans Pride crew including Jennifer, Janice, Susan, Tamara, Tracey, Renée, Bev, Maggie for all the time they took to listen to my concerns about my future and offer support. Thanks to Murray and Marion Smith, Yvonne Delorme, Abida, Jill Vyse, and Mary-Anne McManus for listening and being such dear friends. To Krista Budgen for her friendship, Mel for being there when I really needed her, "Hutch" Hutchinson, and Hayley Melia for unflagging friendship, and thanks to Sarah Harmer-Norris and Alyssa Lake for understanding when 
others didn't. A wealth of gratitude to Tannis Vine and Jasmine Brown and their lovely families for reminding me of the importance of kindness and that it can be spent freely. Thanks also to my steampunk and diesel punk friends, Kathleen, Henri, Bruce, Rebecca, Heather, Adrien, Gerry, Janvier, and others for the fun adventures and support. Thank you to everyone at the Orleans Dojo of Yoseikan Aikido for their support, and in particular to Sensei Joseph Capogreco for his guidance. Special thanks to friends old and new - Kurt Ala-Kantti, Sarah Wibberley and Janel Goyette, for being such outstanding people and so generous with their time and help. Thanks to Lina, who knows the reasons why.

Thanks to my many work colleagues and friends past and present who have been supportive throughout this journey: Dr. Jessica Service for being an extraordinary human being, Anton Maslov, Danièle Laliberté, Fatima Mawani, Karen Koundakjian, Kim McDonald, Valerie Bowman, Pascale Fournier, Austin Lawrence, Kelly MortonBourgon, Guy Bourgon, Lisa Ha, Susan McDonald, and more, including my team at PPAU - Chad, Ayaan, Sukhbir, Jason, and Diane for your support. To my pet family, the ones recently lost - Sam and Fred whom we miss so dearly. To Max and Theodore, I'm sure you'll be glad to have more of my attention. And to Napoleon, joy of my heart, I wish you could have been with us longer to share this moment with me. If I forgot anyone, my heartfelt apologies.

This work is dedicated to my grandmother, Mary McDonald, who helped, along with my mother, to teach me about strength of character and the importance of perseverance regardless of the obstacles. I wish you could have been here to see me get that doctorate finally grandma. Miss you, love you. 


\section{Table of Contents}

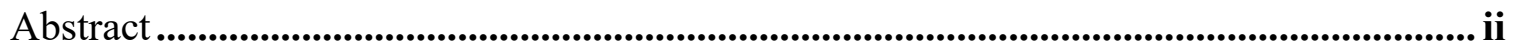

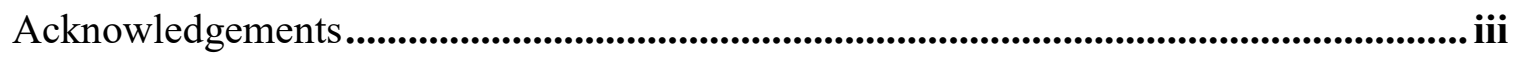

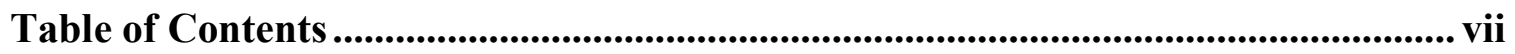

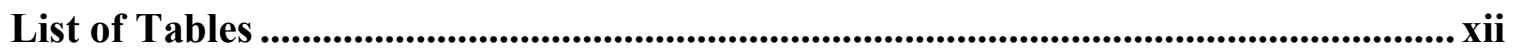

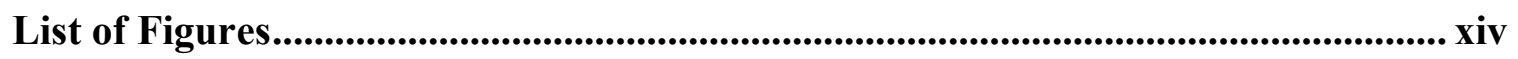

List of Appendices........................................................................................................... XV

Chapter 1: Introduction .............................................................................................................. 1

Chapter 2: Providing context - Police Use of Force and the Rise of Body-worn

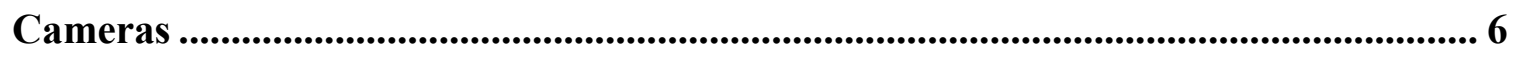

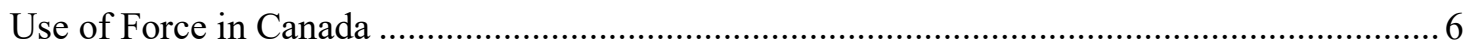

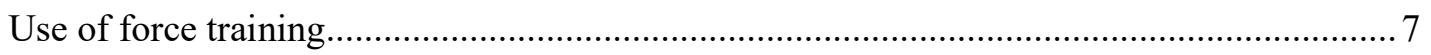

Challenges with making appropriate use of force decisions ........................................... 9

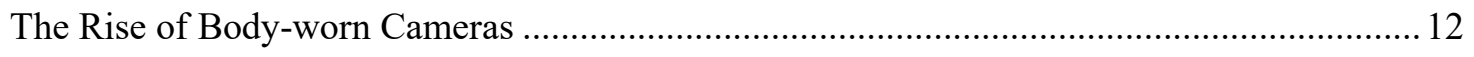

Differences between BWCs and human sensory systems ............................................... 13

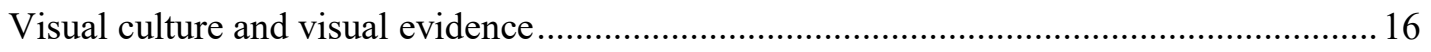

Does an image depict the actual 'truth' of an event? ..................................................... 17

Why does an image depend on interpretation? .............................................................. 19

A real-world example: The Rodney King trial............................................................. 21

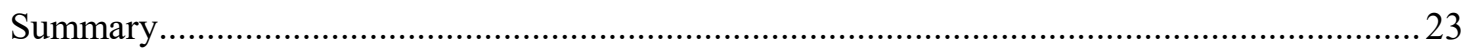

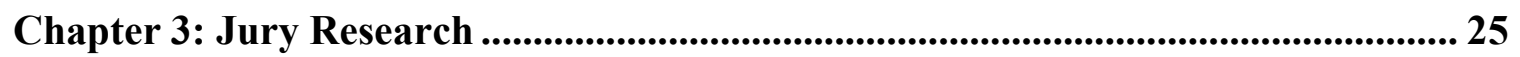

The Story Model and the Multi-Level Theory of Jury Decision-making ................................25

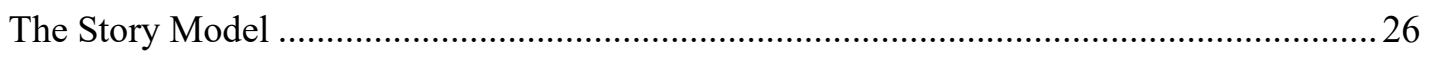

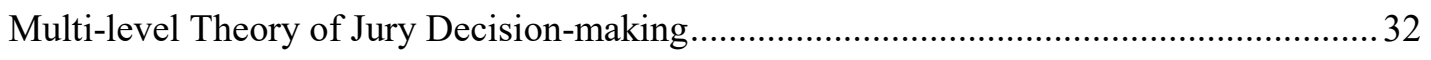

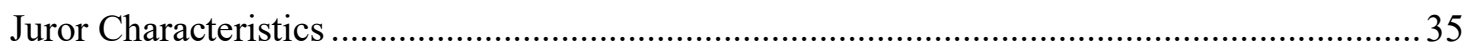




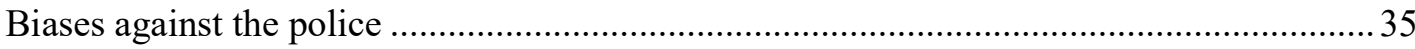

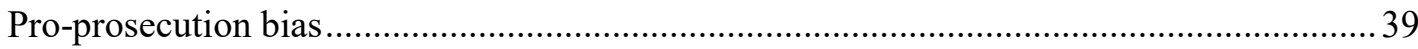

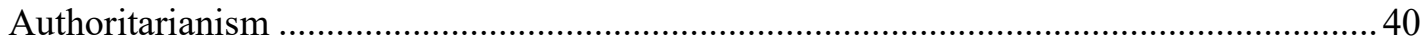

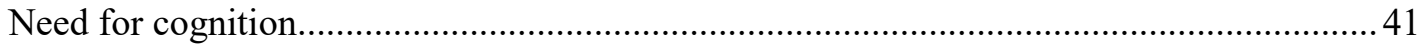

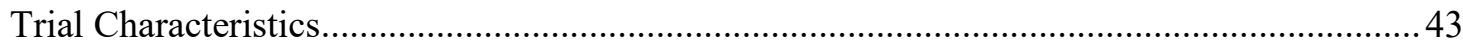

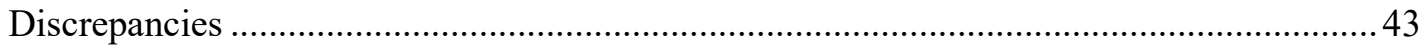

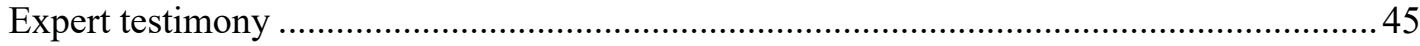

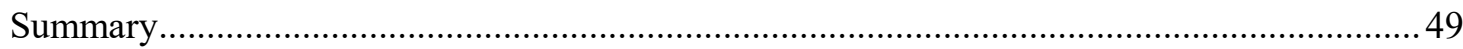

\section{Chapter 4: Public Attitudes and Beliefs Regarding Body Word Camera Use by the} Police (Study 1)........................................................................................................... 51

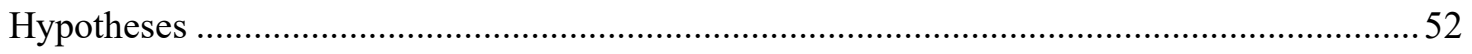

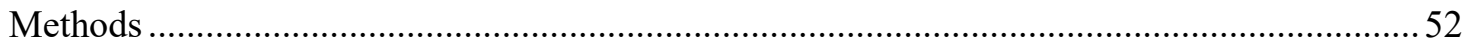

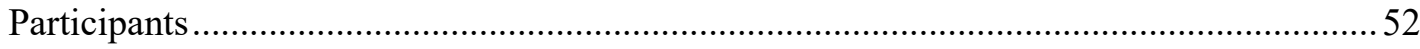

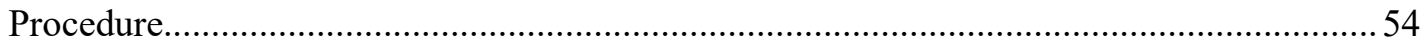

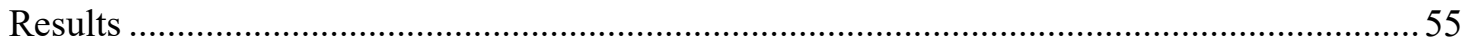

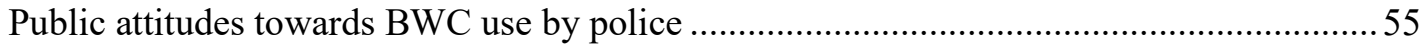

Public beliefs and knowledge regarding visual evidence and its limitations ....................... 61

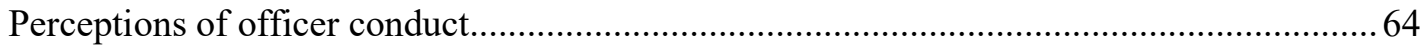

General opinions about the police and the criminal justice system................................... 65

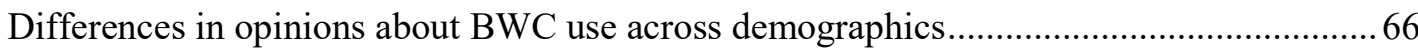

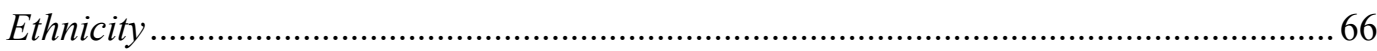

Sex fon

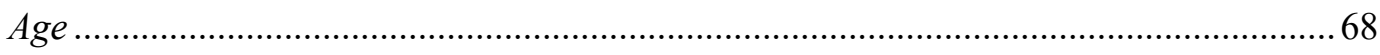

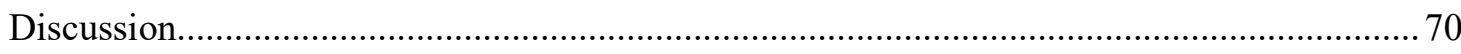

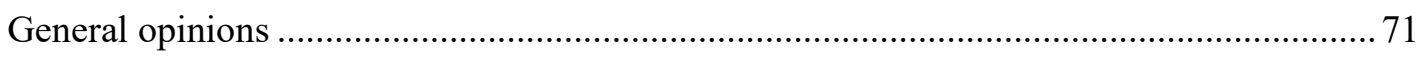

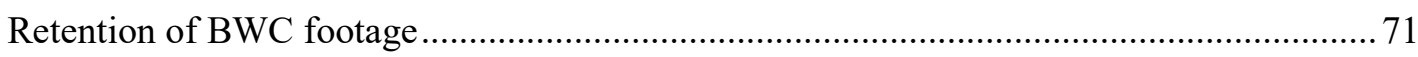




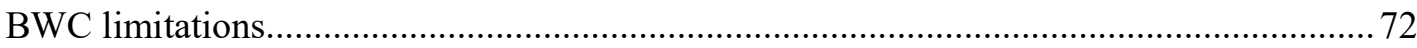

Opinions about police conduct and the criminal justice system ...................................... 73

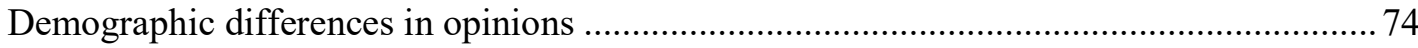

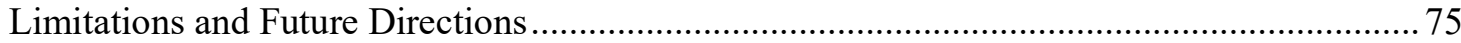

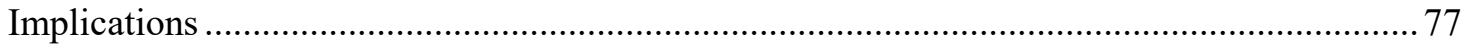

Chapter 5: Mock Juror Perceptions of Body-worn Video Evidence in a Use of Force

Case (Study 2).............................................................................................................................. 80

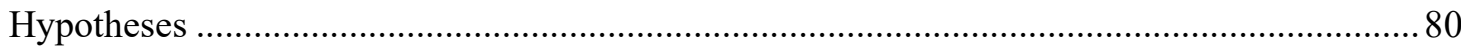

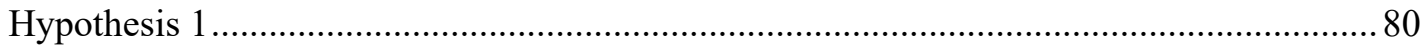

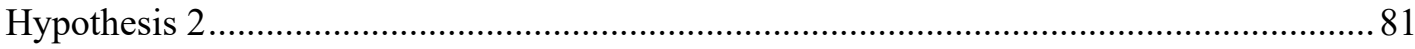

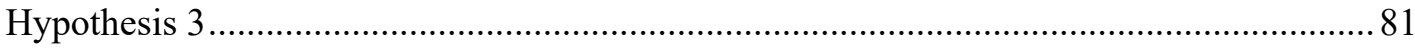

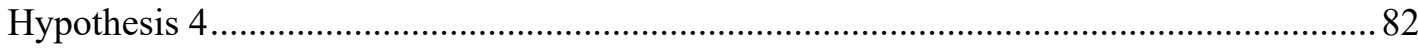

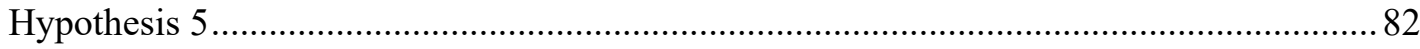

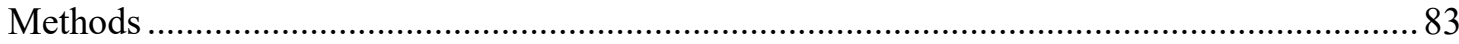

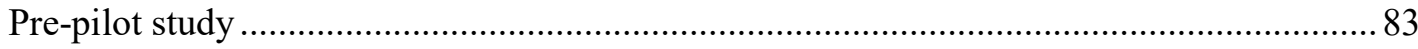

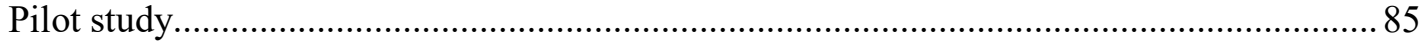

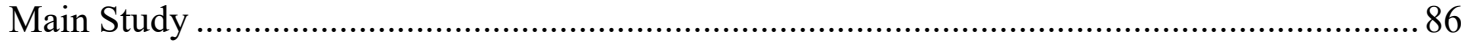

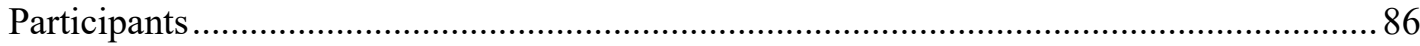

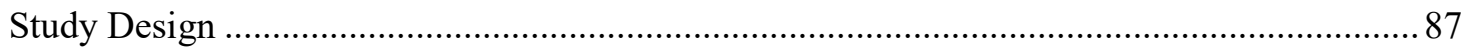

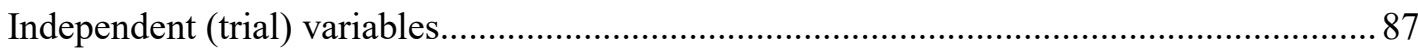

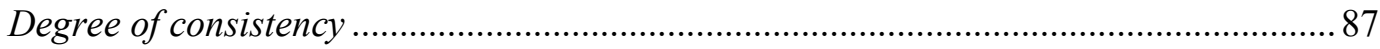

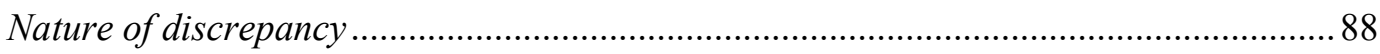

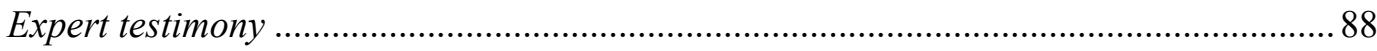

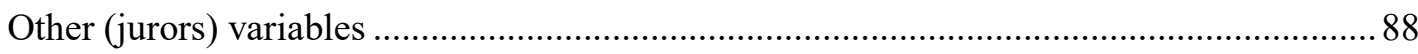

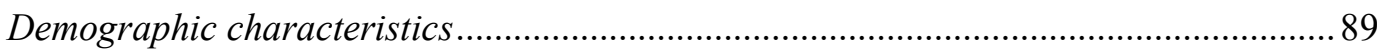

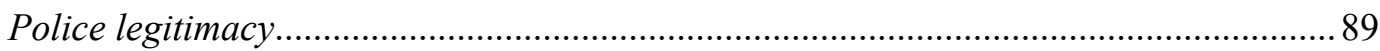




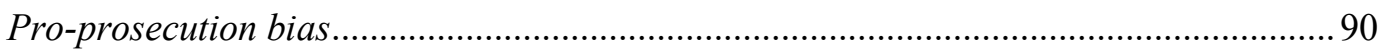

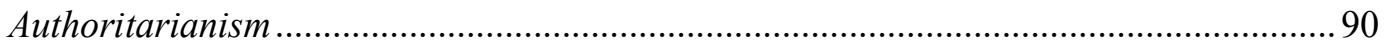

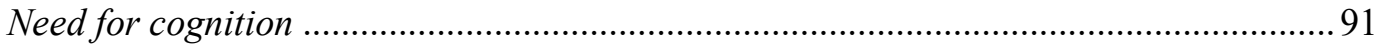

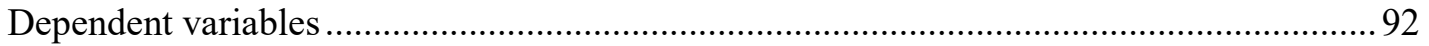

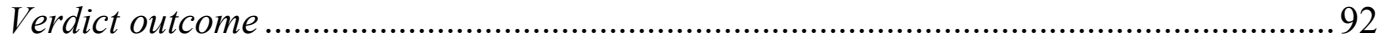

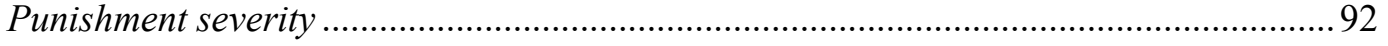

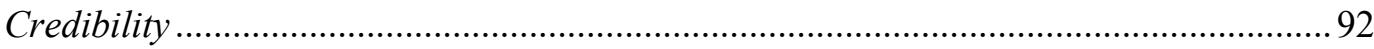

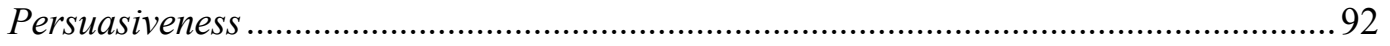

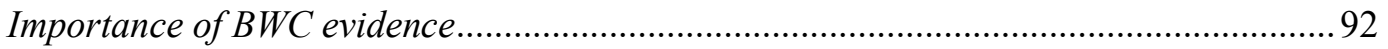

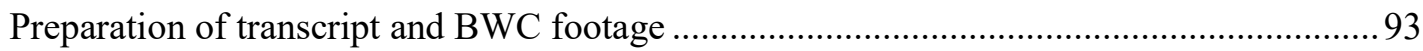

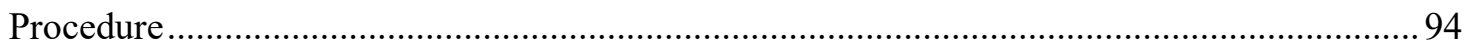

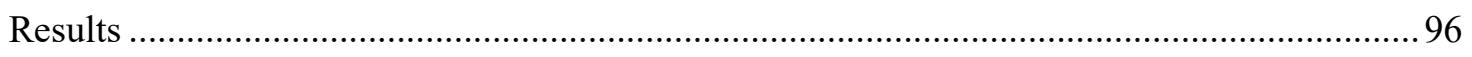

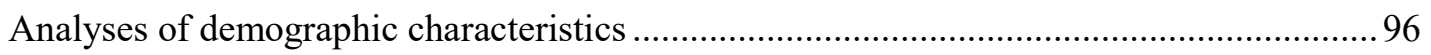

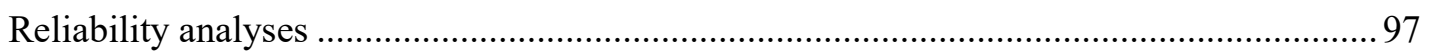

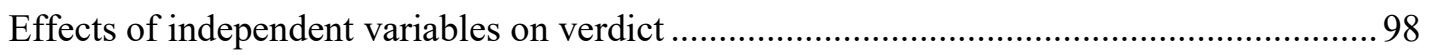

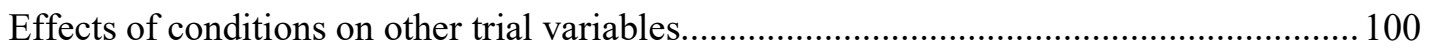

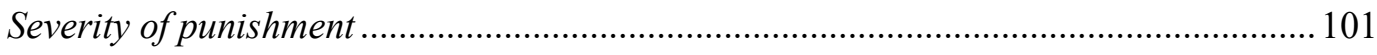

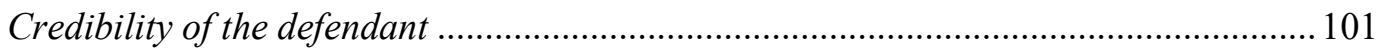

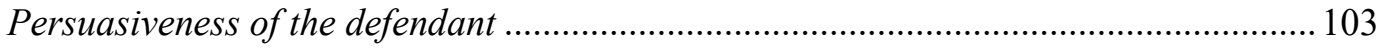

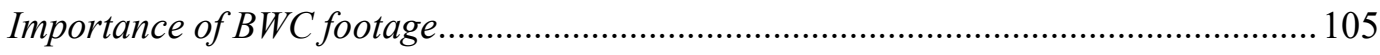

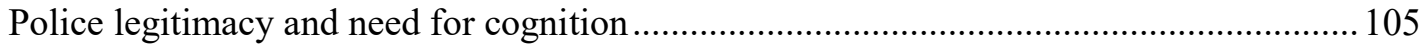

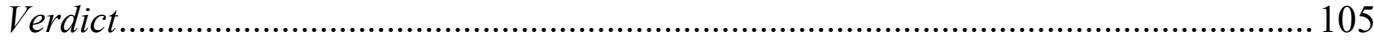

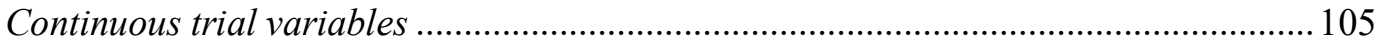

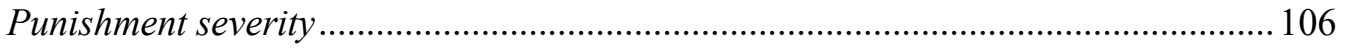

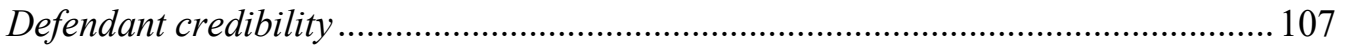

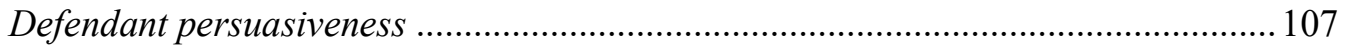




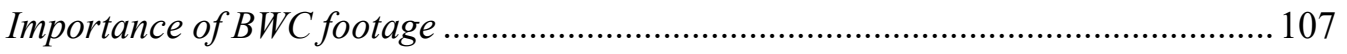

Exploration of possible interactions ....................................................................... 107

Additional exploratory analyses of the PL scale ...................................................... 107

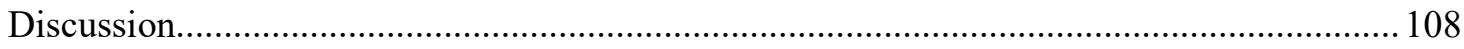

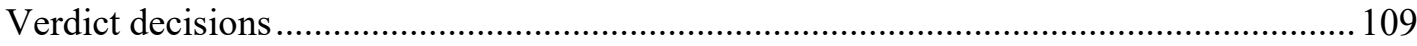

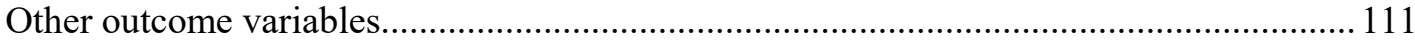

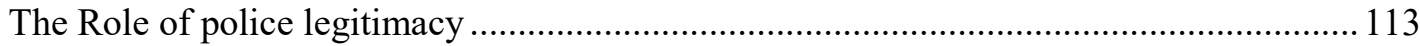

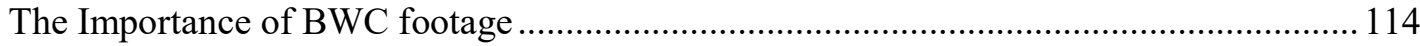

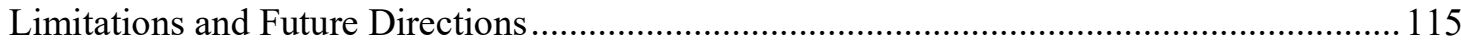

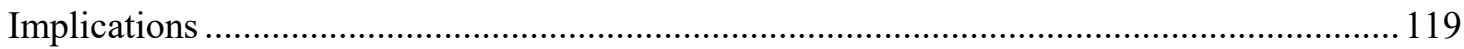

Chapter 6: General Discussion and Conclusion............................................................ 121

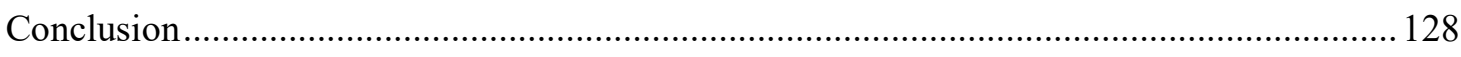

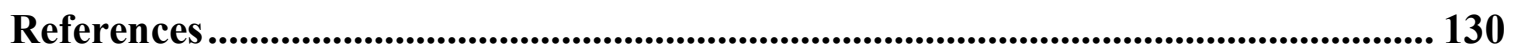




\section{List of Tables}

Table 1 Percentage of Officers Involved in Use of Force Encounters who Experienced

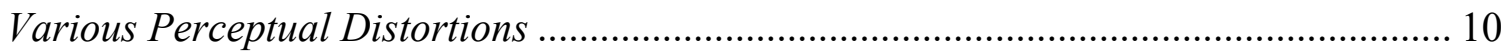

Table 2 Public Attitudes Towards Police Use of BWCs ................................................. 58

Table 3 Public Opinion on When Police Should Not Use BWCs ................................... 59

Table 4 Public Opinion on Retention Length of BWC Footage by Police Services ......... 60

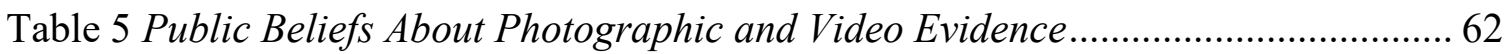

Table 6 Public Knowledge About Photo and Video Limitations .................................... 64

Table 7 Pre-pilot test results regarding what constitutes minimal, moderate, and many

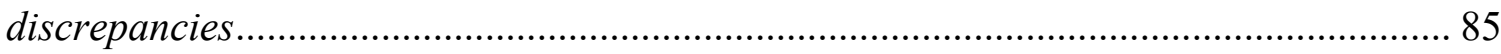

Table 8 Predicting effects of degree of discrepancy, nature of discrepancy and presence

of expert testimony on verdict — summary of logistic regression analysis .................... 99

Table 9 Frequency and percentage of verdict decisions (by condition) ........................ 100

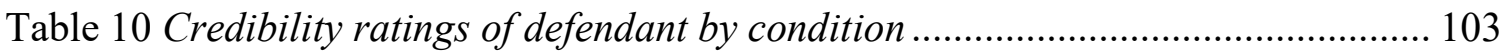

Table 11 Persuasiveness ratings of defendant by condition ........................................ 104

Table 12 Summary of regression analyses for PL and NC on continuous trial outcome

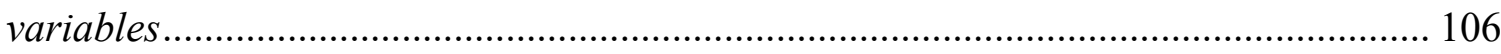

Table 13 Opinions about BWC Use by Ethnicity ......................................................... 199

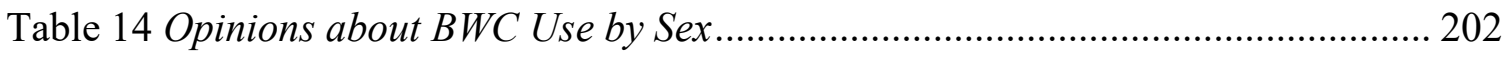

Table 15 Opinions about BWC Use - Regressions for Age ....................................... 205

Table 16 Opinions about BWC Use - Significant Results for Age and Nominal

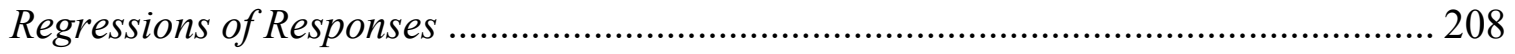

Table 17 Opinions about BWC Use - Odds Ratio ................................................... 209 
Table 18 Predicting effects of police legitimacy subscales on verdict - Summary of logistic regression

Table 19 Predicting effects of police legitimacy subscales and need for cognition on severity of punishment - Summary of regression

Table 20 Predicting effects of police legitimacy subscales and need for cognition on defendant credibility - Summary of regression

Table 21 Predicting effects of police legitimacy subscales and need for cognition on defendant persuasiveness - Summary of regression 


\section{List of Figures}

Figure 1. The National Use of Force Framework (NUFF) model..................................... 8

Figure 2. The Story Model of jury decision-making (adapted from Pennington \& Hastie,

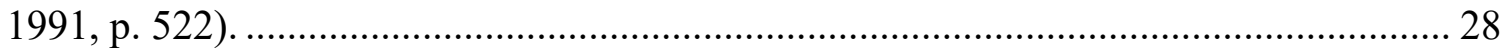

Figure 3. Director's Cut Model of Juror Decision-making (adapted from Devine, 2012, p.

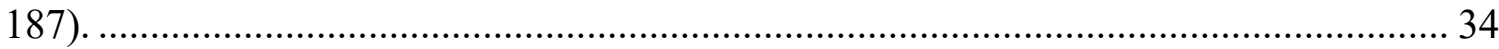




\section{List of Appendices}

Appendix A Informed Consent Form ................................................................ 150

Appendix B Demographics Measure ................................................................. 152

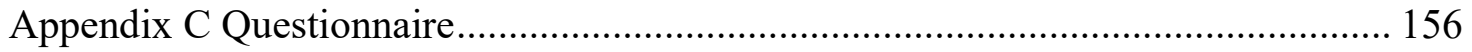

Appendix D Contact Form.......................................................................... 163

Appendix E Police Legitimacy Scales ................................................................... 164

Appendix F Juror Bias Scale.................................................................... 166

Appendix G Items of the Revised Legal Attitudes Questionnaire........................... 168

Appendix H Short Form of the Need for Cognition Scale...................................... 170

Appendix I Consent Form for Pilot for Study 2 .............................................. 172

Appendix J Consent Form for Study 2 ....................................................... 174

Appendix K Study 2: Trial Transcript ....................................................... 176

Appendix M Jury Questionnaire for Study 2 ...................................................... 194

Appendix N Debriefing Form ........................................................................ 198

Appendix O Opinions about BWC Use and Ethnicity ....................................... 199

Appendix P Opinions about BWC Use and Sex .................................................. 202

Appendix Q Opinions about BWC Use and Age............................................. 205

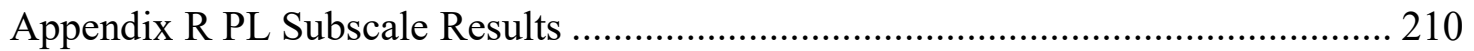




\section{Chapter 1: Introduction}

On August $9^{\text {th }}, 2014$, an unarmed 18-year-old Black man by the name of Michael Brown was shot and killed by a White police officer in Ferguson, Missouri. Conflicting reports of the incident hit the media, with some accounts saying the shooting was unjustified and others saying the officer had no choice but to act with lethal force. Following the incident, racial tensions ignited and riots erupted across Ferguson. Buildings were burned to the ground when a grand jury gave the verdict that no criminal charges would be laid in the shooting (Goodan, 2014). It was a verdict heard around the world and the riots made international news.

This verdict, whether right or wrong, was of critical importance for several reasons, not the least of which is that the events surrounding the Ferguson shooting have potentially changed policing in North America forever - particularly the importance that is placed on police accountability. Immediately following the verdict in this case, President Barack Obama pledged \$263 million dollars to fund 50,000 body-worn cameras (BWCs) for American police agencies in response to plummeting public trust in police services (Sink, 2014). In addition, on May $1^{\text {st }}, 2015$, the United States (US) Department of Justice announced a \$20 million Body-Worn Camera Pilot Partnership Program to determine how BWCs might enhance transparency in policing, promote police accountability, and advance public safety.

Politicians and members of the public across North America are clamouring for the use of BWCs by police, and this call is being extended into other areas of the criminal justice system, such as corrections (ABC, 2015). It may be that BWCs can have the impact that many people hope for by enhancing transparency and increasing 
accountability, not only for police services, but also for the public (e.g., by reducing false accusations of police misconduct). However, the reality is that little empirical research has been conducted to examine the impact of BWCs, despite the fact that BWCs are being used by many police agencies around the world. ${ }^{1}$ The fact of the matter is that we currently do not know how BWCs will impact policing, or the public that police agencies serve. For example, while the public believes that footage from BWCs will provide clear evidence of wrong doing on the part of police officers when it does occur, it is not clear that this will always be the case (e.g., BWC footage may not always be adequate for making such a determination).

An important gap in our knowledge that is of particular concern, especially for the police, relates to how the judicial system will handle BWC footage. While some issues of relevance to the judicial context are being discussed in the BWC literature (e.g., how the police will handle privacy issues if BWC footage is to be introduced as evidence in court; Ellingwood \& Yamamoto, 2014; White, 2014), others issues have, to date, been totally ignored. For example, there appears to be no published research has examined how juror members will evaluate BWC footage and how much weight they will put on such evidence, relative to other evidence. Understanding these issues becomes even more important when one considers the sort of court cases where BWC evidence is likely to be introduced; cases that often involve allegations of excessive force on the part of the police. Not only are the potential consequences for police officers in such cases severe,

\footnotetext{
${ }^{1}$ Body-worn cameras are being used in several police services in the US, Scotland, United Kingdom (UK), and Australia, among other countries, and they are currently being pilot tested in a number of cities in Canada (e.g., Amherstburg, Durham, Edmonton, Calgary, Montreal, Victoria, Vancouver, Saint John, and Toronto), in addition to the Royal Canadian Mounted Police (RCMP). The pilot tests for Montreal, Edmonton, Victoria, and the RCMP found mixed results; the other services are continuing to evaluate the effectiveness and feasibility of BWCs.
} 
but research has also suggested that members of the public endorse a variety of use of force myths (Corey \& Bennell, 2008). These myths may inappropriately influence how jurors assess evidence, including BWC footage, in trials involving use of force by the police (Blaskovits, Ellingwood, Mugford, \& Bennell, 2015; Korva, Yamamoto, \& Bennell, 2014).

Indeed, existing research indicates that the public does not fully comprehend the challenges that officers face when making decisions under stress, nor the processes that are likely to be compromised under such conditions (e.g., performance and decisionmaking; Johnson, 2007). This lack of understanding will no doubt impact the way jurors evaluate evidence presented in the sorts of cases described above. For example, jurors may not appreciate why a police officer's testimony about a use of force encounter contradicts BWC footage of that encounter, leading them to perceive any contradictions as an attempt by the officer to deceive the court. The public's misunderstanding of use of force dynamics may increase the need for expert witnesses to explain the psychological and physiological realities of use of force decision-making so that jurors can base their decisions on an accurate assessment of what they are hearing in the courtroom.

In this dissertation, two studies were conducted with the goal to better understand how potential jurors will evaluate BWC evidence, particularly in court cases that involve allegations of excessive force on the part of the police. The first study involves a survey that examines public perception of BWC use by police officers. While some survey research has been conducted in this area, most surveys focus on the attitudes and opinions of police officers rather than the public (Brown, 2013; Jennings, Fridell, \& Lynch, 2014; Todd, 2015; however, see Crow, Snyder, Crichlow, \& Msykla, 2017; Sousa, Miethe, \& 
Sakiyama, 2015 for recent exceptions). In contrast, this survey examines public perception of BWC use by police (e.g., Does the public think BWCs will be useful? Do people have concerns regarding privacy, or when and where police will turn on BWCs? How long does the public think police video footage should be stored before being destroyed?). Of particular importance for the current dissertation are survey questions that tap into public attitudes related to different forms of evidence that may be used in court cases involving allegations of excessive force (e.g., video versus verbal testimony). The survey provides insight into what the public thinks of BWCs, which may shed light on how BWC footage will be evaluated in a courtroom by jurors.

Drawing on the survey results, the second study in this dissertation explores three issues that are important to consider when BWC footage is used as evidence in court cases involving allegations of excessive force by police. The first issue relates to how discrepancies between a police officer's testimony about an event and BWC footage of that event might impact jurors, particularly when the quantity of such discrepancies varies. The second issue examined in Study 2 is how the nature of these discrepancies influences juror decision-making; specifically, whether jurors make distinctions between discrepancies that are central to the event in question versus peripheral. The final issue examined in this study focuses on the importance of expert testimony about use of force decision-making (specifically, the impact of stress on decision-making).

The structure of the dissertation is as follows. To provide context to these studies, Chapter 2 will be used to discuss police use of force and the emergence of BWCs as a way of enhancing police transparency and accountability. The main focus of that chapter is to demonstrate how performance during (and after) use of force encounters can be 
compromised by factors such as stress, and to show how this may lead to challenges when BWC footage of those encounters is used as evidence in a judicial context. Chapter 3 will situate these discussions in the courtroom by reviewing models of jury/juror decision-making. The primary goal in that chapter is to demonstrate how the various factors examined in the proposed mock juror study relate to these models. Following these chapters, Chapter 4 presents the methods, results, and discussion for the public survey (Study 1). Chapter 5 then presents the methods, results, and discussion for the mock juror study (Study 2). In Chapter 6, the final chapter, a general discussion and conclusion is provided. 


\section{Chapter 2: Providing context - Police Use of Force and the Rise of Body-worn}

\section{Cameras}

Given the focus in this dissertation on how mock jurors evaluate BWC footage when it is presented as evidence in cases involving the alleged use of excessive force on the part of the police, it is important to provide some background on police use of force and BWCs before discussing how these issues might be assessed by jurors in court. The goal of this chapter is to provide context for the reader so that the potential implications of the proposed studies are clear.

\section{Use of Force in Canada}

In Canada, police officers are legally permitted to use force, including lethal force, under certain conditions. Specifically, Section 25 of the Criminal Code of Canada deals with the authority to use force and describes the conditions under which the use of force will be deemed legally appropriate (Criminal Code, RSC, 1985, c. C-46, s. 25). Section 25 emphasises that use of force is justified if officers act on reasonable grounds and only use as much force as is necessary to enforce the law and/or maintain public safety. According to Section 25, "reasonable grounds" is dependent on the officer's reasonable belief that such force was necessary. Thus, what is reasonable is, to a large extent, based on an officer's perception. It has further been acknowledged in two Canadian court cases that an officer's perception of threat is based on an assessment of the incident in question, and that this assessment can be hampered if decisions need to be made in a split-second (Cluett v. The Queen, 1985; Graham v. Connor, 1989). Given this, courts in North America take the position that they must assess an officer's decisions 
from the perspective of a decision-maker who was at the scene at the time, likely faced with challenging conditions of stress and uncertainty.

Use of force training. Because officers are permitted to use force in the course of carrying out their duties, use of force training is provided to them on a regular basis. The primary goal of this training is to teach them how to de-escalate potentially dangerous incidents, and to use force appropriately when it must be used (Beahen, 2008; Canadian Association of Chiefs of Police [CACP], 2000). With respect to their use of force training, Canadian police officers are taught how to use a variety of intervention options, including verbal commands, empty hand techniques (e.g., strikes and stuns), intermediate weapons (e.g., pepper spray and conducted energy weapons), and lethal force (CACP, 2000). In line with the Criminal Code, particular attention is paid to training officers how to use these techniques in a reasonable fashion and only when they are necessary (Beahen, 2008; CACP, 2000).

To assist instructors with these tasks, Canadian police agencies tend to rely on use of force models in their training, such as the National Use of Force Framework (NUFF; see Figure 1). The purpose of this heuristic device is to promote "continuous critical assessment and evaluation of each situation... [and to assist] officers to understand and make use of a variety of force options to respond to potentially violent situations" (CACP, 2000, p. 3). As seen in Figure 1, the assessment by an officer begins in the inner circle. Specifically, officers are encouraged to continually assess any encounter by taking into account relevant environmental issues (e.g., bystander presence), subject behaviours (e.g., threat cues), and tactical considerations (e.g., proximity of back up). Based on the totality of the information the officer is assessing, the officer can decide on the 
appropriate use of force strategy that is required to deal with the situation (represented by the outer ring). The positioning of these use of force strategies in relation to suspect behaviour, which is represented in the grey ring and can vary from cooperative to threat of grievous bodily harm or death, is meant to imply the need for a proportionate response. For example, it would be unreasonable for an officer to use lethal force if the suspect was being cooperative, but it may be reasonable if the suspect is threatening to kill the officer.

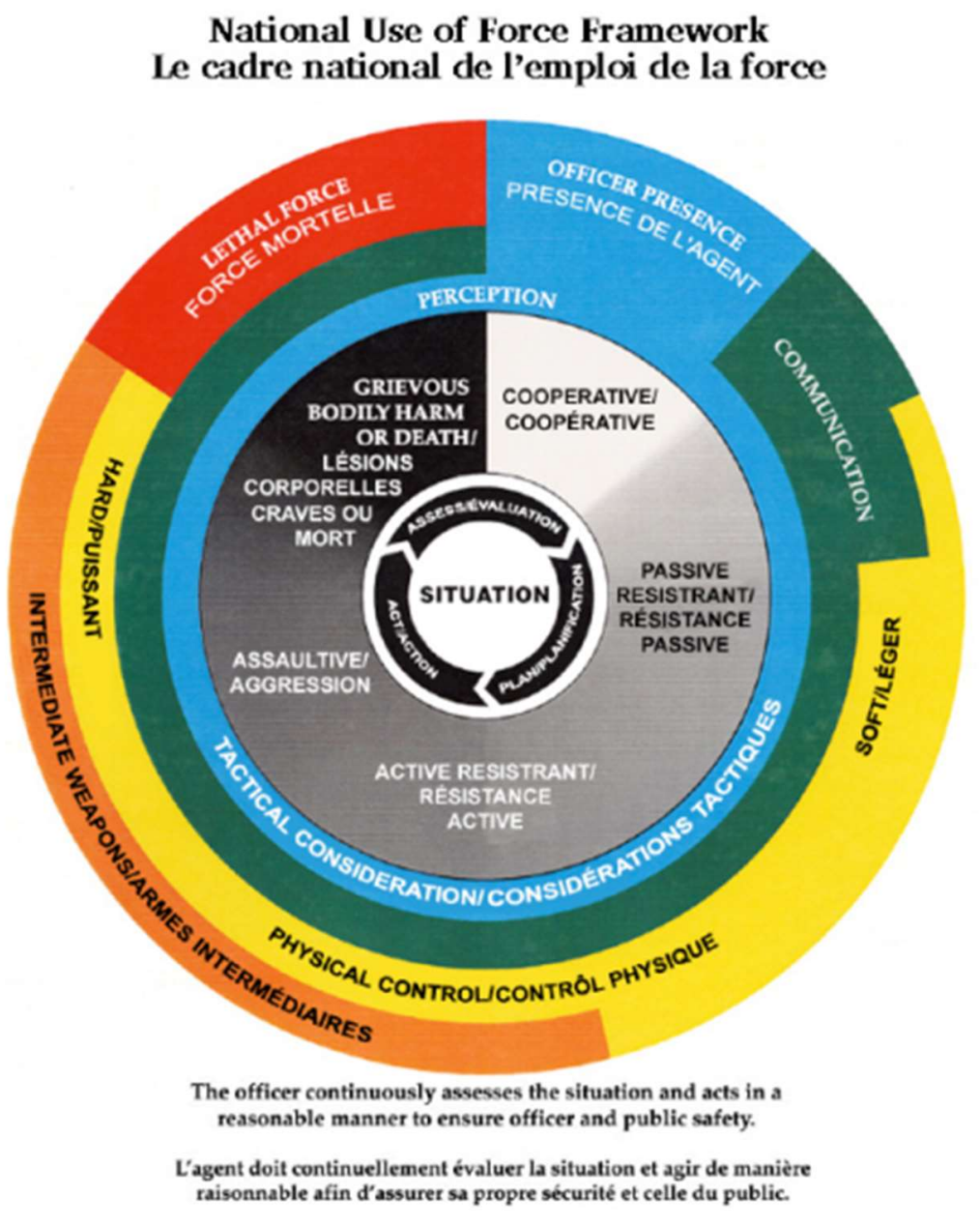

Figure 1. The National Use of Force Framework (NUFF) model.

(Source: Ontario Ministry of Community Safety and Correctional Services

https://www.mcscs.jus.gov.on.ca/english/PSIS/BasicTesting/SecurityGuard StudyGuide/UseofForceTheory/SG_use_of_force.html) 
Challenges with making appropriate use of force decisions. Despite the use of force training officers receive, making appropriate (i.e., reasonable) use of force decisions can still be challenging. In large part, this is because officers can be experiencing high levels of stress when having to make these decisions. This stress can cause physiological changes in the body, including the activation of sub-cortical parts of the brain that are focused more on survival than higher level thinking, and increased blood flow, respiration, and hormones that engage the fight-or-flight response (Sharps, 2009). These changes can negatively influence the officers in a variety of ways.

For example, under such conditions of physiological stress, police officers report experiencing a range of perceptual distortions that may compromise their performance during and after high stress encounters with the public (e.g., Artwohl, 2008; Honig \& Sultan, 2004; Klinger, 2004). These distortions can include, but are not limited to, sound anomalies (e.g., diminished sound volume), tunnel vision (e.g., only seeing central versus peripheral details), time distortions (e.g., a sense of time speeding up), dissociation and paralysis (e.g., feeling disconnected from the situation), going on automatic pilot (e.g., responding in a predetermined way, even if inappropriate), intrusive thoughts (e.g., thoughts that an officer cannot stop, often unrelated to the incident), and memory errors (e.g., forgetting significant aspects of the event). Table 1 provides a summary of research that has examined the prevalence of perceptual distortions experienced by police during use of force encounters (based on interviews and/or surveys following the incident). 
Table 1

Percentage of Officers Involved in Use of Force Encounters who Experienced Various Perceptual Distortions

\begin{tabular}{|c|c|c|c|c|c|c|c|}
\hline & $\begin{array}{c}\text { Solomon } \\
\text { and Horn } \\
(1986)\end{array}$ & $\begin{array}{c}\text { Campbell } \\
\text { (1992) }\end{array}$ & $\begin{array}{l}\text { Honig } \\
\text { and } \\
\text { Roland } \\
\text { (1998) }\end{array}$ & $\begin{array}{c}\text { Klinger } \\
(2001)\end{array}$ & $\begin{array}{c}\text { Rivard } \\
\text { et al. } \\
(2002)\end{array}$ & $\begin{array}{l}\text { Honig } \\
\text { and } \\
\text { Sultan } \\
(2004)\end{array}$ & $\begin{array}{c}\text { Artwohl } \\
(2008)\end{array}$ \\
\hline Sample $(N)$ & 86 & 92 & 348 & 80 & 115 & 982 & 157 \\
\hline $\begin{array}{l}\text { Sounds were } \\
\text { quieter }\end{array}$ & $51 \%$ & $42 \%$ & $51 \%$ & $82 \%$ & $\mathrm{x}$ & $51 \%$ & $84 \%$ \\
\hline $\begin{array}{l}\text { Sounds were } \\
\text { louder }\end{array}$ & $18 \%$ & $\mathrm{x}$ & $23 \%$ & $20 \%$ & $\mathrm{x}$ & $21 \%$ & $16 \%$ \\
\hline $\begin{array}{l}\text { Tunnel } \\
\text { Vision }\end{array}$ & $39 \%$ & $\mathrm{x}$ & $45 \%$ & $42 \%$ & $\mathrm{x}$ & $51 \%$ & $79 \%$ \\
\hline $\begin{array}{l}\text { Automatic } \\
\text { Pilot }\end{array}$ & $\mathrm{x}$ & $\mathrm{x}$ & $\mathrm{x}$ & $\mathrm{x}$ & $\mathrm{x}$ & $\mathrm{x}$ & $74 \%$ \\
\hline $\begin{array}{l}\text { Time Slowed } \\
\text { Down }\end{array}$ & $67 \%$ & $\mathrm{x}$ & $41 \%$ & $40 \%$ & $\mathrm{x}$ & $56 \%$ & $62 \%$ \\
\hline $\begin{array}{l}\text { Time Sped } \\
\text { Up }\end{array}$ & $\mathrm{x}$ & $\mathrm{x}$ & $20 \%$ & $19 \%$ & $\mathrm{x}$ & $53 \%$ & $17 \%$ \\
\hline $\begin{array}{l}\text { Heightened } \\
\text { Detail }\end{array}$ & $18 \%$ & $\mathrm{x}$ & $41 \%$ & $40 \%$ & $\mathrm{x}$ & $56 \%$ & $71 \%$ \\
\hline $\begin{array}{l}\text { Intrusive } \\
\text { Thoughts }\end{array}$ & $\mathrm{x}$ & $\mathrm{x}$ & $\mathrm{x}$ & $\mathrm{x}$ & $\mathrm{x}$ & $\mathrm{x}$ & $26 \%$ \\
\hline Dissociation & $\mathrm{x}$ & $\mathrm{x}$ & $\mathrm{x}$ & $\mathrm{x}$ & $90 \%$ & $\mathrm{x}$ & $39 \%$ \\
\hline Paralysis & $\mathrm{x}$ & $\mathrm{x}$ & $\mathrm{x}$ & $\mathrm{x}$ & $\mathrm{x}$ & $\mathrm{x}$ & $.07 \%$ \\
\hline Memory Loss & $\mathrm{x}$ & $\mathrm{x}$ & $20 \%$ & $\mathrm{x}$ & $19 \%$ & $22 \%$ & $52 \%$ \\
\hline
\end{tabular}

Note. $\mathrm{x}=$ not applicable 
Memory errors are of particular importance for the current study. Researchers have recently begun to examine this issue in the policing context, with most studies indicating that recall accuracy is negatively impacted during moments of acute stress (Lupien et al., 2005; Roozendaal, McEwan, \& Chattarji, 2009; Sharps, 2009). For example, Beehr, Ivanitskaya, Glaser, Erofeev, and Canali (2004) assigned 194 American police officers to one of three stressful conditions where they were exposed to a simulated shooting incident through live fire, a videotape, or a silent non-shooting videotape of the incident. Those exposed to the highest stress condition (live fire) experienced the most problems with their recall accuracy. More recently, Hope, Lewinski, Dixon, Blocksidge, and Gabbert (2012) examined the effect of physical exertion and stress on memory among Canadian police officers. Before completing a training scenario, 52 officers were randomly assigned to an exertion task (punching a heavy bag) or a no-exertion condition. Immediately after taking part in the scenario, both groups of officers completed memory recall and recognition tests. Results identified a significant negative impact of exertion on recall (52\% accuracy compared to $84 \%$ accuracy) and recognition accuracy (27\% accuracy compared to 54\% accuracy).

The fact that officers may suffer from high levels of memory loss following stressful use of force events is critical since memory is relied on by officers when filling out their use of force reports and when articulating their actions, immediately following the event and later on in court. Of relevance to the current research, these issues can lead to discrepancies between an officer's report of what occurred in a use of force encounter and other accounts of the event (e.g., from footage of the encounter through dashcams, BWCs, an eyewitness' account, etc.). These discrepancies might be hard for jurors to 
understand and can potentially result in perceptions that an officer is being intentionally deceitful. These perceptions may impact how jurors make decisions in these cases (e.g., verdicts of guilt or not guilty).

\section{The Rise of Body-worn Cameras}

Despite the challenges just described, it appears that use of force is rarely used in Canada. For example, Hall, Votova and Wood (2013) showed that officers use force in approximately $0.14 \%$ of their encounters (where force is defined as anything including or greater than strikes and stuns). These results are consistent with more recent studies in Canada (e.g., Baldwin et al., 2018). Unfortunately, available statistics also show that, when force is used, it can be applied in a biased fashion. For example, American research suggests that force is disproportionately applied to members of minority racial groups (Gau, Mosher, \& Pratt, 2010; Geller \& Karales, 1981; Gelman, Fagan, \& Kiss, 2007; Kochel, Wilson, \& Mastrofski, 2011; however, for contrasting results see Ridgeway, 2007; Skogan \& Frydl, 2004; Worrall, Bishopp, Zinser, Wheeler, \& Phillips, 2018). While less research of this type has been conducted in Canada, claims have also been made that Canadian police officers apply force disproportionately when interacting with members of minority racial groups (Fitzgerald \& Carrington, 2011; Wortley \& OwusuBempah, 2011; Wortley \& Roswell, 2006). It is largely because of these claims of biased policing that the call for BWCs has surfaced (Boivin, Gendron, Faubert, \& Poulin, 2017).

As indicated in Chapter 1, BWCs are intended to be a means for enhancing police transparency and accountability. Increasingly, it appears that BWCs will serve this function (in part at least) by being used as evidence in court cases involving allegations of excessive use of force. Given this, it is important to understand how mock jurors might 
receive $\mathrm{BWC}$ footage when it is presented as evidence. In particular, since BWC footage is a form of visual evidence, it is important to understand some of the issues that might arise with visual evidence in court (e.g., whether images truly depict "the truth" and how a person's perception of an image can be impacted by various factors). These issues will be focused on in the following sections, but before that is done, a related issue will be briefly discussed - the importance of understanding the difference between BWC technology and human sensory systems.

Differences between BWCs and human sensory systems. Important differences exist between BWCs and the sensory systems of police officers. Some of these differences are relevant to the current studies because jurors may not be aware of them when considering BWC evidence in court. As a result, jurors may assume that officers and BWCs are "recording" the same information during an encounter and they may interpret evidence being presented in court in line with this misunderstanding.

For example, jurors may not realize (or consider) that BWCs do not capture what the human eye tracks, which will inevitably result in discrepancies when an officer's account of an incident is compared to video footage. BWC footage may not indicate where an officer was looking or what an officer was encoding during a use of force encounter, for instance, nor reflect the potential impact that stress (or other factors) have on the human visual system (Force Science Institute, 2010). As but one example, common perceptual effects such as "looming", which occurs when a person perceives threatening objects as closer than they are (Force Science Institute, 2010), cannot be captured by BWCs. Likewise, objects may block the view of a BWC, but the officer may have an unobstructed view, or vice versa (Force Science Institute, 2010). 
In addition, BWCs do not capture all forms of danger cues that an officer could potentially pick up. Indeed, the human eye can capture more "frame-by-frame" images than a BWC will, which means that a split-second danger cue (e.g., a glint of metal) may be visible to the officer, but not show up in a video (Force Science Institute, 2010). The human sensory system can also pick up on smells (e.g., smoke) and other sensations (e.g., a limb tensing) that will go undetected by a BWC. All these differences can result in discrepancies between an officer's testimony about an encounter and BWC footage of that encounter. In addition, BWCs have no depth perception and therefore BWC footage may not capture how close a person was to the officer when the officer decided to apply force, or the distance between the officer and other objects involved in an encounter, such as a moving vehicle (Force Science Institute, 2010). These could lead to further discrepancies between officer testimony and BWC footage.

While not always specific to BWCs, basic research supports these arguments. For example, a wealth of research indicates that the human visual system cannot be compared to a camera due to critical differences between the two (Johansson, 1975). For example, unlike cameras, the eye does not have a shutter and images do not blur as the eye moves (due largely to the fact that the visual system is governed by certain physiological [and mathematical] rules that do not control cameras; Johansson, 1975). Another key difference is that the visual system processes what it is receiving, and extracts conceptual information based on visual input, while a camera simply records what it is pointed at (Potter, Wyble, Hagmann, \& McCourt, 2014). Based on differences in processing speed (e.g., Hung, Babin, \& Coberly, 2016; Thorpe, Fize, \& Marlot, 2014) a camera also captures the world in still images, which then 'blur together' to make the image 'move', 
whereas the human visual system sees the same scene seamlessly. And, of course, a camera cannot record odors, such as smoke, which might indicate danger, or capture depth perception, which may be critical to an officer's risk assessment (while 3D cameras do exist, there are limits to how well the recording simulates human vision and this capability is restricted primarily to medical uses, such as laparoscopic surgeries; Kong et al., 2010). Finally, depending on the camera in question, differences can also exist between cameras and the visual system in terms of being able to see in low-light conditions (Hung et al., 2016; Tinsley et al., 2016).

Other issues, which are unrelated to differences between BWCs and the sensory abilities of officers, are also important to understand as BWC footage makes its way into the courtroom (given that misunderstandings around these issues may bias juror decisions). For example, it will be important to appreciate that a single BWC cannot usually capture a scene properly; multiple camera angles are typically necessary for that purpose (Boivin et al., 2017; also, see Lassiter, Ware, Ratcliff \& Irvin, 2009 for similar arguments in the interrogation room). Consider a sports game and the many camera angles (and replays) that are required to truly understand what occurred in critical moments of play. BWC footage will also encourage second-guessing. This occurs because video reviewed under calm circumstances, distant from the adrenaline, stress, and threat of the actual moment it depicts, or shown in slow motion or freeze-frame, can offer a strikingly different perspective on what happened and how things "should" have transpired (Force Science Institute, 2010). The effect of 20/20 hindsight may negatively impact how triers of fact evaluate an officer's perspective about an incident. Relatedly, BWCs cannot replace officer testimony. While some people may be of the view that 
BWC footage can "speak" for the officer, BWC footage does not speak to the reasons why an officer decided to respond in a particular way; only an officer's verbal testimony can reveal that.

All of the issues described above have the potential to impact how jurors will understand cases involving police officers and BWC footage. It is unlikely that triers of fact will be aware of the issues discussed above unless explicit attempts are made in court to address them (e.g., through expert testimony or judge's instructions). Without educating jurors about these issues, they may put undue weight on BWC evidence thinking of it as a "tell-all" of the incident. This suggestion is supported by research that has considered how people treat visual evidence more broadly.

Visual culture and visual evidence. Although humans are multisensory beings, advancements in technology have led us to be a visually dominant culture. The increased use of social media, such as Facebook, Instagram, and YouTube, has dramatically changed how we interact as a society (David, 2010; Mezey, 2013; Van Dijck, 2011). Visual culture has potentially changed again following the introduction of BWCs in policing with the demand for greater police-controlled surveillance to increase police accountability and transparency.

Understanding visual imagery as evidence is no simple matter. At least two main inter-connected issues arise when photographs and/or video are used as visual evidence in the courtroom (throughout this discussion, video evidence will be the primary focus given the topic of this dissertation). The first issue is video evidence potentially being 
perceived as a depiction of the absolute truth, ${ }^{2}$ thus giving it prejudicial bias beyond its original probative value and negating other "voices" in the court room, such as eyewitness testimony (Mezey, 2013; Mnookin, 1998). The second issue is whether video evidence requires an interpreter (i.e., can a video "speak for itself”?) and the impact that the interpretation has on triers of fact.

Does an image depict the actual 'truth' of an event? Visual images, such as those provided by photographs or video, are often considered to offer the clearest picture of an event and are believed to be a form of absolute truth; that is, the image is thought to tell the "true story" (Mezey, 2013; Mnookin, 1998). Courts appear to support this belief, considering recent US court cases that have shown judges relying on video evidence over contradictory testimony (e.g., Gilfand v. Planey, 2011; McDowell v. Sherrer, 2008; Scott v. Harris, 2007).

Mnookin (1998) examined the power of visual evidence in her critical discussion of the history of photographic evidence in court. She demonstrated how photographs have evolved from illustrative evidence (that is, evidence that helps demonstrate a fact) to independent evidence that does not need to be corroborated or is used solely to corroborate testimony. According to Mnookin, as the use of visual evidence has evolved over time, courts have increasingly considered this evidence to be a "superior substitute for words" (p. 43). This belief gives visual evidence independent probative force where it not only can verify a fact, but it can prove that fact (such as proving the identification of a

\footnotetext{
${ }^{2}$ It is important to stress that while people may believe that something, such as a photograph or video clip, may depict the 'absolute truth', it is important to note that 'truth' cannot be absolute given that truth is subjective and constructed by individuals (Bohm, 1964).
} 
robber without any corroborating evidence in the Canadian court case; $R$. v. Nikolovski, 1996).

Despite these views, visual imagery is not the truth-tell-all that many people believe it is. A growing discourse amongst legal scholars suggests that images do not offer a "seamless and direct knowledge of external reality" (Feigenson, 2014, p. 17). Instead, "images produced by cameras and computers are always mediated, their meaning influenced by aspects of the medium, the context of viewing, and the perceptions of the viewer" (Mezey, 2013, p. 2). For example, Mnookin (1998; citing Sontag, 1978) argues that a photograph's meaning comes not from the image itself, but "only through the relation between the image and its caption or context" (p. 57). Likewise, Butler and Sontag (2007) argued that even the framing of the frame of a photograph can influence the interpretation of a photo, as explained in greater detail below.

To demonstrate how the framing of the frame can influence interpretation of visual evidence, Butler and Sontag (2007) used the photos of detainee torture in Abu Ghraib Prison in Iraq by American soldiers during the Iraq war to illustrate how one can frame the images to define who is deserving of humane treatment (i.e., who is seen as "human") and who is not. Butler and Sontag (2007) also pointed out that "framing of the frame" disregards the importance of who was taking the photo and what was occurring outside the frame of the image when the photograph was taken (let alone which powers are controlling our interpretation of the context of said image). Also, on the point of “framing”, Schwartz, Silbey, Ryan, and Donoghue (2009) point out the importance of considering what image preceded and followed the images being presented; in their own words, "the same shot means different things depending on its relationship to the images 
that it precedes and follows" (p. 875). So, does an image, such as those that could be produced using BWC, show the "absolute truth"? The answer appears to be "not necessarily". As will be discussed in the next section, images do not always provide a clear answer to what has occurred in a situation or event. Instead, viewing images, and developing an understanding of what they depict, is influenced by a variety of external (e.g., what is captured in the image versus what falls outside of the frame) and internal factors (e.g., social and cultural assumptions).

Why does an image depend on interpretation? Mezey (2013) suggests "images cannot speak for themselves because both the images and their viewers have multiple ways of seeing” (Mezey, 2013, pp. 8-9). As a result, what we understand in what we see is based not solely on the content of an image, but also on our individual way of "seeing". He goes on to suggest that what we see is dependent not only on the individual and their personal background, but on cultural assumptions and societal expectations. All of these factors influence how we interpret what we see.

Seeing an image is therefore not a passive experience, but rather an active one because the interpretation of an image depends, in large part, on which discourses and visual representations occur (Butler \& Sontag, 2007; Fiske, 1995). As indicated above, these discourses include an individual's social and cultural assumptions. Other influences, such as camera angle, lighting, and scope all influence what a person sees in an image (Boivin et al., 2017; Lassiter et al., 2009; Schwartz et al., 2009), while not illuminating the viewer as to what may be outside the frame of the image that is captured. Also, the setting of the image (i.e., where it was captured) and where it is viewed (e.g., in a classroom, in a courtroom, etc.) gives the image context (Mezey, 2013). 
An interesting example of how these issues might play out in a use of force context, which will be discussed in more detail below, is the Rodney King case (where a bystander filmed Los Angeles police officers brutally beating King). Fiske (1995) argued that in the Rodney King trial, changing the discourse of King's bodily reactions after a Taser charge - as being toward, rather than away from the officers - "had the effect of changing the reality involved" (p. 919). This slight, but important, change to the discourse partly contributed to what potentially altered King's allegations of excessive force to one of reasonable force given the "threat" King posed to the officers.

There is some research that demonstrates that interpretation of behaviour can depend on the angle of a camera within a judicial context. For example, when participants examine interrogation-induced confessions where the camera is either interviewerfocused or suspect-focused, participants tend to view the suspect's confession as more voluntary and the suspect as more guilty in the suspect-focused condition, indicating a camera perspective bias (Lassiter et al., 2009), There are also many examples in nonjudicial settings that provide empirical support to the concept of an image not giving meaning but being given meaning by the viewer. For example, there is a long history of social psychology researchers examining the influence of racial stereotypes when people are asked to interpret ambiguous images. When individuals are shown photos of people interacting with one another in the same way, for instance, but the primary actor's race is manipulated to be either Black or White, participants tend to rate the Black actor as more aggressive than the White actor (e.g., Duncan, 1976; Johnson, Trawlter, \& Dovidio, 2000; Sagar \& Schofield, 1980). In these studies, the image did not change at all; the only thing that changed was the activation of the observer's stereotypes and biases. 
The often-used Thematic Apperception Test (TAT; Murray, 1938) provides another example. Here, patients are shown ambiguous photos and they tell the clinician what they "see" in the photo. This clinical tool is specifically used because it is known that patients impose their own personality, feelings, thoughts, and beliefs on the ambiguous images. The process of interpreting the ambiguous images is assumed to have clinical value because it informs the clinician how the patient views themselves and the world around them (e.g., Aronow, Weiss, \& Rezinkoff, 2013; Oakland, Douglas, \& Kane, 2015; Serfass \& Sherman, 2013).

These studies demonstrate how the interpretation of visual evidence depends on much more than just the content of the image. Each juror's individual background (i.e., their biases, beliefs, expectations, etc.) will likely play an important role in how an image, such as video footage produced by police, is interpreted within the context of a court case.

A real-world example: The Rodney King trial. Although no examples of court cases involving BWCs could be found to illustrate these points, other US and Canadian cases involving video evidence reveal that there is a trend towards judges and jurors giving undue weight to visual evidence, thus setting a potentially dangerous precedent (e.g., Gilfand v. Planey, 2011; McDowell v. Sherrer, 2008; R. vs. Nikolovski, 1996; Scott v. Harris, 2007). What is shown in these court cases is how video evidence is not a depiction of the absolute truth. Instead, the evidence merely presents one perspective, and the interpretation of such evidence can be affected by the biases, beliefs, and expectations of the jury, and can be potentially manipulated by who is the predominant narrator of the 
evidence. One of the most powerful examples of this is the Rodney King trial mentioned above.

This trial provides a powerful example of the role that video evidence can play in the courtroom. In this case, a number of Lose Angeles police officers were charged after allegations of excessive use of force were brought against them after beating the unarmed King in 1991. A bystander took a video of the incident and the news media immediately portrayed the events as a clear-cut case of police brutality driven by race. Yet, despite this seemingly overwhelming visual proof of guilt, a jury did not convict the officers. How did this occur?

One argument, put forward by Butler (1993), is that the Defence manipulated the interpretation of the video by relying on, and amplifying, "white paranoia" among the majority white members of the jury. Furthermore, Butler (1993) and Fiske (1995) argue that the Defence cleverly controlled the narration of the video, framing it with specific words and images to present King, not as the victim, but rather as a threat that required the officers to use force to protect themselves. For example, the Defence circled a frozen image of King's leg on the video, which was raised a fraction off the ground. They argued that this was a physical threat to the officers surrounding the man on the ground. Rather than raising the possibility that King was experiencing leg spasms due to pain, or that he was attempting to defend himself, the Defence convinced the jury that it was the threat of a severe leg strike that officers reacted to when they struck King. Furthermore, King's refusal to "stay down" was reframed by the Defence as an action by King that compelled the officers to respond with force due to King's non-compliance to state authority - the police (Fiske, 1995). 
Thus, visual evidence in this case was arguably given meaning rather than giving meaning to the jurors; and the meaning that was given appeared to be heavily influenced by the narrator. While other factors clearly played a role in the acquittal of the officers, it seems hard to discount the impact that the above issues might have had on the jurors.

\section{Summary}

Courts in the US and Canada have set precedents that video evidence can be treated as a witness since the video can "speak for itself" (e.g., Gilfand v. Planey, 2011; McDowell v. Sherrer, 2008; R. vs. Nikolovski, 1996; Scott v. Harris, 2007). This is a potentially dangerous precedent because research indicates that visual evidence is not a representation of the absolute truth. Instead, an image is something that we, the viewer, gives meaning to. This is because an image's interpretation depends on the experiences, attitudes, and perspectives of the one observing it (Berger, 1972; Mezey, 2013; Wasserman, 2008) as well as the person who frames the story the image tells (Butler, 1993; 2007; Fiske, 1995). The fact that courts have viewed visual evidence as the absolute truth suggests that they lack visual literacy (Mezey, 2013). A grave concern is that "courts will read visual evidence poorly, over-estimating what it does say and underestimating what it does not say" (Mezey, 2013, p. 29).

These issues raise concerns when it comes to the inclusion of BWCs as visual evidence in court. Will BWC footage be treated as the gold standard against which other accounts are compared to? Are jurors aware of the limitations of video footage? What role do juror biases play when rendering a verdict when BWC footage is present? The studies included in this dissertation will examine public attitudes towards BWCs and will determine how mock jurors treat visual evidence in court. Before describing these 
studies, I will review theories of juror/jury decision-making to situate the sorts of variables that will be examined in my studies within the broader research literature. 


\section{Chapter 3: Jury Research}

Given that the main study included in this dissertation deals with allegations of excessive use of force in criminal court, it is important to address theories of jury and juror decision-making and factors that are important to jury and juror decision-making, particularly as they might pertain to BWC evidence and allegations of excessive use of force. While many trials are not presided by a jury, but by a judge alone (e.g., trials of summary offences), more serious offences such as manslaughter and homicide involve jury trials. In this chapter, two popular theories of jury and juror decision-making will be described. Furthermore, various factors will be discussed that are relevant to the variables examined in the current study, including juror characteristics (i.e., biases towards police, pro-prosecution bias, authoritarianism, and need for cognition) and trial characteristics (i.e., discrepancies between officer testimony and BWC footage, and the presence of expert testimony).

\section{The Story Model and the Multi-Level Theory of Jury Decision-making}

In the previous chapter, the US Rodney King case was mentioned as the most infamous case of visual evidence involving excessive use of force by the police. However, it is important to recall the greater impact the case had after the trial - the 1992 Los Angeles riots that left 53 people dead and over 2,000 people injured. In other words, while the video of the incident was witnessed around the world, it was the verdict at the trial - all four officers being acquitted, despite what was considered by many as a clear abuse of power - that triggered the riots. The importance of understanding the impact of BWCs on police (and public) behaviour cannot be underestimated, but so too must we 
carefully consider the impact of visual evidence (i.e., BWC footage) within the courtroom.

Understanding how factors that influence jury and juror decision-making relate to one another, and potentially impact one another, is a primary goal in the field of jury research. A number of researchers have developed theories to try and enhance our understanding of these issues. Two of these theories will be discussed below, specifically The Story Model of jury decision-making (Pennington \& Hastie, 1986) and the Director's Cut Model from the more recent Multi-Level Theory of jury decision-making (Devine, 2012).

The Story Model. The Story Model of jury decision-making (see Figure 2; Pennington \& Hastie, 1991) is based on the idea that there are many individuals in a judicial setting playing various roles (e.g., a judge, the Crown, the Defence, a defendant, witnesses, experts at times, victims, and if the case is severe enough, a jury composed of people with their own personalities and biases). The Story Model conceptualizes these individuals, especially jurors, not as passive participants, but rather as active observers and interpreters of information; information that is being presented by other individuals in the court room.

According to The Story Model, one can think of individuals in the courtroom (the stage, if you will) as actors playing various roles according to scripts, which differ depending on the role being played. The performance of these actors creates a narrative consisting of different accounts of the events that transpired and led up to the trial. Of course, competing narratives are provided. As each of the actors - the Crown, the Defence, the Judge, the defendant, witnesses, and experts - present aspects of the 
narrative, or their interpretation of the "reality" of a case, jurors create their own story of what transpired, and decide which version of events their story corresponds to (the narrative being presented by the Crown or Defence).

During the jury's deliberation, the competing narratives are interpreted further, while taking into account information the jurors were provided (e.g., opening statements, evidence that was presented, the judge's instructions). Ultimately, all of this information (in addition to the juror's own views, biases, world knowledge, etc.) is incorporated into the juror's ultimate story to arrive at a version of events. This story is then compared and matched to one of the various verdict options provided by the judge to decide whether a defendant is guilty or not guilty. 


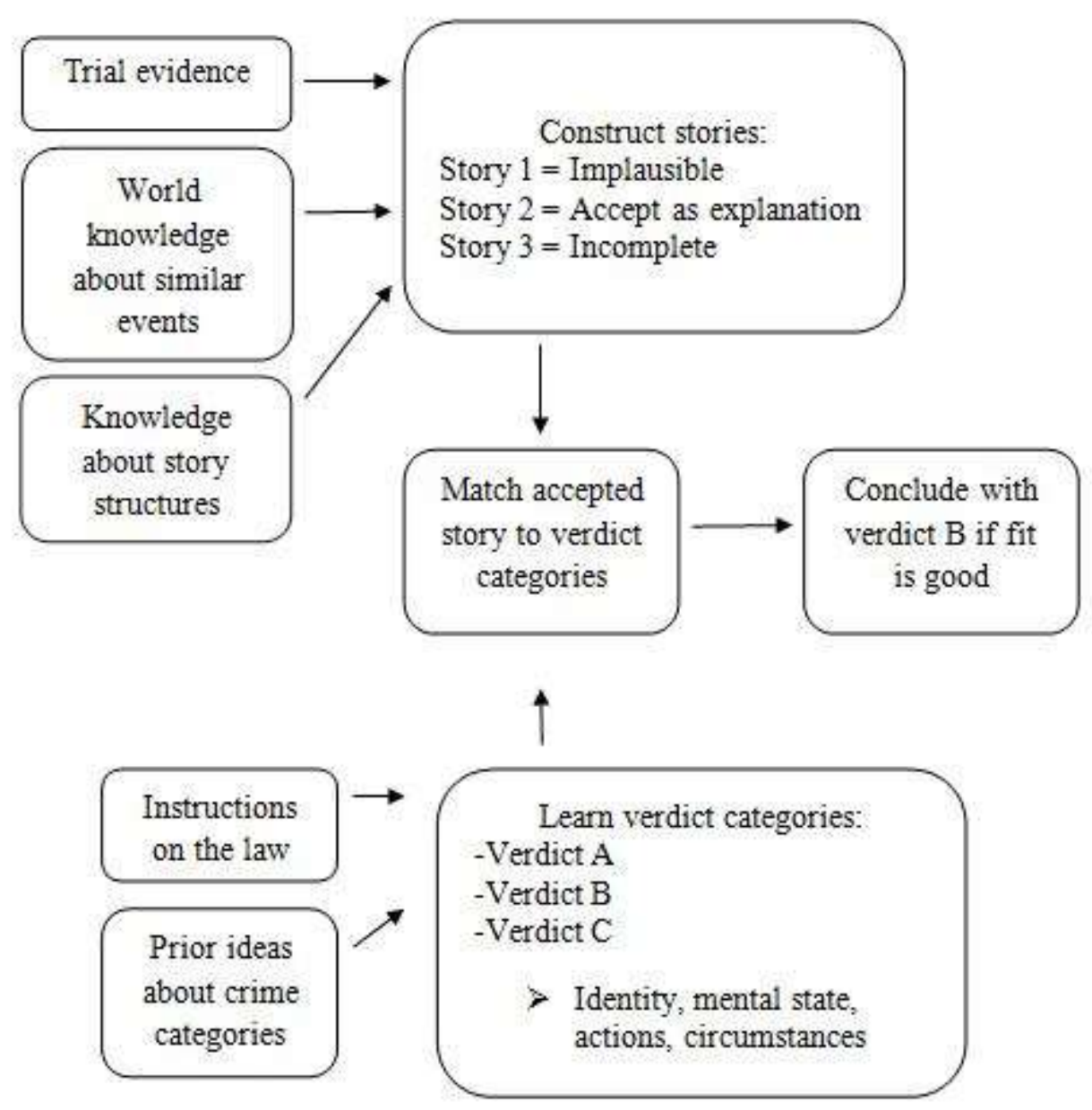

Figure 2. The Story Model of jury decision-making (adapted from Pennington \& Hastie, 1991, p. 522).

How does the formation of a story take place within a jury member according to The Story Model? As highlighted above, The Story Model is grounded in the theory that “jurors impose a narrative story organization on trial information, in which causal and intentional relations between events are central" (Pennington \& Hastie, 1986, p. 243). From the narrative they create, jurors ultimately choose the story presented at trial that best matches their own in order to reach a verdict. 
Pennington and Hastie (1986) hypothesize that The Story Model involves three stages of processing. The first stage is when jurors evaluate the evidence. This is when jurors begin to construct their story based on the evidence and their world knowledge and beliefs. In the second stage, jurors learn what the different verdict categories consist of. It is at this point that the juror processes their own prior knowledge of crime categories and attempts to understand their instructions from the judge. In the third and final stage, story classification, jurors select the verdict category that best matches the narrative they have created throughout the first two stages.

During a trial, a juror may construct multiple stories based on the various story alternatives provided by the Crown and Defence, and the juror's own knowledge and beliefs. However, although a juror may construct more than one story during a trial, Pennington and Hastie (1986) argue that jurors ultimately choose one governing story that will lead to their verdict. The choice of the governing story is based on Pennington and Hastie's (1991) certainty principles of coverage, coherence, uniqueness, and goodness-of-fit. The authors theorized that the principles of coverage and coherence contribute to the credibility and ultimate acceptance of a story while the principles of uniqueness and goodness-of-fit contribute to a juror's level of certainty in their verdict (Pennington \& Hastie, 1991).

Coverage involves how comprehensively the story encompasses the evidence presented; in other words, is all the evidence presented in court by the Crown or Defence used to explain, even create, the story? If the answer to this question is yes, the story will have greater chance of acceptance by a juror, and will result in greater certainty when rendering a verdict, due to its enhanced credibility. The principle of coherence is based 
on the theory that the more consistent and plausible the story presented at trial is, the more likely a juror will be in accepting that story and rendering a verdict that aligns with that story. The principle of coherence has three components that, if present, will result in a higher chance of story acceptance due to its enhanced credibility. The first component of coherence is consistency. The more consistent the story is with the evidence presented, the greater the coherence. This facet of coherence is particularly important to the proposed studies, given discrepancies between officer testimony and BWC footage will be examined. The second component of coherence, plausibility, refers to the extent to which the story and the juror's knowledge of the world coincide (e.g., if a juror believes police in general are corrupt, a juror will be more accepting of an officer being guilty in an excessive use of force trial). The third component to coherence is the completeness of the story. A story told at trial that is missing information, such as important evidence, is less likely to be accepted by the juror and will decrease a juror's certainty when rendering a verdict due to the story's decreased credibility.

The third principle, uniqueness, refers to whether more than one plausible story is presented. If multiple stories can be created, which are comparable with respect to their coverage and coherence, the lack of uniqueness will decrease a juror's certainty, and therefore confidence, in their verdict. This third principle is related to the fourth and final principle, which is goodness-of-fit. Assessments of goodness-of-fit occur during the third stage of the story model, which is when jurors choose the story that best matches the verdict options they have been given. The more the story (with respect to coverage, coherence, and uniqueness) fits with the verdict classification, the higher the goodness- 
of-fit, and the greater the certainty the juror will have in rendering their verdict (Pennington \& Hastie, 1991).

Since The Story Model was first proposed, a number of researchers have set out to test the model. Due to the challenges of attempting to test the model in its entirety, researchers typically explore some specific aspect of the model. For example, in one of the original studies, Pennington and Hastie (1986) found that when participants drawn from a jury pool were presented with video of a filmed murder trial, story formation occurred. The participants were extensively interviewed about not only their verdict, but about how they came to their verdict. The results demonstrated that jury members "created cognitive representations of the evidence in the case, the verdict categories presented in the trial judge's instructions and the procedures they were to follow according to law to reach a verdict" (p. 1); in other words, jurors organized information presented to them into a story, which is consistent with The Story Model. Furthermore, the results of this study revealed that a juror's cognitive representation of the evidence was highly correlated with their verdict. Therefore, differing verdicts (i.e., murder in the $1^{\text {st }}$ degree, $2^{\text {nd }}$ degree, manslaughter, self-defence) were an outcome of different stories created by the jurors regarding mental states and goals attributed to the defendant (despite evidence and jury instructions being equivalent across jurors). This suggests that jurors construct their own stories based on how they process/perceive the evidence, choose verdict categories that coincide with their world knowledge, and classify stories according to the verdict that the story matches.

In a further test of The Story Model, Voss, Wiley, and Sandack (1999) presented mock jurors with a mock homicide trial, where they manipulated the coherence and the 
chronological sequence of the prosecutor's verbal presentations (by omitting details and logical sequences from sentences). They found that when the prosecutor's coherence was low and the chronological sequence was out of order, the mock juror's rendered fewer guilty verdicts compared to the baseline (control) condition. This supports The Story Model's principles of coherence; by making the story more difficult to follow, the narrative presented by the prosecution did not coincide with the mock juror's knowledge of story structure and thus, decreased the likelihood of the story being accepted by the juror.

In a more recent study, Klettke, Graesser, and Powell (2010) examined how an expert's credentials (clinical Ph.D. vs. M.A. in counselling), evidence strength (high vs. low strength), and coherence (consistent vs. inconsistent with expert's testimony) influenced jury decision-making in a child sexual abuse case. Dependent variables were ratings of guilt, effectiveness of evidence, and credibility of the victim. Results showed that when evidence strength was high and coherence was consistent, participants were significantly more likely to render a guilty verdict, rate the expert as more effective, and rate the victim as more credible.

Multi-level Theory of Jury Decision-making. Another jury decision-making model addresses how a juror cognitively processes information presented at trial and derives verdict decisions. Devine's (2012) Multi-level Theory of Jury Decision-making is an expansion of Pennington and Hastie's (1986) Story Model. Like The Story Model, Devine's model still incorporates the theory that jurors develop their own narrative during a trial. However, Devine expanded the story concept, suggesting it is comprised of two levels: a juror decision model and a jury decision model. Due to the focus of the 
proposed studies on juror decision-making, and not the jury deliberation process, only the juror model will be discussed in this document.

According to Devine (2012), the first level of his Multi-Level Theory focuses on the juror decision-making process. Devine refers to this level as The Director's Cut Model of Juror Decision-making (see Figure 3), given the analogies he makes to film. Like the Story Model, the processes at this level involve a heavy reliance on personal schemas (referred to as stories), which guide the juror through the trial (e.g., opening and closing statements, evidence, testimony, visual aids). Like editing a movie, Devine hypothesizes that jurors will discard some of the evidence (or "footage" in his film analogy) if it does not fit the "final cut" of the "film" (i.e., the story, or the juror's personal view of what happened; Devine, 2012). What cut of the film is accepted depends on aspects similar to The Story Model, such as the credibility and coherence of the film cut, and its singularity/uniqueness (i.e., there are no competing alternative versions of the film). As in The Story Model then, juror stories are thought of as mental representations of the trial, which "involves a fundamental interaction between what is seen and heard in the courtroom and what jurors already "know"' (Devine, 2012, p. 187).

As can be seen in Figure 3, many factors can influence a juror's narrative and thus, their ultimate verdict decision. Pre-trial publicity (PTP) exposure, number of charges, and seriousness of the offence are features of the case that can influence the story a juror creates. A juror's own characteristics, including trust in the legal system, the extent to which they have the trait of authoritarianism, and one's need for cognition (NC), are also important factors that can influence story construction, as well as verdict decisions. Finally, personal characteristics of the defendant, such as the defendant's 
socioeconomic status, attractiveness, or demeanour can influence jurors in their decisionmaking process.

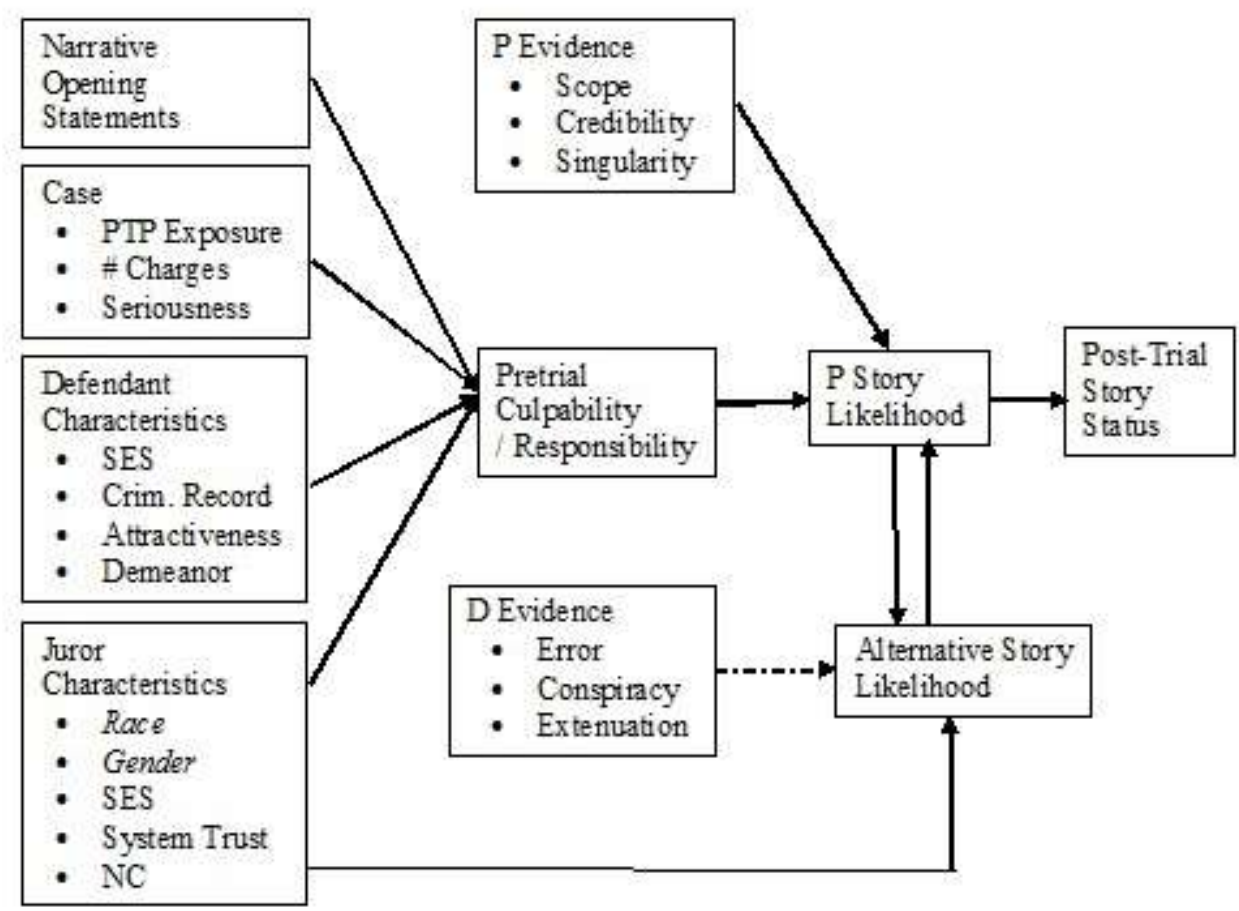

Figure 3. Director's Cut Model of Juror Decision-making (adapted from Devine, 2012, p. 187).

Similar to The Story Model, the Director's Cut Model suggests that the scope, credibility, and uniqueness (termed here as singularity) that can be attached to evidence presented by the prosecution play a part in story creation. In addition, the number of plausible alternatives (labelled as conspiracy and extenuation in Figure 3), as well as errors (inconsistencies), that the Defence can point out in the case presented by the prosecution impacts what kind of story the juror creates and ultimately accepts when they render a verdict.

Due to the focus of the current study on how juror's weight BWC (and other) evidence, and how jurors evaluate that evidence to arrive at individual verdict decisions, 
The Story Model and Director's Cut Model of Devine's (2012) Multi-Level Theory are the appropriate models to focus on for the current studies. Specifically, these models were used to provide a framework for understanding how various aspects of evidence during trials, in addition to juror characteristics, influence the narratives that jurors construct around court cases that involve BWC evidence and allegations of excessive use of force by the police. Based on a review of previous research, certain aspects of these models appear to be particularly important to examine for the purposes of the current project. Not only are some of the features described below found to be among the strongest predictors of juror decision-making, they are also most relevant to the specific type of court case that will be focused on in this dissertation. The variables and related research can be categorized into two sections: juror characteristics (i.e., biases against the police, pro-prosecution bias, authoritarianism, and need for cognition) and trial characteristics (i.e., discrepancies between evidence and expert testimony).

\section{Juror Characteristics}

Before a trial even begins, a juror comes to the courtroom with background characteristics or qualities that will influence the type of story they will create. These variables can include biases against the police (e.g., due to negative media exposure, personal experiences, etc.), pro-prosecution (or pro-defence) biases, one's level of authoritarianism, and a juror's need for cognition. Each of these variables will be examined in the current study so they will be briefly described here.

Biases against the police. Members of the public can be negatively biased against the police and this can potentially have a large impact on how they will treat police officers when they appear as defendants in court. Such biases can emerge from 
many sources, including the media (Klinger, 2004). The media is sensationalistic when it comes to crime and in particular to any potential officer wrong-doing caught on camera (Dowler, Fleming, \& Muzzatti, 2006; Doyle, 2006; Klinger, 2004). Fatal police-public interactions are irresistible targets for news media that follow the adage, "If it bleeds, it leads" (Klinger, 2004, p. 213). According to police researchers, media tends to focus on sensationalistic storytelling, painting police officers as trigger happy before gathering proper facts that would allow them to provide a more accurate story (Klinger, 2004). Meanwhile, heroic efforts by police are often found buried in the back pages of newspapers, if they are covered at all.

While no studies could be found that have examined how media biases against the police will impact how officers are treated in court, research has demonstrated that pretrial publicity (PTP) of the sort we are talking about (i.e., publicity that paints an individual, a case, or a situation negatively) can potentially have a strong impact on how jurors evaluate information in court, and the sorts of verdict decisions that they reach (e.g., Devine, Buddenbuam, Houp, Studebaker, \& Stolle, 2009; Hope, Memon, \& McGeorge, 2004; Ruva, \& LaVasseur, 2012). That being said, research findings on the effects of PTP are complex. For example, the effects of PTP appear to depend on a range of variables, such as whether mock jurors are given the chance to deliberate, what the PTP specifically focuses on, whether the PTP is general and similar to the case at hand, etc. (Burke, 1998; Greene \& Loftus, 1984; ; Mullin, Imrich, \& Linz, 1996; Ruva \& McEvoy, 2008).

Given this, it is useful to rely on meta-analytic results to determine if PTP impacts outcome variables such as verdicts. At least one meta-analysis focusing on jury studies 
has included an examination of PTP. This meta-analysis found a significant, positive effect. More specifically, in their meta-analysis consisting of 23 studies that yielded 44 effect sizes, Steblay, Besirevic, Fulero, and Jimenez-Lorente (1999) showed a modest, but significant relationship between negative PTP and guilty verdicts $(r=.16 ; k=23)$. In other words, greater exposure to negative PTP against the defendant increased the chance of jurors choosing guilty verdicts. Similar results are reported in other, more recent studies that have examined the impact of PTP (e.g., Devine et al., 2009; Hope, Memon, \& McGeorge, 2004; Ruva \& McEvoy, 2008).

Of course, negative PTP is not the only potential source of biases against the police. A range of other experiences with the police can potentially lead to views about them that can ultimately colour how people interact with police and treat them (including in a court of law). For example, socio-legal research indicates that some minority groups may have less trust in the police due to experiences with racial profiling (Harris, 1999) or disproportionate policing/enforcement (Smith \& Hawkins, 1973). Other research suggests that indirect experiences with the police (e.g., hearing of others who had a positive or negative experience with the police) can also have a significant impact on attitudes towards law enforcement (Rosenbaum, Schuck, Costello, Hawkins, \& Ring, 2005). Whatever the reason one has biases for or against the police, jury research demonstrates that attitudes towards a group, such as the police, can often predict juror/jury verdicts and other outcome variables.

For example, Casper, Benedict, and Perry (1989) found that mock jurors in a civil lawsuit against the police who committed illegal searches viewed officer testimony more favourably and awarded less cost for damages to the plaintiff when the person held a 
more positive view towards the police. In a more recent study, Farrell, Pennington, and Cronin (2013) examined actual juror decisions from 1,940 jurors that presided over 210 non-capital felony trials using data from the National Center for State Courts. Among their results, they found that higher ratings of confidence and trust in the police resulted in a pro-prosecution bias prior to deliberation. Another study found that it was vicarious experiences with police (e.g., experiences of friends and family) that had the greatest impact on a person's attitudes and resulted in stereotypes towards police that were more resistant to change (Rosenbaum et al., 2005).

These issues are of relevance to the studies in this dissertation because they suggest that pre-existing biases against the police (either positive or negative) will partially determine how evidence is evaluated in trials involving police officers and, ultimately, how verdicts are reached. For example, if a police officer is charged due to allegations of excessive force and their testimony contradicts footage from a BWC, those who are predisposed to view the officer negatively (e.g., police can't be trusted) will likely evaluate the discrepancies as a sign of deceit, rather than reflecting different perspectives, or as a legitimate failure of memory. Using the terminology of The Story Model or the Director's Cut Model, if a story being presented to jurors (e.g., by the Defence) contradicts pre-existing negative biases towards the police (i.e., the juror does not view the police as legitimate), the plausibility or credibility of the story will be reduced, which will in turn negatively impact the coherence and general acceptability or certainty of the narrative. Even in the face of contradictory evidence (e.g., an expert explaining why discrepancies occur), individuals predisposed to view police officers as less legitimate will likely be resistant to such stories. To examine these issues, I 
attempted to assess the views that participants in Study 2 have towards the police, and determine the extent to which those views relate to dependent variables of interest (e.g., verdict decisions, punishment severity, credibility assessments).

Pro-prosecution bias. As indicated in the previous section, attitudinal predispositions comprise an important part of juror decision-making. One predisposition that has been shown to correlate with verdict outcomes is whether jurors are proprosecution or pro-defence (as measured, for example, by tools such as the Juror Bias Scale [JBS]; Kassin \& Wrightsman, 1983). In terms of predictive validity, scales like the JBS have been found to significantly predict juror verdicts across different samples. For example, research has demonstrated that jurors with a pro-prosecution bias are more likely to convict a defendant (e.g., Beck, Lecci, \& Myers, 2013; Tang \& Nunez, 2003; Warling \& Peterson-Badali, 2003). Devine and Caughlin's (2014) recent meta-analysis confirms this, indicating that a pro-prosecution bias (as measured by the JBS) is a significant predictor of guilty verdicts (JBS-Total Score weighted $r=.22, k=17$ ).

Based on the ability of the JBS to predict verdicts, it is important to incorporate the measure into the current study in order to ascertain if pro-prosecution predispositions predict verdict outcomes (and other variables) when considering cases involving police officers equipped with a BWC who have allegedly exhibited excessive force. As described above, according to The Story Model and the Director's Cut Model, such preexisting biases will likely play an important role in determining the narrative that jurors create (e.g., which narratives are plausible and thus, coherent). This, in turn, will influence verdict decisions (i.e., the goodness-of-fit between the constructed narrative 
and the verdict options) and other variables of interest, such as the credibility of defendants.

Authoritarianism. Another juror characteristic that can be a significant predictor of verdict type, and other trial-related variables, is authoritarianism. Authoritarianism is a personality trait marked by intolerance, favouring punishment for those that deviate from conservative societal norms, support for conservative values, the belief in the use of power, including force, to enforce those values, and rigid and inflexible thinking (Kravitz, Cutler, \& Brock, 1993). It has been hypothesized that jurors with higher levels of authoritarianism are more likely to convict defendants and endorse more severe sanctions, given that they are more likely to perceive defendants as social deviants (Devine \& Caughlin, 2014).

For some time, research has demonstrated that people high in authoritarianism are more likely to render guilty verdicts and endorse harsher punishments (Boehm, 1968; Jones, Jones, \& Penrod, 2015; Lundrigan, Dhami, \& Mueller-Johnson, 2013). In addition, more than one meta-analysis has highlighted the significant relationship between authoritarianism and verdict decisions. For example, Narby, Cutler, and Moran (1993) found a positive, moderately significant relationship showing that jurors who scored higher in authoritarianism were more likely to find the defendant guilty (weighted $r=.16$, $k=20$ ). Likewise, Devine and Caughlin's (2014) meta-analysis supports authoritarianism as one of the strongest predictors of verdict (weighted $r=.17, k=36$ ), with the most significant results occurring when authoritarianism was measured using the Revised Legal Authoritarianism Questionnaire (RLAQ; Kravitz et al., 1993; weighted $r=.21, k=$ 11). 
The ability of authoritarianism to predict verdicts can be explained by The Story Model and Director's Cut Model in that both state that a juror's prior knowledge and beliefs play an important role in the narratives they create and accept when rendering verdicts. Indeed, the Director's Cut Model specifically highlights authoritarianism as a factor that influences story construction on the part of the juror. Existing research warrants the inclusion of this construct in the current study. The present study examines if authoritarianism is equally predictive of verdicts when the defendant on trial is a police officer. Due to the intrinsic ties between policing and conservative values (Suziedelis \& Lorr, 1973; Walker \& Kratcoski, 1985; Zamble \& Annesley, 1987), and the police service's role in upholding societal norms through law enforcement, it is unclear how participants high in authoritarianism will respond to cases where a police officer has been charged with excessive force.

Need for cognition. As discussed previously, it has been determined through jury research that jurors are "active interpreters of trial information rather than passive recipients of evidence" (Neitzel, McCarthy, \& Kerr, 1999, p. 44). However, researchers have also determined that jurors differ in terms of their predisposition or desire to process information and in how they process information. For example, research has found that some individuals process information systematically, whereas others tend to rely on shortcuts to make quick and easy decisions (Caccioppo \& Petty, 1982). The tendency to process information more systematically, which requires greater cognitive effort, is referred to as the need for cognition (NC). As outlined in the Director's Cut Model (Devine, 2012), NC is an important characteristic that may play a vital role when jurors assess evidence and create narratives during a trial. 
Using a Need for Cognition Scale developed by Cacioppo and Petty (1982), studies have examined the role of NC in the jury setting and this research has shown that individuals characterised by high-NC (versus low-NC) tend to be more sensitive to discrepancies or flaws in logic and process information, such as evidence, more thoroughly (DeWitt, Richardson, \& Warner, 1997; Graziono, Panter, \& Tanaka, 1990; Kassin, Reddy, \& Tulloch, 1990). Also, high-NC individuals tend to be more discerning than low-NC individuals regarding the quality of scientific evidence presented by expert witnesses (Leippe, Eisenstadt, Rauch, \& Seib, 2004; McAuliff \& Kovera, 2008). A recent meta-analysis showed that NC was a weak, though significant, predictor of verdicts $(r=-$ $.07, k=10, p<.05)$, whereby jurors who are low in NC tended to be more prone to render guilty verdicts (Devine \& Caughlin, 2014).

While NC is not necessarily a strong predictor of verdicts, it could provide important information in Study 2 regarding how this specific quality predisposes people to evaluate BWC evidence as well as related expert testimony. For example, it may be that high-NC jurors will appreciate or understand the limits of video footage to a greater extent than low-NC individuals, or jurors characterised by high-NC may invest more effort in understanding the testimony of expert witnesses (e.g., when explaining the impact of stress and the perceptual distortions that can occur for police during use of force incidents) and thus, be more persuaded by such testimony. Therefore, a juror's level of NC may play a critical role when jurors construct narratives during a trial because it may impact how the juror processes evidence and testimony (e.g., by allowing them to identify and process apparent inconsistencies in ways that low-NC jurors cannot; Devine, 2012; Pennington \& Hastie, 1991). 


\section{Trial Characteristics}

During a trial, many variables come into play that could impact a juror's decision. The two variables that were manipulated in the current study, which are described here, include discrepancies (degree and nature of discrepancies) and expert testimony.

Discrepancies. Consistency in testimony (e.g., across witnesses, or between a witness and some other piece of evidence) is an important aspect of trials that can influence juror verdicts and other variables (e.g., witness/defendant/lawyer credibility). Recall that both of the models discussed previously (Devine, 2012; Pennington \& Hastie, 1986) have consistency of a story as an important determinant for which version of events will be accepted by jurors. According to these models, the more consistent the testimony, the more coherent a story will be, and more coherent stories are more likely to be accepted by a juror. Although no research exists examining consistency in police testimony for use of force cases, a few studies examining eyewitness consistency have been conducted. These studies potentially shed light on what might occur in cases where, for example, a police officer testifying about a use of force encounter provides testimony that contradicts BWC footage.

Studies in the eyewitness context tend to show that guilty verdicts may be associated with inconsistent testimony being given by witnesses. For example, Lindsay, Lim, Marando, and Cully (1986) conducted a series of experiments manipulating eyewitness inconsistencies. Undergraduate students $(N=60)$ were exposed to defendants that varied in attractiveness (very attractive, not very attractive) and to conditions where inconsistencies in eyewitness testimony varied (i.e., in one manipulation the eyewitness identified the defendant as blond previously, but the defendant had brown hair). The 
researchers hypothesized that defendant attractiveness, when high, would negate the impact of testimony inconsistencies. While their main hypothesis was not supported, jurors in this study rendered more guilty verdicts when they rated the witness as being significantly more consistent. Even more recently, Semmler and Brewer (2002) found that eyewitnesses providing inconsistent testimony were perceived by mock jurors as less effective and the prosecution less credible. Inconsistent testimony also resulted in reduced guilty verdicts (perceptions of culpability).

Another issue related to discrepancies, which may influence jury decisionmaking, is whether the discrepancies are central or peripheral in nature. A central error or discrepancy can be defined as recollection of an action or detail that is essential to the event either because it is spatially proximal to the event/action and/or because it is thematically proximal to the story (Luna \& Migueles, 2009; Wright \& Stroud, 1998). In contrast, a peripheral discrepancy is an error that "is irrelevant to or removed from time and space from the main action" and is therefore thematically distal from the story (Luna \& Migueles, 2009. P. 406). In the case of criminal trials, the "story" is the issue at trial pertaining to the event that surrounds the guilt or innocence of the defendant. Research indicates that the nature of the discrepancy (central or peripheral) influences jury decision-making.

Berman, Narby, and Cutler (1995), for example, examined eyewitness credibility as perceived by jurors $(N=100)$ when witness inconsistencies were manipulated. Eyewitness testimony varied across four conditions: consistent testimony provided by the eyewitness; central (i.e., relevant) inconsistencies only; peripheral (i.e., non-relevant) inconsistencies; and combined inconsistencies (central and peripheral). Results 
demonstrated that inconsistencies in testimony resulted in a decrease in guilty verdicts. Specifically, guilty verdicts decreased gradually across conditions: no inconsistencies present (32\%), peripheral inconsistencies $(20 \%)$, central inconsistencies $(12 \%)$, central and peripheral inconsistencies $(8 \%)$. These results confirmed that inconsistencies in testimony influence the likelihood of jurors rendering guilty verdicts, and that the degree to which guilty verdicts are impacted depends on the nature of the inconsistencies. They also found that these inconsistencies resulted in decreased perceptions of eyewitness credibility, similar to other studies (e.g., Bruer \& Pozzulo, 2014; Tenney, MacCoun, Spellman, \& Hastie, 2007).

Indirectly, the results of these studies support the coherence facet of The Story Model and Devine's Director's Cut Model by showing that when narratives being produced in court lack consistency or credibility, jurors are less likely to convict. What are the implications of these sorts of results for the current study? In the present case, these results suggest that jurors' perceptions of an officer's inconsistencies at trial may influence perceptions of the officer's credibility and the coherence of the narrative being presented, which will ultimately impact verdict decisions (by influencing goodness-of-fit between constructed narratives and verdict options). Furthermore, these studies suggest that the nature of the inconsistencies, or discrepancies, might be useful to consider; important (or central) discrepancies will likely have a more significant impact on narrative construction and acceptance and so confirm the decision to include these variables in current study.

Expert testimony. The Supreme Court of Canada has defined the role of expert testimony as the following: 
An expert's function is precisely this: to provide the judge and jury with a readymade inference which the judge and jury, due to the technical nature of the facts, are unable to formulate. "An expert's opinion is admissible to furnish the Court with scientific information which is likely to be outside the experience and knowledge of a judge or jury. If on the proven facts a judge or jury can form their own conclusions without help, then the opinion of the expert is unnecessary" (in (Turner [1974], 60 Crim. App. R. 80, at p. 83, per Lawton L.J as cited in $R v$. Mohan, [1994] 2 SCR 9)

Thus, unlike eyewitnesses in court, who can only speak to what they observed, expert witnesses can provide their opinions on matters within specific boundaries. Indeed, experts called to testify in court are called "to provide an opinion with respect to those facts which will help the judge, jury or tribunal reach its conclusion" (O’Melia, 1991, p. 2). This means expert witnesses may have a significant influence on jurors when they must decide on a verdict during a trial.

Indeed, research clearly indicates that expert testimony can have an influence on jurors and juries, and the role of the expert is considered in both The Story Model and the Director's Cut Model (Devine, 2012; Pennington \& Hastie, 1986). For example, according to The Story Model, depending on the information provided by the expert and their perceived credibility, an expert can influence the coherence of a story by clearing up inconsistencies or by making a story more complete. Experts can also impact the uniqueness of a story by, for example, providing multiple interpretations of a piece of evidence that are equally probable. 
Numerous studies have been conducted that shed light on issues of importance to the current study, despite the fact that these studies have not examined the role of expert testimony specifically in cases involving the police. For example, Finkel, Meister, and Lightfoot (1991) examined the role of expert testimony in relation to a self-defence claim in a trial involving a woman (the defendant) who killed a man who was abusing her. The expert condition comprised of testimony explaining battered woman syndrome (BWS) to the jurors. These researchers found that mock jurors in the expert testimony condition (versus a no-expert condition) were more likely to view the killing as self-defence and more likely to view the defendant as someone who was unable to think clearly or reasonably (and was therefore perceived as less culpable).

Schuller and Hastings (1996) reported similar findings. They examined the impact of expert testimony in a murder trial where a woman killed her abusive partner. Schuller and Hastings tested three conditions: an expert who pathologized BWS (e.g., clinical explanations of BWS), an expert who avoided using pathology terminology when describing BWS and focused more on social agency (e.g., sufferers of BWV feel helpless, trapped, and cannot perceive viable alternatives), and a condition with no expert testimony. Results revealed that mock jurors rendered more lenient verdicts and were more favourable towards the defendant's claim of self-defence in both expert testimony conditions compared to the no-expert condition, suggesting that expert testimony can affect which story a potential juror constructs and which verdict ultimately matches their narrative.

A meta-analysis conducted by Neitzel et al. (1999) confirms the impact that expert testimony has in jury decision-making studies. Findings from the meta-analysis 
indicated that expert psychological testimony has an average weighted effect size that is modest, but significant $(r=.16)$, when examining whether such testimony can influence jury verdicts. Additional analyses in the meta-analysis indicated that specific testimony (i.e., testimony that is specific to the case details) has a particularly strong effect on verdicts (much stronger than no testimony $[r=.22]$, but also stronger than general testimony $[r=.13])$.

Research beyond this meta-analysis has uncovered various moderators related to the impact of expert testimony in jury research. For example, the impact of expert testimony on variables like verdict decisions has been found to vary as a function of the complexity of the testimony (more impact when the testimony is complex; e.g., Schuller, Terry, \& McKimmie, 2005) and the timing of the testimony (more impact when the testimony is delivered post-evidence; e.g., Leippe, Eisenstadt, Rauch, \& Seib, 2004). Other research has shown that the characteristics of the expert can influence the impact of the testimony being provided. For example, some research has shown that male experts (under certain conditions at least, such as when the testimony is complex) are seen as more credible (e.g., Schuller et al., 2005), whereas other studies have found female experts to have a greater impact on jury outcomes (e.g., Memon \& Schuman, 1998; Schuller \& Cripps, 1998). Other research has demonstrated that the credentials of the expert matters, particularly when the technical complexity of the testimony is high (e.g., Cooper, Bennett, \& Sukel, 1996). Additionally, research has suggested that the "likeability" of an expert, and how extraverted they are perceived to be, can impact perceptions of their credibility by mock jurors (Brodsky, Neal, Cramer, \& Ziemke, 2009). 
Within the court case examined in this dissertation, the role of the expert may be particularly useful given misconceptions that the public might have about use of force encounters, police performance in such encounters, and the role of BWC in policing. It may be that expert witnesses can play a pivotal role in such cases, by correcting misconceptions for example, and that the presence of an expert will impact how jurors evaluate testimony and render verdicts. Given this, the presence of expert testimony will be one of the variables that is manipulated in the main study that comprises this dissertation.

\section{Summary}

The theories that were explored and the research that was cited in this chapter suggest that the juror is an active participant during a trial and that various aspects of the juror and the trial can play a critical role in how evidence is weighed, witnesses are evaluated, and verdicts are determined. More specifically, according to these theories and studies, a juror's pre-existing biases (e.g., pro-prosecution leanings) and tendencies (e.g., need for cognition) will influence the narratives that jurors create over the course of a trial and influence the verdicts that jurors render. Likewise, trial characteristics, such as the presence of expert testimony, will impact juror decision-making.

The main study in this dissertation examines how a range of juror and trial characteristics influence the evaluation of evidence (particularly BWC footage), the perceptions of the defendant, and verdict decisions in trials involving allegations of excessive use of force by police. This study will have answers to questions such as: Do negative attitudes towards police impact how officers are treated in criminal trials? Do pro-prosecution or authoritarian biases impact juror decision-making in trials involving 
police officers as defendants? Does one's need for cognition make jurors more sensitive to trial characteristics, such as the distinction between central and peripheral discrepancies between officer testimony and visual evidence? 


\section{Chapter 4: Public Attitudes and Beliefs Regarding Body Word Camera Use by the Police (Study 1)}

While the use of BWCs by police is increasing, to date, no empirical research has been conducted that examines juror perceptions and decision-making for this specific type of visual evidence. The primary goal of this dissertation is to address this lack of research by examining some fundamental questions that will likely arise when BWC footage is used as evidence in court cases involving allegations of excessive use of force on the part of the police. It is especially pertinent to examine these issues within court cases dealing with the issue of excessive use of force because: (1) the driving force behind BWC adoption by police services is the need for greater police accountability when using force in the field, and (2) increasingly, officers are facing allegations for excessive force and BWCs are likely to be a key piece of evidence in these types of cases as more and more police services begin to adopt the technology.

In order to inform how the main study comprising this dissertation should be conducted, it was decided that it would be informative to have a better understanding of public attitudes and beliefs about BWC use by the police. Although a number of studies have examined police officer views of BWCs (e.g., Brown, 2013; Jennings et al., 2014; Todd, 2015), fewer empirical studies have been conducted to date that examines the public's opinions regarding BWCs (Crow et al., 2017; Sousa et al., 2015). Thus, the purpose of Study 1 is to examine Canadian public opinion regarding BWC use by the police.

More specifically, the survey constructed for this dissertation examines specific issues including: (1) the extent to which the public thinks BWC will be useful (e.g., Will 
it decrease police misconduct? Will it improve police officer behaviour?), (2) the extent to which the public is aware of the limitations of BWCs (e.g., Is the public aware that video lacks depth perception? Is the public aware that BWCs do not capture as many frames/second as the human visual processing system?), and (3) public beliefs regarding BWC footage as evidence in criminal court (e.g., Does the public believe that video evidence tells the whole truth compared to other types of evidence? When discrepancies exist between officer testimony and BWC footage, does the public think that the officer is being dishonest?). The survey also captures the demographic characteristics of respondents, which will allow us to examine how these characteristics relate to various attitudes and beliefs about BWCs.

\section{Hypotheses}

The survey conducted in Study 1 is purely exploratory in nature. As such, no formal research questions or hypotheses are being proposed.

\section{Methods}

Participants. Participants for Study 1 were drawn from online community samples using Qualtrics Panels. All those who completed the study received remuneration (the amount was a standard rate set by Qualtrics). Study 1 involved a sample of 230 Canadian participants. For the current dissertation, all participants had to

meet the requirements of being 18 years of age (old enough to be called for jury duty in Canada) and being a Canadian citizen. Failure to meet those requirements disqualified individuals from participating in Study 1.

Out of the 230 respondents, the sample was $56.1 \%$ female, with the remainder being male. The age of respondents ranged from 18 to 88 years of age $(M=46.27$; $\mathrm{SD}=$ 
14.83). The sample was $83.5 \%$ White, $9.1 \%$ Asian, $1.7 \%$ East Indian, $1.3 \%$ Black, $0.9 \%$ Indigenous, 0.4\% Latin/Hispanic, and 0.4\% Middle Eastern. Some of these sample characteristics correspond relatively well to the broader demographic profile of Canadians. For example, the current sample approximates the 2018 gender breakdown in Canada, which suggests that $50.4 \%$ of Canadians are female. ${ }^{3}$ The mean age of our participants also approximates the average age of Canadians in 2018 (42.2 years). ${ }^{4}$ Ethnicity was more difficult to compare to Canadian data given that our ethnicity categories differed from those reported in other studies (that being said, it does seem that some ethnic groups were under-represented in our study, such as Indigenous participants). ${ }^{5}$

In terms of education level, $41.3 \%$ of respondents had graduated college or earned a bachelor's degree, $26.1 \%$ had some college or university education, $15.7 \%$ had only a high school degree, $11.7 \%$ had completed a master's or doctorate degree, $3.9 \%$ had completed some high school, and $1.3 \%$ had completed a medical degree. With respect to political affiliation, $37.4 \%$ of respondents identified as having no political affiliation, $26.1 \%$ identified as Liberal, $17.8 \%$ identified as Conservative, $14.8 \%$ identified as New Democratic Party, 2.6\% identified as Green Party, and 1.3\% identified as Bloc Quebecois. A total of $8.3 \%$ of respondents identified as being (or having been) in law enforcement (i.e., a police officer, correctional officer, or security officer). As far as we can tell, these variables also correspond reasonably well to Canadian statistics related to the highest level education attained by Canadians (although we could not locate data for

\footnotetext{
${ }^{3} \mathrm{http}: / /$ worldpopulationreview.com/countries/canada-population/

${ }^{4} \mathrm{https}$ ://www.indexmundi.com/canada/demographics_profile.html

${ }^{5} \mathrm{https}: / /$ www.indexmundi.com/canada/demographics_profile.html
} 
all of the categories we sampled), ${ }^{6}$ as well as current party standings in this country (which may be considered a proxy for individual political affiliations). ${ }^{7}$

Regarding exposure to BWCs in the media, $46.1 \%$ of respondents indicated that they had read news stories regarding BWCs and their potential strengths and/or limitations. A total of $69.1 \%$ of respondents reported being familiar with the police shooting of Michael Brown that had occurred in Ferguson, Missouri (which resulted in the initial push to implement BWCs in the US). A total of $72.6 \%$ participants responded that they had seen depictions of police captured on video, whether via news or social media, although only $14.8 \%$ reported having seen such depictions "a lot". When asked specifically if they had seen BWC footage depicting police use of force incidents, in the news or through social media, $42.6 \%$ of respondents said they had, although only $12.2 \%$ responded that they had seen BWC depictions of police use of force through media "a lot”. A reasonably large number of respondents were unsure if their local police used BWCs $(60.4 \%)$.

Procedure. Participants were directed to an online survey delivered via the Qualtrics survey platform. Upon clicking the study URL, participants were asked to read an informed consent form (Appendix A) that provided them with all of the essential details regarding their participation. Those who agreed to participate then proceeded to the inclusion criteria (Are you 18 years of age or older? Are you a Canadian citizen?) that are part of a larger demographic questionnaire (Appendix B). If they met the inclusion criteria, participants then proceeded to complete the demographics questionnaire and

\footnotetext{
${ }^{6} \mathrm{https}: / / \mathrm{www} 12$. statcan.gc.ca/census-recensement/2016/dp-pd/hlt-fst/edusco/Table.cfm?Lang $=\mathrm{E} \& \mathrm{~T}=11 \& \mathrm{Geo}=00 \& \mathrm{View}=2 \&$ Age $=2$

${ }^{7}$ https://www.ourcommons.ca/Parliamentarians/en/partystandings
} 
move onto the survey questionnaire (see Appendix C). Once they completed the questionnaire, participants were thanked for their time and given a form that reiterated the purpose of the study and provided contact information should they have any questions or concerns (Appendix D). All participants were automatically credited the agreed upon amount for their participation $(\$ 1.00)$ in accordance with the terms and conditions of membership in the Qualtrics survey panel. The study lasted for one testing session of approximately 25 minutes.

\section{Results}

The results are structured as follows. First, we examine public attitudes towards the use of BWCs by the police. This is followed by an exploration of public beliefs and knowledge regarding BWC limitations. We then turn to questions that asked about perceptions of officer conduct, and about general opinions regarding the police and the criminal justice system. The final set of results presented below relate to demographic differences in opinions about BWCs (based on ethnicity, sex, and then age).

Public attitudes towards BWC use by police. The first set of items focused on concerns over being video recorded. Responses to these survey items indicate that, overall, respondents were not very concerned with police wearing BWCs. Indeed, the majority of respondents did not feel particularly concerned about being recorded by either the public or by the police. The two questions related to these concerns used a scale from 1 (not at all concerned) to 7 (extremely concerned). The average rating of the first question, "How concerned are you with being video-recorded (including surreptitiously) by other people?" was 2.97 (SD = 1.91), demonstrating relatively little concern. The average rating for the second question, "How concerned are you with police officers 
wearing a device that would video-record their conduct while performing their duties in public?" was even lower $(M=2.70 ; \mathrm{SD}=1.93)$. When asked how concerned they are about being recorded publicly, the largest proportion of respondents $(34.8 \% ; n=80)$ answered that it was rarely on their mind at all. When asked how concerned they are about being recorded by the police, the largest proportion of respondents $(42.6 \%, n=98)$ answered that they were "not at all concerned".

The next set of questions shown in Table 2 focused on opinions towards police use of BWCs (responses were given on 7-point Likert scales where $1=$ strongly agree, 4 $=$ neutral, and $7=$ strongly disagree). The means in Table 2 tend to all fall below the midpoint and the standard deviations are small. This suggests that respondents generally agree that police wearing BWCs will increase public trust in police, enhance officer accountability, reduce false reports of misconduct against police, and improve police investigations by providing evidence. The only exceptions were two items. First, responses to the item, "Officers should be able to control when a body-worn camera records", showed that respondents tended to disagree that police should be able to control when $\mathrm{BWCs}$ record $(M=4.70, \mathrm{SD}=1.89)$. This suggests a lack of trust in police autonomy over BWCs among our respondents. Secondly, responses to the item, "The use of body-worn cameras by police violates my right to privacy", tended to indicate some degree of public concern over privacy $(M=4.48, \mathrm{SD}=1.65)$. Note that in both cases, the means do not indicate these are serious concerns for the respondents.

Also of note in Table 2 is that community respondents appear to agree more with the view that BWCs will reduce police misconduct, rather than improve citizen behaviour. A $t$-test was conducted to compare the belief that BWCs would improve 
police versus citizen behaviour. There was a significant difference found, indicating that respondents agreed that BWCs would improve police behaviour $(M=2.59, \mathrm{SD}=1.40)$ significantly more than citizen behaviour $(M=3.03, \mathrm{SD}=1.48) ; t(229)=-5.563, p<$ $.001, d=-.31,95 \%$ CI [-.44, -.18]. This difference was associated with a small effect size. 
Table 2

Public Attitudes Towards Police Use of BWCs

\begin{tabular}{lcc}
\hline Opinion & Mean & SD \\
\hline $\begin{array}{l}\text { Officers should be able to control when a body-worn camera records } \\
\text { The use of body-worn cameras by police violates my right to privacy }\end{array}$ & 4.70 & 1.89 \\
$\begin{array}{l}\text { Body-worn cameras should only record when police are approaching } \\
\text { a possible incident/potential suspect }\end{array}$ & 3.82 & 1.93 \\
$\begin{array}{l}\text { Police should alert people before they record them with a body-worn } \\
\text { camera }\end{array}$ & 3.34 & 1.78 \\
$\begin{array}{l}\text { If police wore body-worn cameras, I would feel safer } \\
\begin{array}{l}\text { Police officers wearing a body-worn camera would improve citizen } \\
\text { behaviour while on duty }\end{array}\end{array}$ & 3.15 & 1.45 \\
$\begin{array}{l}\text { The use of body-worn cameras by police will increase public trust in } \\
\text { the police }\end{array}$ & 3.00 & 1.41 \\
$\begin{array}{l}\text { Body-worn cameras should be recording at all times when police are } \\
\text { on duty }\end{array}$ & 2.80 & 1.55 \\
$\begin{array}{l}\text { Police officers wearing a body-worn camera would improve officer } \\
\text { behaviour while on duty }\end{array}$ & 2.59 & 1.40 \\
$\begin{array}{l}\text { The use of body-worn cameras by police will reduce false misconduct } \\
\text { reports against the police by the public }\end{array}$ & 2.37 & 1.31 \\
$\begin{array}{l}\text { The use of body-worn cameras by police will make police more } \\
\text { accountable for any misconduct }\end{array}$ & 2.29 & 1.28 \\
\begin{tabular}{l} 
by providing much needed evidence (i.e., caught in the act on video) \\
\hline
\end{tabular} & 2.13 & 1.11 \\
\hline
\end{tabular}

Note. $S D=$ standard deviation

7-point Likert scale where $1=$ strongly agree, $4=$ neutral, and $7=$ strongly disagree.

Table 3 presents results related to when respondents think BWCs should be turned off. The majority of respondents felt that BWCs should be turned off when officers are on break $(66.5 \%)$, one third of respondents felt that BWCs should be turned off when 
children are present (33.0\%), while just under one third felt BWCs should be turned off when the public requests the officer not to record them (27.0\%). Approximately one quarter of respondents felt that BWCs should be turned off when the officers are in a person's residence $(25.7 \%)$ and slightly less felt that BWCs should be turned off when police are interviewing an informant $(23.9 \%)$. Just over one in five respondents felt BWCs should be turned off when police are attending community events, such as a parade $(21.3 \%)$, when police are investigating a sexual assault $(20.9 \%)$, and when police are involved in everyday interactions with the public (20.9\%). Only $10.0 \%$ of respondents felt that BWCs should be turned off when police are investigating a domestic dispute.

Table 3

Public Opinion on When Police Should Not Use BWCs

\begin{tabular}{lcc}
\hline Police recordings should be turned off when: & Frequency & Percent (\%) \\
\hline Police are on break & 153 & 66.5 \\
A member of the public requests to not be recorded & 76 & 33.0 \\
Children are present & 62 & 27.0 \\
Police are in a person's residence & 59 & 25.7 \\
Police are interviewing an informant & 55 & 23.9 \\
Police are attending community events such as parades & 49 & 21.3 \\
Police are investigating a sexual assault & 48 & 20.9 \\
Police are involved in everyday interactions with the public & 48 & 20.9 \\
Police are investigating a domestic dispute & 23 & 10.0 \\
\hline
\end{tabular}

Note. Categories are not mutually exclusive; $N=230$. 
When asked how long BWC video recordings should be retained by police services, answers varied, as seen in Table 4. The largest proportion of respondents felt that video recordings should be retained for 1 year $(21.7 \%)$. The second largest group of respondents felt that video recordings should be retained forever $(17.4 \%)$. These results demonstrate how wide-ranging community responses are regarding video retention.

Table 4

Public Opinion on Retention Length of BWC Footage by Police Services

\begin{tabular}{lcc}
\hline $\begin{array}{l}\text { How long video BWC video recordings should be retained } \\
\text { by police: }\end{array}$ & Frequency & Percent \% \\
\hline Destroyed immediately afterwards & 14 & 6.1 \\
3 months & 28 & 12.2 \\
6 months & 22 & 9.6 \\
1 year & 50 & 21.7 \\
3 years & 32 & 13.9 \\
5 years & 28 & 12.2 \\
10 years & 16 & 7.0 \\
Forever & 40 & 17.4 \\
\hline
\end{tabular}

Note. $N=230$.

When asked about their willingness to pay higher taxes to ensure local police services are equipped with BWCs, answers from respondents varied. The largest number of respondents were undecided (neither agreed or disagreed; $25.2 \% ; n=58$ ). When combining the range of responses for agreed and disagreed statements respectively (e.g., agree $=$ strongly agree, agree, or somewhat agree), $41.3 \%$ agreed that they would pay taxes and $33.5 \%$ disagreed that they would, indicating that the larger proportion of 
respondents supported paying higher taxes to ensure their local police services are equipped with BWCs.

\section{Public beliefs and knowledge regarding visual evidence and its limitations.}

Respondents displayed a strong belief that photographic and video evidence represents the "truth". Recalling that lower numbers represent agreement, responses shown in Table 5 indicate that respondents had a strong tendency towards believing that video evidence is infallible (i.e., video recordings tell the truth; $M=2.64, \mathrm{SD}=1.25$ ), and yet participants also recognized that video evidence is able to be manipulated $(M=2.63$, SD $=1.37)$. In fact, as discussed in Chapter 2, research suggests that video is not a truth tellall, as "truth" is interpreted differently by different people and depends on many variables such as the angle of the camera, what happened before and after the video (i.e., framing of the frame), the predispositions of the viewer, how the video is captioned, who is controlling the narration, and more (Butler \& Sontag, 2007; Mezey, 2013; Schwartz et al. 2009). 
Table 5

Public Beliefs About Photographic and Video Evidence

\begin{tabular}{|c|c|c|}
\hline Belief & Mean & SD \\
\hline $\begin{array}{l}\text { In court, I would view video evidence of a potential crime presented by the } \\
\text { prosecution as more credible than video evidence presented by the defence } \\
\text { (the lawyer representing the accused) }\end{array}$ & 3.94 & 1.25 \\
\hline $\begin{array}{l}\text { In court, I would view video evidence of a potential crime introduced by the } \\
\text { judge to be more credible than video evidence presented by the prosecution or } \\
\text { the defence }\end{array}$ & 3.80 & 1.25 \\
\hline $\begin{array}{l}\text { In court, I would view a video recording from a police officer (via a body- } \\
\text { worn camera) as more credible than a video recording from a bystander (via a } \\
\text { cell phone or handheld camera) }\end{array}$ & 3.63 & 1.43 \\
\hline $\begin{array}{l}\text { Video produced from body-worn cameras is consistently of very high visual } \\
\text { quality }\end{array}$ & 3.50 & 1.20 \\
\hline A photograph tells the truth by providing an image & 3.28 & 1.53 \\
\hline $\begin{array}{l}\text { A photograph of an incident gives a more accurate account than eyewitness } \\
\text { testimony of the same incident }\end{array}$ & 3.12 & 1.37 \\
\hline A video recording tells the truth about the recorded event & 2.64 & 1.25 \\
\hline A video can be altered/manipulated after the video was recorded & 2.63 & 1.37 \\
\hline $\begin{array}{l}\text { A video of an incident gives a more accurate account than eyewitness } \\
\text { testimony of the same incident }\end{array}$ & 2.62 & 1.21 \\
\hline A photograph can be altered/manipulated after the photo has been taken & 2.19 & 1.26 \\
\hline
\end{tabular}

Note. $S D=$ standard deviation

7-point Likert scale where $1=$ strongly agree, $4=$ neutral, and $7=$ strongly disagree.

Responses directly related to knowledge of camera and video limitations

demonstrate that there are a number of uncertain or blatantly false ideas about video that are endorsed by jury-eligible Canadians. As seen in Table 6, the majority of respondents chose "don't know" for all limitation questions, except in two cases where the greatest proportion of respondents answered "yes:" (1) "Can a video recorder capture depth perception?" (47.4\% responded yes) and (2) “Can a video recorder record a scene as fast as the human visual system can process that scene?" (49.6\% yes). In both of these cases, 
the answer "yes" is false. Video does not capture depth perception, nor can video cameras record a scene as fast as the human visual system can process that scene (Force Science Institute, 2010). ${ }^{8}$

When examining the yes/no answers, we can see that, overall, the majority of respondents answered the questions incorrectly (i.e., they answered yes, when in reality the correct answer is no). For example, more respondents believed, than disbelieved, that a video camera can pick up subtle threat cues (e.g., the flash of metal in a person's hand that could be a knife or a gun) to the same degree that the human visual system can (false). There were only two exceptions to this pattern of results: (1) a slightly greater proportion of respondents believed that a camera (photo) cannot capture depth perception $($ no $=29.6 \%$ vs. yes $=26.1 \%)$ and (2) respondents were evenly split on whether they thought a camera could capture a scene in poor lighting better than the human eye $(29.1 \%$ for yes and no).

In sum, based on the results in Table 6 , there are only two cases where more respondents answered questions correctly than incorrectly (i.e., in line with the realities of what we know about video technology). Even then, the percentages were less than 1/3 of the total number of respondents. Furthermore, the majority of respondents always answered questions incorrectly ("yes") or indicated that they were unsure of the answer (“don't know"), suggesting that the majority of respondents did not recognize photo and video limitations.

\footnotetext{
${ }^{8}$ Although there have been recent advancements in surgery and scientific lab settings for specialized camera videos to provide depth perception, such technology is not widely available to the general public at this time (https://pro.sony/s3/cms-static-content/uploadfile/79/1237492477079.pdf).
} 
Table 6

Public Knowledge About Photo and Video Limitations

\begin{tabular}{lcccc}
\hline Limitation & $\begin{array}{c}\text { Yes } \\
(\mathbf{\%})\end{array}$ & $\begin{array}{c}\text { No } \\
(\mathbf{\%})\end{array}$ & $\begin{array}{c}\text { Don't know } \\
(\mathbf{\%})\end{array}$ & Reality \\
\hline $\begin{array}{l}\text { Can a camera capture depth } \\
\text { perception? }\end{array}$ & 26.1 & 29.6 & 44.3 & No \\
$\begin{array}{l}\text { Can a video recorder capture depth } \\
\text { perception? }\end{array}$ & 47.4 & 10.4 & 42.2 & No \\
$\begin{array}{l}\text { Can a camera capture a scene in } \\
\text { poor lighting or darkness better } \\
\text { than the human eye can see? }\end{array}$ & 29.1 & 29.1 & 41.7 & Yes \\
$\begin{array}{l}\text { Can a video recorder record a } \\
\text { scene in poor lighting or darkness } \\
\text { better than the human eye can see? }\end{array}$ & 30.9 & 24.3 & 44.8 & Yes \\
$\begin{array}{l}\text { Can a video recorder record a } \\
\text { scene as fast as the human visual } \\
\text { system can process that scene? }\end{array}$ & 49.6 & 16.5 & 33.9 & No \\
$\begin{array}{l}\text { Can a video recorder pick up on } \\
\text { subtle threat cues (for example, } \\
\text { tensing of a suspect's body, flash } \\
\text { of metal), the same as the human } \\
\text { visual system can? }\end{array}$ & 33.9 & 27.4 & 38.7 & No \\
\hline
\end{tabular}

Perceptions of officer conduct. A number of items were presented to respondents, which attempted to capture their views about officer conduct in situations that could occur when using BWCs. For example, participants were presented with the following scenario: "During an incident where a police officer had to use force on a suspect, the officer said they turned on their body-worn camera, but it did not record. If you were to hear this explanation in a court case involving allegations of excessive use of force by the police officer, would you see the officer as being dishonest?" of the participants surveyed, only $18.7 \%$ thought the officer would be telling the truth in this situation. The majority of respondents believed the officer to be dishonest (48.3\%), while 
$33 \%$ responded "other". The "other" responses were varied, including: respondents wanted to know if the BWC malfunctioned, respondents wanted information about whether the officer had a history of questionable conduct, respondents indicated their answers would depend on the context of the situation, etc.

Interestingly, a shift in public perceptions of officer honesty was observed when the nature of the discrepancies (between officer testimony and BWC footage) varied. For example, in answering the question of how they would perceive the officer when, "An officer testifies in a use of force court case that he was standing beside a bush, but a video of the incident shows it was a mailbox", the largest number of participants responded that they would interpret this as the officer being mistaken (57.0\%), with only $20 \%$ perceiving the officer as lying. However, when the error in testimony was arguably more central to the issue of use of force, such as, "An officer testifies in a use of force court case that the suspect was lunging at him with a bat, but the video shows the suspect was walking with a bat", the largest number of respondents perceived the officer as being dishonest (42.2\%), with only $23.9 \%$ of respondents perceiving the officer as being honestly mistaken. Therefore, it would appear that the nature of the discrepancy is critical to how individuals perceive these discrepancies.

General opinions about the police and the criminal justice system. The final section of the survey asked respondents about various policing issues and the criminal justice system (e.g., their views regarding expert witnesses). When respondents were asked if stress in a use of force event can cause problems with respect to an officer's memory of the event, respondents generally agreed $(M=2.77, \mathrm{SD}=1.13)$. Respondents also generally agreed that experts hired by the Defence or Prosecution only report what 
the side that hired them wants to hear $(M=3.51, \mathrm{SD}=1.35)$. Similarly, there was general agreement that expert witnesses presented by the Defence are only hired guns whose goal is to get the accused acquitted even when evidence suggests the defendant is guilty $(M=$ $3.74, \mathrm{SD}=1.43)$

Differences in opinions about BWC use across demographics. A closer examination of responses across demographic variables was conducted. Significant results were found across three different demographic categories: ethnicity, sex, and age.

Ethnicity. To examine if any of the responses to survey items differed across ethnic groups, responses were aggregated by group and Hedges' $g$ (a measure of effect size that is appropriate for comparisons between two groups with uneven sample sizes) was calculated. ${ }^{9}$ Due to the small number of respondents who belonged to ethnic groups other than White, these respondents were combined into a non-White group $(n=38)$ and compared to the White group $(n=192)$.

Results showed that, overall, there were no significant difference in responses based on ethnicity, except for two questions. ${ }^{10}$ First, for the question, "In court, I would view video evidence of a potential crime presented by the prosecution as more credible than video evidence presented by the defence (the lawyer representing the accused)" there was a significant difference in responses (and a near medium effect size), indicating that non-White respondents $(M=3.50 ; \mathrm{SD}=1.18)$ were significantly more likely to agree with this statement than White respondents $(M=4.03 ; \mathrm{SD}=1.25) t(74)=-2.81 ; p=.006$, $g=.43 ; 95 \%$ CI $[.08, .78]$. Secondly, non-White respondents $(M=4.11 ; \mathrm{SD}=1.74)$ were

\footnotetext{
${ }^{9}$ Hedges' $g$ has the same cut-offs as Cohen's $d: .20=$ small effect, $.50=$ medium effect, $.80=$ large effect (Rosenthal \& Rosnow, 1991).

${ }^{10}$ A table containing all the results, including non-significant findings, can be found in Appendix O. Only significant results are discussed in the text.
} 
significantly more likely, compared to White respondents, to agree that police officers should be able to control when a body-worn camera records $(M=4.82 ; \mathrm{SD}=1.90) t(74)$ $=-2.21 ; p=.006, g=.38 ; 95 \% \mathrm{CI}[.03, .73]$. This finding was associated with a small Hedges' $g$.

Three significant differences were found when using chi-square analyses to examine the categorical responses to questions between ethnicity groups. Phi $(\varphi)$ or Cramer's V was calculated, as appropriate, depending on the contingency tables (i.e., $\varphi$ for $2 \times 2$ contingency tables, Cramer's $\mathrm{V}$ for larger than $2 \times 2$ tables). ${ }^{11}$ First, when presented with the item, "An officer testifies in a use of force court case that he was standing beside a bush, but a video of the incident shows it was a mailbox. Would your tendency be to view this officer as dishonest, mistaken or not sure?", the number of participants that thought the police officer was dishonest differed significantly by ethnicity, $\chi^{2}(3, N=230)=8.48, p=.034, V=.19$. Examination of the adjusted standardized residuals indicated that more non-White respondents than White respondents viewed the officer as dishonest. Second, when asked, "Can a video capture depth perception?", significantly more non-White respondents than White respondents believed a video could capture depth perception even though it cannot, $\chi^{2}(2, N=230)=$ $7.00, p=.026, V=.17$. Finally, there was a significant difference, with non-White respondents (72.0\%) exhibiting higher agreement than White respondents $(40.4 \%)$ to the item stating that BWCs should not record when children are present, $\chi^{2}(1, N=230)=$ $8.19, p=.004, \varphi=.25$.

\footnotetext{
${ }^{11}$ Cut-offs for $\varphi: .10=$ small effect, $.30=$ medium effect and $.50=$ a large effect size. For Cramer's V, cutoffs depend on the df (Cohen, 1988). A short list of Cramer's V cut-offs for reference can be found here: http://www.real-statistics.com/chi-square-and-f-distributions/effect-size-chi-square/
} 
Sex. When sex differences were examined, only one $t$-test was found to be significant. ${ }^{12}$ Specifically, female respondents $(M=3.96 ; \mathrm{SD}=1.35 ; N=129)$ believed that expert witnesses for the Defence are only hired guns that are there to help get the accused acquitted (even when the evidence suggests they may be guilty) to a lesser degree compared to male respondents $(M=3.47 ; \mathrm{SD}=1.47 ; N=101) t(228)=2.65 ; p=$ $.009, g=-.35,95 \%$ CI [-.61, -.09]. Curiously, there was no significant sex difference for the belief about whether experts only report for the side they are hired to testify on behalf of (whether it be Defence or Crown).

Meanwhile, chi-square tests on categorical responses revealed two significant sex differences. First, fewer females $(45.0 \%)$ than males $(50.5 \%)$ believed (even though it is not true) that video provides depth perception, $\chi^{2}(2, N=230)=6.15, p=.046 ; V=.16$. Second, females $(23.3 \%)$ were less likely than males $(40.6 \%)$ to believe (even though it is true) that video can "see" in darkness or low lighting better than the human eye, $\chi^{2}(2, N=$ 230) $=8.12, p=.017, V=.19$.

Age. Regression analyses were conducted to examine if any (continuous) responses to items on the survey differed by participant age. A total of six significant findings emerged from the analyses. ${ }^{13}$ First, as age increased, the degree to which respondents were concerned about being video recorded while out in public decreased, $\beta$ $=-.03, t(228)=-3.50, p<.001,95 \%$ CI $[-.05,-.01])$. Age also explained a statistically significant (but small) proportion of variance in the likelihood of being concerned with being recorded while out in public, $R^{2}=.05, F(1,228)=12.27, p=.001$. Second, as age

\footnotetext{
12 A full table of all findings, including non-significant results, can be found in Appendix P.

13 A full table of all findings, including non-significant results, can be found in Appendix Q.
} 
increased, the degree to which respondents were concerned about being video recorded by police officers decreased, $\beta=-.03, t(228)=-2.87, p=.005,95 \%$ CI $[-.04,-.01]$. Age also explained a statistically significant (but small) proportion of variance in the likelihood of being concerned with being recorded by police using BWCs, $R^{2}=.04, F(1$, 228) $=8.22, p=.005$.

Third, age predicted how strongly a respondent believed the use of BWCs would improve officer behaviour. As age increased, respondents' belief that the use of BWCs would improve officer behaviour decreased, $\beta=-.01, t(228)=-2.28, p=.023,95 \%$ CI [$.03,-.00]$. Age also explained a significant (but small) proportion of variance in belief that the use of BWCs would improve officer behaviour, $R^{2}=.02, F(1,228)=5.20, p=$ .023. Of note, no significant relationship was found between age and beliefs that BWCs would improve citizen behaviour. Fourth, as age increased, respondents believed more strongly that officers should announce if they are recording people, $\beta=.02, t(228)=$ $2.75, p=.007,95 \% \mathrm{CI}[.01, .04]$. Age also explained a statistically significant (but small) proportion of variance in the belief that officers should announce if they are recording people, $R^{2}=.03, F(1,228)=7.54, p=.007$.

Fifth, as age increased, respondents' belief that BWCs would improve investigations decreased, $\beta=-.01, t(228)=-2.70, p=.007,95 \%$ CI $[-.02,-.00]$. Age explained a statistically significant (but small) proportion of variance in the likelihood to believe that BWCs would improve investigations, $R^{2}=.03, F(1,228)=7.28, p=.007$. Finally, the sixth significant finding was that, as age increased, belief that the use of BWCs by police violates privacy increased, $\beta=.03, t(228)=3.75, p<.001,95 \% \mathrm{CI}[.01$, .04]. Age explained a statistically significant (but small) proportion of variance in the 
likelihood to believe that the use of BWCs by police violates privacy, $R^{2}=.06, F(1,228)$ $=14.02, p<.00$.

To examine the association between age and categorical responses, nominal logistic regression analyses were conducted. The response to two questions were found to be statistically significant. First, for the question, "An officer testifies in a use of force court case that he was standing beside a bush, but a video of the incident shows it was a mailbox. Would your tendency be to view this officer as dishonest or mistaken?", there was a statistically significant, but small effect. The proportion of people responding "dishonest" as compared to "not sure" depended on age (Wald $=5.36, b=.04, p=.021)$. The odds ratio (OR) indicates that the odds of responding "dishonest" compared to "not sure" increased by 1.04 as age increased by 1 unit. Similarly, the odds of responding "mistaken" versus "dishonest" increased by 1.05 as age increased by 1 unit (Wald= $15.75, b=.05, p<.001)$. Curiously, there was no significant relationship between age and any responses to the question that related to a central error (i.e., "An officer testifies in a use of force court case that the suspect was lunging at him with a bat, but the video shows the suspect was walking with a bat. How would you view the officer...?").

The other significant finding related to the question, "Can a video capture depth perception?" The proportion of people responding "no" as compared to "don't know" depended on age (Wald $=4.77, \mathrm{~B}=.04, p=.029)$. The odds of responding "don't know" compared to the correct answer "no" increased by 1.04 as age increased by 1 unit.

\section{Discussion}

Study 1 consisted of a survey that was designed to capture the views of Canadian respondents towards BWCs and a range of other related issues. More specifically, we 
were interested in views related to: (1) general opinions about BWC use by police, (2) knowledge regarding BWC limitations, (3) perceptions of officer conduct, and (4) opinions about various policing issues and the criminal justice system. Below, findings related to each of these issues are discussed.

General opinions. The findings from the survey of Canadian respondents suggest that there is general approval for BWC use by police and that the public generally believes the use of BWCs will lead to: improved accountability, increased trust in police, reduced false reports of misconduct against police, and higher quality police investigations by providing better evidence. These findings are in line with previous research cited in Chapter 2 that has examined public opinions of police use of BWCs (e.g., Crow et al., 2017; Sousa et al., 2015).

Importantly, the present research suggests that these positive attitudes may even translate into citizen behaviour that is supportive of BWC use by the police. For example, many people who responded to the current survey indicated that they would be willing to pay higher taxes to ensure that the police can adopt BWCs. This finding is consistent with other research recently conducted in Canada, which has examined this issue more directly. Using regression analysis, Ferrara, Emeno, Ellingwood, Bennell, and Schultheis, (2019) found that positive attitudes towards BWCs (e.g., If police wore BWCs I'd feel safer) and perceived knowledge of BWC-related issues (e.g., I have read reports about BWCs) strongly predict support for paying higher taxes to ensure BWCs can be used by the police.

Retention of BWC footage. While the majority of participants appeared to endorse generally positive views of BWC use by the police, there were certainly items 
included on the survey that were associated with much higher levels of disagreement among respondents. For example, respondents clearly had different views regarding how long BWC video footage should be stored. There was no clear majority response to this survey item. While it is difficult to know for sure why the respondents had different views on this issue, it may be due to the fact that respondents (and the public more generally) are unaware of the costs and benefits associated with video storage and retention.

There are definite advantages to long-term retention of video footage, such as when cases are appealed in court, but long-term storage and retention also comes at a high financial cost. Indeed, storage and retention are by far the highest costs associated with BWC use for police services and this appears to be one of the main reasons why some police services do not adopt BWCs (Pfeffer, 2016; Valiante, 2019). If participants were provided with detailed information regarding storage and retention costs and benefits prior to asking them for their opinions on these sorts of issues, their answers may have been quite different. Providing additional information about legal and privacy considerations may also help the public develop more informed opinions regarding the challenges faced by police services when storing and retaining video footage.

BWC limitations. An important way in which the current survey differs from other BWC opinion surveys, relates to the inclusion of questions focused on BWC limitations. Generally, responses to these questions suggests that respondents view video evidence as infallible (i.e., a video tells the truth). The majority of respondents either answered the video limitation questions incorrectly or responded that they did not know if the stated information, all of which is supported through research, was true or not. In 
other words, the majority of survey respondents believed video evidence to be infallible, but they were simultaneously unaware (or unclear) on BWC limitations.

These findings may have serious implications when visual evidence is presented in a court of law (and thus, the findings are clearly relevant to Study 2). For example, if such evidence is seen as infallible by jurors (or judges) and thought to demonstrate the "whole truth", undue weight may be put on this evidence (e.g., preference will be given to the video evidence over other forms of evidence, such as officer testimony), which may unduly influence verdict decisions. Furthermore, these findings speak to the potential value of bringing expertise into the court room (e.g., through expert witness testimony) in cases that include visual evidence such as BWC footage, in order to educate the court about these limitations. Despite the obvious reservations that our respondents had towards the use of expert witnesses in court, the use of expert witnesses in such cases would likely alleviate some of these concerns (at least based on the literature reviewed in Chapter 3; e.g., Finkel et al., 1991; Schuller \& Hastings, 1996).

Opinions about police conduct and the criminal justice system. Interestingly, not all of the findings emerging from the current survey were positive. Indeed, there are some signs that our survey respondents do not fully trust the police. For example, in early sections of the survey, responses to items clearly indicated a degree of concern over police officers having the autonomy to choose when to record. Similarly, many of our respondents indicated that they would not trust a police officer who allegedly used excessive force if he/she indicated that they turned their BWC on, but it failed to record the incident. 
Of most relevance to the current study were findings related to how people responded to scenarios where discrepancies existed between officer testimony about an incident and BWC footage of that incident. While respondents sometimes saw such discrepancies as honest mistakes, this was not always the case. In particular, when the discrepancies related to central (versus peripheral) discrepancies (i.e., important aspects of an incident, such as the way a subject was behaving before force was utilized by the responding officer), survey respondents were much more likely to view the officer as being dishonest. Such a finding may mean that when such discrepancies surface in the court room, jurors may be more likely to find officers charged with excessive force guilty.

Demographic differences in opinions. While generally there were not a lot of demographic differences in the way that people responded to the survey, there were some potentially important results. Unfortunately, the findings from the survey do not provide a clear picture of what the differences actually mean. For example, some of the ethnic differences suggested that non-White respondents may be more suspicious of police officers, or lack the trust in police that White respondents possess (e.g., non-White respondents were more likely to view peripheral discrepancies [between officer testimony and BWC footage] as the result of police dishonesty rather than legitimate memory errors). This difference might be expected given that it is consistent with other research that has examined perceptions of police legitimacy among minority and non-minority groups (e.g., Crow et al. 2017). However, in other cases, quite different results emerged. For example, it appears that more non-White respondents than White respondents believe that police officers should have a choice regarding when they record using their BWCs 
(i.e., police officers should have a degree of autonomy when it comes to making this decision). Why these seemingly contradictory findings exist is unclear at the moment. Resolving this matter will likely require more focused research that specifically targets this issue (e.g., the use of focus groups to understand why people from various ethnic backgrounds endorse the views they do about the police and their use of BWCs).

Similar things could be said about other demographic differences. For example, with respect to age differences, older respondents appear less concerned with being recorded by police, potentially suggesting that younger respondents have less trust in the police. However, younger respondents were more likely to believe that the use of BWCs would improve officer behaviour and police investigations, and they endorse the view that it is not as important for officers to announce when they are recording people or situations. Again, more focused research is clearly required to get to the bottom of what these results actually mean. As discussed in Chapter 3, it is also possible of course that these sorts of differences may be due to various biases or predispositions that could be measured in future research (and are in Study 2); things like authoritarianism or perceptions of police legitimacy, for example.

\section{Limitations and Future Directions}

There are a number of limitations associated with Study 1 that are worthy of further discussion. The first limitation relates to sample size. While the sample size was reasonable, additional participants might make the sample more representative of Canadians and potentially increase the generalizability of the findings. A larger sample would also likely result in a more diverse sample, which would have allowed to conduct more rigorous statistical tests of demographic differences. For example, collecting a 
larger, more diverse sample in the future might eliminate the need to combine non-White ethnic groups, which would allow for more fine-grained analyses of ethnic differences.

The second limitation, which can be attributed to the online nature of the study, is that there were no controls in place to reduce interruptions (e.g., phone calls, breaks), distractions (e.g., watching TV, conversations), or anything else that might have interfered with participants completing the survey carefully. This is a potential problem with many online studies. This limitation speaks to the need in future surveys to include attention checks in the survey to encourage respondents to focus and take care when answering questions.

A third limitation is that other measures were not included alongside the survey, which may have provided us with insights into why respondents endorsed specific views. For example, as highlighted in previous chapters, various biases or predispositions (e.g., authoritarianism) may impact the attitudes expressed in the survey, and may account for some of the demographic differences that were observed in this study. It would likely be useful in future survey research to have respondents complete other scales to measure these biases and predispositions, such as police legitimacy scales and authoritarianism. This would allow researchers to formally examine (e.g., through regression analyses or structural equation modelling) how these things influence attitudes towards BWCs, the police, and the criminal justice system more generally.

Finally, like many other studies that rely on surveys (e.g., Adams \& Cox, 2008; Rossi, Freedman, \& Lipsey, 1999), it was not possible to probe respondents to determine exactly why they hold the beliefs/attitudes they hold about BWCs (and the other issues examined in the survey). In other words, while we now have a better understand of what 
the sampled Canadians feel about BWCs, we do not fully understand why they hold the views they do. As argued above, surveys are probably not the best research tool to use for this purpose. The use of focus groups may be better suited to this task, and results from such research will significantly contribute to our understanding of public attitudes towards the topics examined in Study 1.

\section{Implications}

Despite these limitations, a lot was learned from Study 1, and there are several implications of this research that are important to highlight. One set of implications are practical. For example, the results of this survey seem to indicate that, despite some concerns, the public generally supports BWC use by the police and sees value in the use of this technology. Indeed, consistent with other public opinion surveys, our respondents see BWCs as way to improve accountability, increase trust in police, reduce false reports of misconduct against police, and enhance the quality of police investigations. A sizable group of respondents indicated that they are even willing to pay higher taxes to ensure their local police use BWCs. If these findings can be replicated with a larger, more diverse sample, they should be considered when Canadian police services are deciding whether to adopt BWCs.

The results also speak to the need for action on a variety of fronts. Some of these initiatives can be led by the police. Most obviously, due to the lack of knowledge regarding BWC video footage limitations, public education efforts spearheaded by the police are urgently required to address these knowledge gaps. This would hopefully decrease the probability that video footage will be misinterpreted and it would presumably increase (even further) the support for this type of technology. Other action 
items will fall on people involved in the judicial system. For example, the fact that video footage could easily be misinterpreted in court, by a jury or judge, suggests that expert testimony related to this type of evidence (including the limitations of video footage) would be useful. Indeed, the use of expert testimony might assist jurors in more appropriately processing the evidence they are presented with and allow them to make more informed verdict decisions. Lawyers and judges need to seriously consider this.

From a theoretical perspective, the survey results appear to support what is known about visual evidence already. For example, consistent with research discussed in Chapter 2, our respondents clearly see BWCs as a tool that can produce valuable evidence (evidence that can shed light on what occurs during police-public interactions). While the survey does not tell us how the respondents would actually respond to BWC footage if it were presented as evidence in court, it tells us how they think they would respond; and the findings consistently indicate that our respondents think they would put a lot of weight on this evidence, seeing it as an objective account of what occurred during an encounter (to the point where they would prioritize the footage over other accounts, such as testimony provided by officers involved in the incident).

The survey results presented here also suggest that additional research would be useful on a variety of topics. Addressing the various limitations discussed above in future survey research should be an obvious priority, as should research designed to establish where attitudes towards BWCs come from. It would also be extremely useful to determine how the sorts of beliefs/attitudes observed in this type of research manifest in court when mock jurors are presented with visual evidence, such as BWC footage of use of force events. A first step in this direction is presented in the next chapter, where Study 
2 is described. As discussed below, the findings from the current survey were essential in setting the overall direction of that study, in terms of the general issues that are explored.

For example, findings from Study 1 suggest the public lacks an understanding of BWC limitations. This potentially means that problems could occur when BWC footage is introduced as evidence in a court of law. The findings from Study 1 also speak directly to the sorts of variables that might be important to manipulate in mock juror studies. For instance, given how the respondents to our survey treated instances where officer testimony contradicts BWC video footage, it is important to examine this issue by manipulating the types of discrepancies that may exist between officer testimony and BWC footage, both in terms of their number (few vs. many discrepancies) and their nature (peripheral vs. central discrepancies). Likewise, it would be interesting to determine if expert testimony might be useful for clarifying issues for jurors when BWC evidence is presented (e.g., why there might be discrepancies between officer testimony and BWC footage). The fact that individual differences existed in how our survey respondents viewed issues related to BWCs also suggests that various measures of individual differences could prove critical when studying the role of BWC evidence in court. As described in detail in the next chapter, Study 2 empirically examines all of these issues. 


\section{Chapter 5: Mock Juror Perceptions of Body-worn Video Evidence in a Use of Force Case (Study 2)}

Study 2 examines how mock jurors handle cases where discrepancies exist between a police officer's account of what occurred in a use of force event and BWC footage of that event. More specifically, this study explores how mock jurors are impacted by the degree of such discrepancies (few vs. many) and the nature of such discrepancies (peripheral vs. central). How expert testimony impacts mock jurors is also investigated, specifically when that testimony speaks to the nature of use of force events and the likelihood that discrepancies between officer testimony and BWC footage will emerge. Finally, Study 2 examines how various predispositions can significantly influence a juror's decision-making, including one's perceptions of police legitimacy, pro-prosecution biases, level of authoritarianism, and need for cognition.

\section{Hypotheses}

Several hypotheses, which are based on the models discussed in Chapter 3 and/or the research discussed in that chapter, will be tested in Study 2. These include the following.

Hypothesis 1. Discrepancies in Study 2 relate to inconsistencies between what the police officer (defendant) says occurred in a lethal use of force event and what the BWC footage reveals about the encounter. The degree of discrepancies in Study 2 will vary from few discrepancies (2) to many discrepancies (6). It is hypothesised that, when mock jurors are exposed to trials with many (vs. few) discrepancies between officer testimony and BWC footage of the event, they will:

(a) be more likely to render verdicts of guilty; 
(b) assign more severe punishment to the defendant (i.e., officer);

(c) perceive the defendant (i.e., officer) as less credible;

(d) perceive the defendant's (i.e., officer's) testimony as less persuasive; and

(e) perceive the BWC footage as more important evidence.

No two-way or three-way interactions are expected with the other independent variables described below (nature of discrepancies or presence of expert testimony).

Hypothesis 2. The nature of discrepancies in Study 2 will also vary such that the discrepancies discussed in Hypothesis 1 either focus on peripheral discrepancies (spatially and thematically distant from the action) or central discrepancies (spatially and thematically proximal to the action). It is hypothesised that, when mock jurors are exposed to trials with central (vs. peripheral) discrepancies between officer testimony and BWC footage of the event, they will:

(a) be more likely to render verdicts of guilty;

(b) assign more severe punishment to the defendant (i.e., officer);

(c) perceive the defendant (i.e., officer) as less credible;

(d) perceive the defendant's (i.e., officer's) testimony as less persuasive; and

(e) perceive the BWC footage as more important evidence.

No two-way or three-way interactions are expected with the other independent variables (degree of discrepancies or presence of expert testimony).

Hypothesis 3. In Study 2, expert testimony will be either present or absent. When present, the expert will speak to the dynamics of use of force encounters and the effect that these encounters can have on officers (e.g., discrepancies will likely exist between officer testimony and BWC footage given the physiological demands of use of force 
encounters). It is hypothesised that, when mock jurors are exposed to trials without expert testimony (vs. with expert testimony), they will:

(a) be more likely to render verdicts of guilty;

(b) assign more severe punishment to the defendant (i.e., officer);

(c) perceive the defendant (i.e., officer) as less credible;

(d) perceive the defendant's (i.e., officer's) testimony as less persuasive; and

(e) perceive the BWC footage as more important evidence.

No two-way or three-way interactions are expected with the other independent variables (degree of discrepancies and nature of discrepancies).

Hypothesis 4. It is hypothesised that mock jurors with negative views of police legitimacy (as measured using the general PL scale by Tankebe, Reisig, \& Wang, 2016) will:

(a) be more likely to render verdicts of guilty;

(b) assign more severe punishment to the defendant (i.e., officer);

(c) perceive the defendant (i.e., officer) as less credible;

(d) perceive the defendant's (i.e., officer's) testimony as less persuasive; and

(e) perceive the BWC footage as more important evidence.

No interactions are expected between negative views of PL and the independent variables described above. Potential interactions with the other juror characteristics described below (pro-prosecution biases, authoritarianism, and NC) will be explored, but no hypotheses about these interactions are being proposed.

Hypothesis 5. It is currently unclear how need for cognition (NC) will relate to a mock juror's likelihood of rendering guilty verdicts and choosing harsher punishments. It 
is also unclear how $\mathrm{NC}$ will relate to ratings of officer credibility and persuasiveness, and the importance of the BWC footage. Based on previous research conducted in non-police settings, however, it is hypothesised that mock jurors with high $\mathrm{NC}$ will be more sensitive to the degree and nature of discrepancies. Therefore, it is expected that, when mock jurors are higher in $\mathrm{NC}$ as measured by the Need for Cognition Short-Form scale (NCSF), they will:

(a) be more likely to render verdicts of guilty;

(b) assign more severe punishment to the defendant (i.e., officer);

(c) perceive the defendant (i.e., officer) as less credible;

(d) perceive the defendant's (i.e., officer's) testimony as less persuasive; and

(e) perceive the BWC footage as more important evidence.

Potential interactions with other juror characteristics (negative biases towards the police, pro-prosecution biases, and authoritarianism) will be explored, but no hypotheses about these interactions are being proposed.

Hypotheses similar to 4 and 5 were going to be tested for authoritarianism and pro-prosecution biases, however psychometric testing of the scales used to measure these constructs indicated that they were unreliable in the current study (see below for more details). As a result, these scales/constructs were not assessed in the current study.

\section{Methods}

Pre-pilot study. Prior to conducting a pilot study (to ensure that there were no floor or ceiling effects for outcome variables associated with the transcripts) and the main study, a pre-pilot study was conducted to determine what constitutes "few" vs. "many" discrepancies when considering contradictions between officer testimony and BWC 
footage. A total of 54 participants responded to a request using Facebook to participate in the pre-pilot study. Participants received no reward or monetary benefit for their participation. All participants met the criteria of being Canadian citizens, 18 years of age or over, and had not committed an indictable offence, in accordance with Canadian jury criteria. The sample was primarily female $(n=43 ; 79.6 \%)$ and the mean age of the sample was 41.26 years $(\mathrm{SD}=14.19)$. Participants were sent a link to a short Qualtrics survey. The survey provided participants with some context (i.e., an officer was involved in a use of force incident and discrepancies exist between his testimony about what happened and BWC footage of the event). Participants were then asked to indicate how many discrepancies they consider minimal, moderate, or many. As indicated in Table 7, results of the study indicated that the average number of discrepancies that people consider to constitute a minimal number is around 2 , a moderate number is around 4, and large number is around 6 . To increase the saliency of the degree of discrepancy variable in the main study, it was decided to only use two categories of discrepancies: "few" (2 discrepancies) versus “many" (6 discrepancies). 
Table 7

Pre-pilot test results regarding what constitutes minimal, moderate, and many discrepancies

\section{Type of Discrepancy}

\begin{tabular}{lccc} 
& Minimal & Moderate & Many \\
\hline Mean (SD) & $1.89(1.34)$ & $4.19(2.22)$ & $5.61(2.60)$ \\
Range & $0-9$ & $1-15$ & $1-16$ \\
\hline
\end{tabular}

Note. $S D=$ standard deviation

Pilot study. Prior to conducting the main study, a pilot study was conducted to assess the trial transcripts used in Study 2. This pilot study was conducted to ensure there were no floor or ceiling effects associated with transcripts (with respect to verdict decisions). The mock court transcript that was planned to be used for the main study was used, but the transcript had all manipulations removed. That is, the transcript for Study 2 was used without the inclusion of any discrepancies or expert testimony.

For the pilot study, Facebook friends of the researcher were recruited and a link to a Qualtrics survey was provided to those individuals who consented to participate (see Appendix I). Participants for the pilot study had to meet the criteria of being Canadian citizens and 18 years of age or older (i.e., jury eligible), and had not committed an indictable offence, in accordance with Canadian jury criteria. Participants were then randomly assigned to either the video condition (transcript with BWC footage evidence) or the no video condition of the transcript. The participants then read the manipulationfree version of the transcript for Study 2. After reading the transcript, participants were 
asked to render a dichotomous verdict (guilty or not guilty). They were then given a debriefing form (Appendix N). Participants received no reward or monetary benefit for their participation.

Twenty-two participants completed the survey. The overall verdict split of guilty/not guilty was $50 \% / 50 \%$, indicating that the transcript had no pre-existing floor or ceiling effects prior to manipulations being introduced. When separated into the video/no video conditions, the verdict splits remained within a 40/60 split either direction (guilty or not guilty); $42 \% / 58 \%$ (video condition) and $60 \% / 40 \%$ (no video condition). Given this, it was decided that the transcript could be used for the main study.

\section{Main Study}

Participants. All participants for Study 2 were undergraduate students from participant pools at two Ontario universities. Participants were recruited via the SONA system at both universities and participation was limited to students who were 18 years of age or older, fluent in English, Canadian citizens, and had no prior convictions for indictable offences, in accordance with Canadian jury criteria. A total of 2,388 students began the study and received course credit for their participation. Out of those, 1,293 completed the entire study (54.15\%). Out of these 1,293 participants, a total of 692 participants (53.52\%) passed all five manipulation and attention check questions and were thus retained for the main study. All participants received $0.5 \%$ towards their course grade.

The 692 participants in Study 2 ranged in age from 18 to 64 years, and had a mean age of 21 years $(\mathrm{SD}=5.01)$. Nine participants did not declare their exact age beyond stating they were 18 years of age or older. The sample was predominantly White 
(65.9\%), followed by Black (9.4\%), Asian (8.1\%), Other (6.8\%), Middle-Eastern (5.9\%), Hispanic (1.4\%), Indigenous (1.2\%), Prefer Not to Say (.9\%), and three undeclared $(0.4 \%)$. The majority of participants were female $(66 \%)$, with one undeclared $(1 \%)$, and the rest being male $(33 \%)$. Over a third of participants, the largest proportion, identified as having no political affiliation (36.4\%), followed by Liberal (29.6\%), Conservative (14.6\%), NDP (13.3\%), Green Party (3.8\%), Other (1.0\%), Bloc Quebecois (.3\%), with seven undeclared $(1.0 \%)$.

\section{Study Design}

Participants in Study 2 were randomly assigned to one of eight conditions in a 2 (Degree of consistency: few vs. many inconsistency) by 2 (Nature of discrepancy: peripheral vs. central) by 2 (Expert testimony: present vs. absent) between-subjects factorial design.

Independent (trial) variables. The first three independent variables listed below were manipulated in Study 2.

Degree of consistency. Discrepancies in Study 2 refer to inconsistencies between the officer's (defendant's) testimony about what occurred in the lethal force encounter and the BWC footage of that encounter. A total of 6 details were provided by the officer within the trial transcript. These details were manipulated so that either few (2) of the details were inconsistent with the BWC footage or many (6) of the details were inconsistent with the BWC footage. All statements were reviewed by an experienced firearms instructor from a Canadian law enforcement agency to ensure that they were valid. 
Nature of discrepancy. The discrepant details discussed above also varied in terms of their nature; they were either peripheral to the case or central to the case. Central discrepancies are statements by the officer that contradict what is seen in the BWC footage and are of high (legal and/or operational) relevance and thus thematically proximal to the issue at trial (e.g., the officer testifies that he heard the suspect say something threatening when in fact the BWC footage reveals the suspect did not say a word). Peripheral details are statements by the officer that contradict what is seen in the BWC footage and are of low (legal and/or operational) relevance that are thematically or spatially distal from the issue at trial (e.g., the officer states he saw the suspect talking to three people when there were only two people depicted in the BWC footage). All statements were reviewed by an experienced firearms instructor from a Canadian law enforcement agency to ensure they were valid.

Expert testimony. The presence of expert testimony was also examined to determine if it had a significant impact on the dependent variables. Expert testimony was either present or absent. When present, the expert testified that the discrepancies exhibited by the officer in his testimony are feasible considering processing issues that can arise during a use of force incident. More specifically, the expert testified to the fact that cognitive functions, such as attention and memory, are impaired during high stress incidents and can result in memory failures.

Other (jurors) variables. A number of other juror variables were included for the analyses and are described below. 
Demographic characteristics. Age, sex, political affiliation, and ethnicity data were collected for the purpose of examining if any relationships exist between mock juror demographics and any of the dependent variables.

Police legitimacy. To measure police legitimacy, the PL scale developed by Tankebe et al. (2016) was used, as previously discussed. This scale contains 16-items on a 4-point Likert scale with higher scores demonstrating greater levels of perceived PL. The scale contains four sub-scales: police lawfulness, distributive fairness, procedural fairness, and effectiveness. Example items include: "When police deal with people, they always behave according to the law" (police lawfulness), "The police ensure that citizens receive the outcome they deserve under the law" (distributive fairness), "The police treat citizens with respect" (procedural fairness), and "There are not many instances of crime in my neighborhood" (effectiveness).

The scale was originally validated across two different samples in the US and Ghana. That research confirmed the expected four-factor structure with items loading on the predicted factors. Additionally, good to acceptable internal consistency was found within the US and Ghana samples, respectively. The Cronbach alphas for the subscales were: .76 for the US and .57 for Ghana for lawfulness, .87 for the US and .80 for Ghana for procedural fairness, .73 for the US and .69 for Ghana for distributive fairness, and .62 for US and .69 for Ghana for effectiveness. No alpha scores for the overall PL scale were provided. Importantly, recent research has provided similar support for the four-factor PL scale with a Canadian sample (Ewanation, Bennell, Blaskovits, \& Baldwin, 2019). For the list of items forming the PL scale, please refer to Appendix E. 
Pro-prosecution bias. While different measures have been created to assess proprosecution biases, one commonly used measure that will be used in the current study is the Juror Bias Scale (JBS; Kassin \& Wrightsman, 1983). The JBS is a 22-item scale that measures whether a person favours the prosecution or the defence by assessing an individual's pretrial predispositions. The measure is divided into two sub-scales. The first scale assesses the probability of commission (PC). This refers to the likelihood a person (the juror) is predisposed towards convicting a defendant and captures pro-prosecution biases. The PC sub-scale includes statements like "A suspect who runs from the police most probably committed the crime". The other sub-scale, reasonable doubt (RD), assesses the extent to which an individual perceives the burden of proving guilt as lying with the prosecution; it is intended to capture pro-defence biases (Devine \& Caughlin, 2014). The RD sub-scale includes statements such as "Too many innocent people are wrongfully imprisoned." High scores on the JBS indicate a pro-prosecution or PC bias, while low scores suggest a pro-defence or RD bias.

The JBS is well validated and is commonly used to assess juror biases. More specifically, research suggests that the overall Cronbach's alpha score for the JBS ranges from .67 to .81 (Kassin \& Wrightsman, 1983). For a list of the items in the JBS, please refer to Appendix F.

Authoritarianism. As previously defined, authoritarianism is a personality trait wherein the individual values conservative norms, favours punishment, and endorses the use of force by the established ruling party to keep order and enforce those norms. The Revised Legal Authoritarianism Questionnaire (RLAQ23; Kravitz et al., 1993) was used to measure authoritarianism in Study 2. The RLAQ23 is a 23-item questionnaire. The 
items on the RLAQ23 were taken from the longer, original 30-item LAQ, where participants indicate their level of agreement using 6-point response scales. The RLAQ23 is made up of three subscales: the authoritarianism sub-scale captures how right-wing an individual is, how much they endorse authority, and how punitive they are; the antiauthoritarianism sub-scale assesses how left-wing an individual is, how much they reject authority in general, and how much an individual places blame for antisocial acts on the existing authority (e.g., the government); and the equalitarian sub-scale measures to what extent an individual is traditional, yet liberal, and expresses attitudes that are nonextremist (Kravitz et al., 1993).

Research has demonstrated that the overall alpha scores associated with the RLAQ23 are reasonable (ranging from .63 to .83). The alpha scores for the authoritarianism, anti-authoritarianism, and equalitarian sub-scales have been found to range from .48 to $.75, .58$ to .73 , and .62 to .65 , respectively (Kravitz et al., 1993 ; Lundrigan et al., 2013; White \& Knowles, 2013). For a list of the items in the RLAQ23, please refer to Appendix G.

Need for cognition. To measure participants' tendency to engage in effortful cognitive activity, the Need for Cognition Short-Form (NCSF; Cacioppo, Petty, \& Kao, 1984) was used. The NCSF is a shorter version of the original Need for Cognition Scale (NCS; Cacioppo \& Petty, 1982). The NCSF is an 18-item scale that measures the "tendency to engage in and enjoy effortful cognitive activity" (Cacioppo, Petty, Feinstein, \& Jarvis, 1996, p. 197). Items are measured using 5-point scales where participants rate items as being "extremely characteristic" (1) to "extremely uncharacteristic" (5). Previous research has validated the NCSF (alpha scores range from .74 to .91; Berzonski 
\& Sullivan, 1992; Cacioppo et al., 1996; Verplanken, Hazenberg, \& Palenewen, 1992).

The full list of items included in the NCSF can be seen in Appendix H.

Dependent variables. The main study focuses on the following dependent variables.

Verdict outcome. This variable was measured dichotomously (guilty vs. not guilty).

Punishment severity. Participants were also asked to rate the degree of punishment they felt the defendant should be sentenced to, ranging from 0 for no punishment to 10 for maximum punishment (25-year sentence).

Credibility. Credibility is defined as "the quality of being trusted and believed in". ${ }^{14}$ Therefore, credibility is similar to believability. The credibility of the defendant was rated using a 7-point scale ( $1=$ "not credible at all" to 7 "extremely credible").

Persuasiveness. The people who are, in Devine's (2012) words, 'actors' in the trial (e.g., attorneys, witnesses, experts) can influence the outcomes of a trial. Persuasion is defined as "human communication that is designed to influence others by modifying their beliefs, values, or attitudes" (Simons, 1976, p. 21). Ratings of persuasiveness of the defendant was measured using a 7-point scale $(1=$ "not persuasive at all" to $7=$ "very persuasive").

Importance of $\boldsymbol{B W C}$ evidence. To determine the degree to which participants deem the BWC footage to be significant to their verdict, participants were asked to rate on a 7-point scale how important $(1=$ "not important at all" to 7 "extremely important") the evidence was to their verdict.

\footnotetext{
${ }^{14}$ https://www.google.ca/\#q=definition+credibility
} 
Preparation of transcript and BWC footage. The pilot-tested transcript (described in more detail below) that was used in Study 2 (including the BWC footage included as part of it) was based on an actual incident captured by an officer's BWC (the Roy shooting). ${ }^{15}$ However, the people and the setting were given pseudonyms. In the original incident, an officer was called as backup for another officer who approached a subject who was suspected of being an armed man at a gas station convenience store. When questioned, the man flashed a gun. The two officers demanded he stop and let them approach him, at which point the man turned and ran. The first officer ran after the subject and he and the subject fought over the subject's gun. When the first officer was clear, the second officer shot the subject. The first officer had managed to get the gun from the subject and shot him approximately two times. The second officer shot a total of 15 times. The subject died of his injuries. This event is an ideal scenario for the mock transcripts and video footage because it presents a very fast-moving scenario, requiring split-second decision-making on the part of the officers in a potentially lethal incident. Body-worn footage of the incident was also available and given the fast-paced interaction, discrepancies between the officers' testimony and the BWC footage of the event would be expected.

The above scenario, including the BWC footage, was embedded within a mock court transcript. The transcript begins with opening remarks from the judge. The transcript then proceeds to the presentation of the case by the Crown and the Defence where participants were presented with the study manipulations. The transcript closes with the judge's instructions for how the mock jurors should consider the case when

\footnotetext{
${ }^{15} \mathrm{https}: / /$ www.youtube.com/watch?v=O_PLtuMECe8
} 
rendering a verdict. More specifically, Study 2 was based on eight versions of the transcript, with each version differing depending upon the condition the participant was randomly assigned to. As indicated above, the conditions varied depending on the degree of consistency between the police officer's testimony and the BWC footage (few vs. many), the nature of the discrepancies (peripheral vs. central), and whether expert testimony is present or not (to explain the discrepancies). For the full transcript for Study 2, please refer to Appendix K (note that the transcript included in Appendix K provides all variations of the manipulations and will never be seen by participants; instead, the participants received a transcript with 2 peripheral, 2 central, 6 peripheral, or 6 central discrepancies).

\section{Procedure}

Potential participants in Study 2 were directed to an online Qualtrics survey. ${ }^{16}$ Upon clicking the study URL, participants were asked to read an informed consent form that provided them with all of the essential details regarding their participation (see Appendix J). Those who agreed to participate then proceeded to the inclusion criteria questions (i.e., "Are you 18 years of age?” and "Are you a Canadian citizen?”; see Appendix B). Eligible participants were directed towards the online study.

Participants were first presented with a demographics questionnaire (the same questionnaire that was used in Study 1; see Appendix B). Upon completion of the demographic questionnaire, participants were directed to read a randomly assigned transcript. As discussed above, the trial transcripts describe a use of force encounter

\footnotetext{
${ }^{16}$ An abundance of research suggests that online jury studies produce results that are comparable to findings that emerge when conducting jury studies in the lab (e.g., Birnbaum, 2000; Buchanan \& Smith, 1999; Riva, Teruzzi, \& Anolli, 2003).
} 
between a police officer and a civilian, which resulted in the death of the civilian. More specifically, the participants read one of eight transcripts: (1) few discrepancies/peripheral discrepancies/no expert testimony, (2) few discrepancies/peripheral discrepancies/with expert testimony, (3)few discrepancies/central discrepancies/no expert testimony, (4) few discrepancies/central discrepancies/with expert testimony, (5) many discrepancies/peripheral discrepancies/no expert testimony, (6) many discrepancies/peripheral discrepancies/with expert testimony, (7) many discrepancies/central discrepancies/no expert testimony, and (8) many discrepancies/central discrepancies/with expert testimony.

After participants read their transcript, they filled out a questionnaire to give their dichotomous verdict, punishment severity rating, credibility and persuasiveness ratings, and importance of BWC evidence rating (see Appendix M for questionnaire). To enhance the validity of the study results, manipulation checks were embedded in the transcript questionnaire. These manipulation checks included five multiple-choice questions regarding details of the trial (to ensure the participants were paying attention to and understanding the material; see Appendix L for examples of the manipulation checks). If participants did not answer the manipulation check questions correctly, they were excluded from the study.

After the transcript questionnaire, each participant in Study 2 completed the PL scale, the JBS, the RALQ23, and the NCSF, in random order to control for potential order effects. These questionnaires were provided at the end of the study to ensure they did not prime or bias the participant prior to reading the transcript and answering the questions regarding the trial. 
After these questionnaires were completed, participants were given a debriefing form (see Appendix N). This form reiterated the purpose of the study, discussed its importance, provided the participant with additional material they could read if they were interested in learning more about the issues examined in the study, and provided contact details for the researchers involved with the study and the Chair of the ethics committee. The entire session took approximately 45 minutes.

\section{Results}

The first set of results presented below relate to analyses examining the demographic characteristics of the sample and their relationship to the dependent variables being studied in Study 2 (verdict, punishment severity, defendant credibility, defendant persuasiveness, and importance of BWC evidence). Following this, the reliability of the various scales that were provided to participants were examined. For the remainder of the Results section, the main analyses are presented, which examined the impact of key manipulations (degree of discrepancies, nature of discrepancies, and availability of expert testimony) on the full range of dependent variables. Finally, analyses are presented that examine the relationships between the PL and NCSF scales and these same dependent variables (as described below, the RLAQ23 and JBS were not examined due to their psychometrics properties).

Analyses of demographic characteristics. Exploratory analyses were conducted to examine how the demographic characteristics of the participants related to the dependent variables (e.g., verdict, severity of punishment, credibility and persuasiveness of the defendant, and importance of BWC evidence). These analyses showed that no 
relationship existed between any demographic feature and the outcome variables, with a few exceptions.

A significant negative relationship between age and severity of punishment was found, such that younger participants provided harsher punishment, $r=-.13, p=.005$. In addition, a significant relationship was also found between sex and verdict, such that females were more likely to give guilty verdicts, $\varphi=.24, p<.001$.

Given these results, to make sure that no demographic differences existed between conditions (to ensure that the demographic characteristics of the participants, rather than the manipulated variables, would not explain any between-condition differences), analyses were conducted. Statistical testing revealed no demographic differences across any of the conditions.

Reliability analyses. Reliability analyses for each scale (i.e., RLAQ23, JBS, PL, NCSF) were conducted to determine if the scales met specific psychometric criteria (i.e., internal consistency scores of $\geq .70$; Kline, 1999) that would allow them to be included in further analyses. The PL and NCSF were both associated with acceptable internal consistency scores (Cronbach alphas of .90 and .87, respectively; Kaplan \& Saccuzzo, 1982; Nunnally \& Bernstein, 1994). The subscales of the PL scale were also found to be reasonably reliable: $\alpha=.74$ for lawfulness, $\alpha=.90$ for procedural fairness, $\alpha=.79$ for distributive fairness, and $\alpha=.72$ for effectiveness.

However, the RLAQ23 and JBS were both associated with poor to bad reliability (Cronbach alphas of .63 and .13, respectively). Sub-scales for the RLAQ23 and JBS were examined to determine if they could be retained for future analyses. However, the alpha scores for the sub-scales were also below the acceptable .70 cut-off (i.e., RLAQ23 
authoritarianism $\alpha=50$, anti-authoritarianism $\alpha=.44$, equalitarianism $\alpha=.45$; JBS pro-culpability $\alpha=.50$, reasonable doubt $\alpha=.12$ ). Due to the low reliability scores associated with the RLAQ23 and JBS, and their sub-scales, these scales were not included in the main analyses. Only the PL scale and NCSF were retained.

Effects of independent variables on verdict. To test hypotheses 1(a), 2(a), and 3(a), that more guilty verdicts would be rendered when mock jurors are presented with officer testimony characterized by many discrepancies (versus few), central discrepancies (versus peripheral), and no expert testimony (versus expert testimony), a hierarchical logistic regression analysis was conducted (see Table 8). More specifically, these hypotheses were tested by including each of the three independent variables in the first step of the analysis. This step appeared to fit the data well, as demonstrated by a significant chi-square $(p=.005)$ and a statistically non-significant Hosmer and Lemeshow Test $(p=.745)$.

As can be seen by the results provided in Table 8, the degree and nature of discrepancies did not significantly impact verdicts in the first step of the analysis, contrary to hypothesis 1(a) and 2(a). However, there was a significant effect found for expert testimony, which supports hypothesis 3(a). As indicated in Table 8, the odds of responding "guilty" compared to "not guilty" decreased by $46 \%(\mathrm{OR}=.54)$ when the participants were exposed to expert testimony that discussed how stress in use of force situations can impact an officer's memory.

It was also explored whether any of the two-way or three-way interactions between these variables were significant by including two-way interactions in step 2 of a 
hierarchical regression model, and the three-way interaction in step 3. None of these interactions were found to be significant.

Table 8

Predicting effects of degree of discrepancy, nature of discrepancy and presence of expert testimony on verdict - summary of logistic regression analysis

\begin{tabular}{lccccc}
\hline \multicolumn{1}{c}{ Predictor } & Wald & b & p & OR & 95\% CI \\
\hline Step 1 & & & & & \\
Degree of discrepancy & .00 & -.00 & .990 & 1.00 & $.71,1.40$ \\
Nature of discrepancy & .07 & -.05 & .789 & .96 & $.68,1.34$ \\
Expert testimony & 12.36 & -.61 & .000 & .541 & $.38,1.41$ \\
Step 2 & & & & & \\
Degree x Nature & .89 & -.33 & .347 & .72 & $.36,1.43$ \\
Degree x Expert & .23 & .17 & .632 & 1.18 & $.60,2.35$ \\
Nature x Expert & 2.24 & .53 & .135 & 1.69 & $.85,3.37$ \\
Step 3 & & & & &
\end{tabular}

Note. $b=$ regression coefficient, $p=$ probability, $O R=$ odds ratio, $C I=$ confidence interval

To examine the main effect of expertise in more detail, Table 9 displays the frequency and percentage of verdicts across conditions for the 692 responses. The results in this table reveal that, regardless of condition, there are notably more guilty verdicts than not guilty verdicts. Furthermore, and consistent with the results in Table 8, when 
expert testimony is absent, there is an increase in the number of guilty verdicts, and a decrease in the number of not guilty verdicts, across all conditions. This suggests that the presence of expert testimony has an influence on jury decision-making in this study, regardless of whether participants are presented with few or many discrepancies between officer testimony and BWC footage, or discrepancies that are peripheral or central.

Table 9

Frequency and percentage of verdict decisions (by condition)

\begin{tabular}{lccc}
\hline Condition & Expert & \multicolumn{2}{c}{ Verdict } \\
& Witness & Guilty $\boldsymbol{n}(\%)$ & Not Guilty $\boldsymbol{n}(\mathbf{\%})$ \\
\hline Few discrepancies/peripheral discrepancies & Present & $54(63.5 \%)$ & $31(36.5 \%)$ \\
& Absent & $66(80.5 \%)$ & $16(19.5 \%)$ \\
Few discrepancies/central discrepancies & Present & $63(72.4 \%)$ & $24(27.6 \%)$ \\
& Absent & $74(76.3 \%)$ & $23(23.7 \%)$ \\
Many discrepancies/peripheral discrepancies & Present & $50(66.7 \%)$ & $25(33.3 \%)$ \\
& Absent & $79(83.2 \%)$ & $16(16.8 \%)$ \\
\hline & Present & $60(65.9 \%)$ & $31(34.1 \%)$ \\
\hline
\end{tabular}

Effects of conditions on other trial variables. The following section examines hypotheses 1 (b) to (e), 2 (b) to (e), and 3 (b) to (e) using a series of hierarchical linear regressions. More specifically, it was examined whether a greater number of discrepancies (degree), central discrepancies (nature), and the absence of expert 
testimony (expert) result in harsher punishment ratings, decreased perceptions of defendant credibility and persuasiveness, and greater importance being placed on BWC video as evidence.

Severity of punishment. With respect to punishment severity, the model fit in step 1 was non-significant, $F(3,500)=1.20, p=.308, R^{2}=.01$, indicating that the model was a bad fit. None of the independent variables significantly impacted punishment severity. More specifically, the degree of the discrepancies $(b=.27, p=.167)$ and the nature of the discrepancies $(b=.11, p=.573)$ did not significantly predict harsher punishment, nor did the presence of expert testimony $(b=-.24, p=.220)$. Thus, hypotheses $1(b), 2(b)$, and 3(b) were not supported in this study. It was also explored whether any of the two-way or three-way interactions between these variables were significant by including these interactions in steps 2 and 3 of a hierarchical regression model, respectively. None of these interactions were found to be significant.

Credibility of the defendant. A similar regression analysis was run to examine the impact of the independent variables on ratings of defendant credibility. The model fit was significant at step $1, F(3,689)=5.79, p=.001, R^{2}=.03$, indicating that the model was a good fit with the data despite the $R^{2}$ being low. Surprisingly, results indicated that a higher number of discrepancies predicted increased defendant credibility ratings $(b=.27$, $p=.013)$, contrary to hypothesis $1(\mathrm{c})$. Also contrary to hypothesis $2(\mathrm{c})$, central discrepancies did not result in decreased ratings of defendant credibility $(b=.02, p=$ $.860)$. The only hypothesis that was supported in this section was hypothesis 3(c). As expected, the presence of expert testimony did predict higher ratings of defendant credibility $(b=.36, p=.001)$. It was also explored whether any of the two-way or three- 
way interactions between these variables were significant by including these interactions in steps 2 and 3 of a hierarchical regression model, respectively. None of these interactions were found to be significant.

As seen in Table 10, a descriptive analysis conducted to examine ratings of defendant credibility in more detail shows that the defendant was viewed as less credible when a high number of discrepancies existed between the defendant's testimony and BWC footage of the use of force incident $(M=3.69, \mathrm{SD}=1.42)$ compared to when only a few discrepancies exist $(M=3.43, \mathrm{SD}=1.48$; means and standard deviations are collapsed across conditions). Defendant credibility ratings were also higher when participants were exposed to expert testimony $(M=3.78, \mathrm{SD}=1.39)$ compared to when they were not $(M=3.38, \mathrm{SD}=1.43$; means and standard deviations are collapsed across conditions). 
Table 10

Credibility ratings of defendant by condition

\section{Condition}

\section{Expert Credibility}

Witness Mean SD

Present $3.69 \quad 1.28$

Few discrepancies/peripheral discrepancies

Absent $\quad 3.14 \quad 1.40$

Few discrepancies/central discrepancies

Present $\quad 3.64 \quad 1.48$

Many discrepancies/peripheral discrepancies

$\begin{array}{lll}\text { Absent } & 3.25 & 1.44 \\ \text { Present } & 3.72 & 1.36\end{array}$

Absent $\quad 3.63 \quad 1.43$

Present $\quad 3.89 \quad 1.44$

Many discrepancies/central discrepancies

Absent $\quad 3.51 \quad 1.44$

Note. $S D=$ standard deviation

Persuasiveness of the defendant. Next, regression analysis was run to examine the impact of degree of discrepancies, nature of discrepancies, and expert testimony on ratings of defendant persuasiveness. The model fit was significant at step $1, F(3,685)=$ $4.39, p=.005, R^{2}=.02$, indicating the model was a good fit with the data despite the $R^{2}$ being low. There was one significant result. The presence of expert testimony was associated with higher ratings of defendant persuasiveness to a statistically significant degree $(b=.38, p<.001)$, thus supporting hypothesis $3(\mathrm{~d})$. Contrary to hypotheses $1(\mathrm{~d})$ and 2(d), neither the degree nor the nature of discrepancies significantly predicted ratings of defendant persuasiveness $(b=.04, p=.716$ and $b=-.07, p=.515$, respectively). It was 
also explored whether any of the two-way or three-way interactions between these variables were significant by including these interactions in steps 2 and 3 of a hierarchical regression model, respectively. None of these interactions were found to be significant.

As seen in Table 11, a descriptive analysis conducted to examine ratings of defendant persuasiveness shows that the defendant was viewed as less persuasive when expert testimony was not presented to participants $(M=3.42, \mathrm{SD}=1.41)$ compared to when expert testimony was presented $(M=3.82, \mathrm{SD}=1.39$; means and standard deviations are collapsed across conditions).

Table 11

Persuasiveness ratings of defendant by condition

\section{Condition}

\section{Expert Persuasiveness}

\begin{tabular}{cccc} 
& Witness & Mean & SD \\
\hline Present & 3.81 & 1.47
\end{tabular}

Few discrepancies/peripheral discrepancies

Few discrepancies/central discrepancies

Absent $\quad 3.26 \quad 1.40$

Present $\quad 3.90 \quad 1.41$

Absent $\quad 3.44 \quad 1.44$

Present $\quad 3.84 \quad 1.32$

Many discrepancies/peripheral discrepancies

Absent $\quad 3.70 \quad 1.37$

Present $\quad 3.71 \quad 1.34$

Many discrepancies/central discrepancies

Absent $\quad 3.29 \quad 1.41$

Note. $S D=$ standard deviation 
Importance of $\boldsymbol{B} \boldsymbol{W C}$ footage. Finally, regarding ratings of how important the BWC footage was as evidence, the model fit was non-significant at step $1, F(3,686)=$ $.90, p=.442, R^{2}=.00$. The results of the regression analysis revealed that no significant main effect was found for the degree of discrepancies $(b=-.05, p=.564)$, the nature of the discrepancies $(b=.14, p=.129)$, or the presence of expert testimony $(b=-.01, p$ $=.884)$. Thus, hypotheses 1(e), 2(e), and 3(e) were not supported in this study. It was also explored whether any of the two-way or three-way interactions between these variables were significant by including these interactions in steps 2 and 3 of a hierarchical regression model, respectively. None of these interactions were found to be significant.

Police legitimacy and need for cognition. A series of regression analyses were run in order to investigate hypotheses 4 and 5 regarding the significance of the PL and NCSF scales for predicting verdict (hypotheses $4[\mathrm{a}]$ and 5[a]), severity of punishment (hypothesis 4[b] and 5[b]), defendant credibility (hypothesis $4[\mathrm{c}]$ and 5[c]), defendant persuasiveness (hypothesis $4[\mathrm{~d}]$ and $5[\mathrm{~d}]$ ), and the importance of BWC evidence when rendering a verdict (hypothesis $4[\mathrm{e}]$ and $5[\mathrm{e}]$ ).

Verdict. Results of a logistic regression analysis indicated that PL significantly predicted verdict. More specifically, in line with hypothesis 4(a), lower scores on the PL were associated with an increased number of guilty verdicts (Wald $=47.23, \mathrm{~B}=-.74, p$ $<.001, \mathrm{OR}=.48)$. In contrast, hypothesis $5(\mathrm{a})$ was not supported as the analysis showed that lower scores on the NCSF were associated with an increase in guilty verdicts (Wald $=4.90, \mathrm{~B}=-.02, p=.026, \mathrm{OR}=.98)$.

Continuous trial variables. Table 12 presents the results from regression analyses that examined the ability of PL and NC to predict continuous trial variables, including 
severity of punishment, credibility and persuasiveness of the defendant, and the importance of BWC evidence in rendering verdict. Each variable is discussed briefly below.

Table 12

Summary of regression analyses for PL and NC on continuous trial outcome variables

\begin{tabular}{|c|c|c|c|c|c|c|c|}
\hline Outcome & Scale & $b$ & bSE & B & $p$ & $R^{2}$ & $95 \% \mathrm{CI}$ \\
\hline \multirow{2}{*}{ Punishment } & $\mathrm{PL}$ & -.61 & .10 & -.28 & $<.001$ & .08 & $-.81,-.42$ \\
\hline & $\mathrm{NC}$ & -.13 & .10 & -.06 & .198 & $<.01$ & $-.32, .07$ \\
\hline Defendant & PL & .53 & .05 & .38 & $<.001$ & .14 & $.43, .63$ \\
\hline credibility & $\mathrm{NC}$ & .07 & .06 & .05 & .200 & $<.01$ & $-.04, .18$ \\
\hline Defendant & PL & .41 & .05 & .29 & $<.001$ & .09 & $.30, .51$ \\
\hline persuasiveness & $\mathrm{NC}$ & -.07 & .06 & -.05 & .208 & .05 & $-.18, .04$ \\
\hline Importance of & PL & -.03 & .05 & -.03 & .486 & $<.01$ & $-.13, .06$ \\
\hline BWC & $\mathrm{NC}$ & .08 & .05 & .06 & .109 & $<.01$ & $-.02,17$ \\
\hline
\end{tabular}

Note. $b=$ regression coefficient, $b S E=$ regression standard error, $B=$ standardized coefficient, $p=$ probability, $R^{2}=$ coefficient of determination, $95 \% C I=$ confidence interval

Punishment severity. As seen in Table 12, results of the regression analysis indicate that PL had a negative relationship with severity of punishment, confirming hypothesis 4(b) that when perceptions of PL decrease, the severity of punishment given to the defendant (a police officer) by mock jurors increases. In contrast, $\mathrm{NC}$ was not 
significantly associated with punishment severity $(p=.198)$. Thus, hypothesis $5(\mathrm{~b})$ was not supported.

Defendant credibility. Results shown in Table 12 indicate that hypothesis 4(c) was supported, since higher PL scores were significantly associated with higher defendant credibility ratings $(p<.001)$. Contrary to hypothesis $5(\mathrm{c})$, however, no statistically significant relationship was found between NC and ratings of defendant credibility $(p=$ $.200)$.

Defendant persuasiveness. As seen in Table 12, results indicate that hypothesis 4(d) was supported since higher PL scores were significantly associated with higher defendant persuasiveness ratings $(p<.001)$. There was no statistically significant relationship found between $\mathrm{NC}$ and defendant persuasiveness ratings $(p=.208)$. Therefore, hypothesis 5(d) was not supported.

Importance of BWC footage. Finally, analyses were conducted to determine if higher PL and NCSF scores resulted in increased ratings of the importance assigned to BWC evidence. The results shown in Table 12 indicate non-significant results for both $\operatorname{PL}(p=.486)$ and NC $(p=.109)$. Thus, hypotheses 4(e) and 5(e) were not supported in this study.

Exploration of possible interactions. Additional analyses were run to explore if there were any significant interactions between PL and NCSF and the outcome variables described above. No significant interactions were found for any of the outcome variables. Additional exploratory analyses of the PL scale. Due to the significant findings related to the PL scale, further examination was conducted with the four PL sub-scales. A full description of the results for the PL sub-scales can be found in Appendix R. The 
procedural fairness sub-scale significantly predicted verdict, defendant credibility, and defendant persuasiveness. More specifically, as perceptions of procedural fairness decreased, the odds of the verdict being guilty increased $(b=-.40, p=.016, \mathrm{OR}=.76)$, while increases in perceptions of procedural fairness resulted in more favourable ratings of defendant credibility $(b=.22, p=.011)$ and defendant persuasiveness $(b=.24, p=$ .008). Ratings on the police lawfulness sub-scale significantly predicted, severity of punishment and defendant credibility. In this case, the less police were seen as lawful, the odds of the verdict being guilty increased $(b=-.35, p=.015, \mathrm{OR}=.70)$, the greater the severity of punishment requested by the participants $(b=-.40, p=.004)$, while increased perceptions of lawfulness resulted in more favourable ratings of defendant credibility $(b=$ $.18, p=.017)$. Finally, ratings on the distributiveness fairness sub-scale predicted defendant credibility; higher scores on this subscale were associated with more favourable ratings of defendant credibility $(b=.22, p=.003)$. No other significant relationships were found.

\section{Discussion}

This study set out to build on the results of Study 1 by examining how BWC footage would be treated when presented as evidence in a mock court case involving allegations of excessive use of force by a police officer, especially when that footage contradicts the testimony of the officer involved in the incident. Particularly of interest was how a variety of trial outcome variables, including verdict decisions, severity of punishment, defendant credibility and persuasiveness ratings, and the importance placed on the BWC footage evidence were influenced by three variables: the degree of discrepancies between officer testimony and the BWC footage (few vs. many), the nature 
of those discrepancies (peripheral vs. central), and whether expert testimony was presented, to provide participants with a better understanding of use of force dynamics (especially the impact that stress can have on memory).

Verdict decisions. The main analyses revealed that only expert testimony was significant in predicting verdict. In this case, when expert testimony was presented to participants, they were less likely to render guilty verdicts. Presumably, this is because participants exposed to the expert testimony had a better understanding of use of force dynamics and perceived the discrepancies between the defendant's testimony and the BWC footage as a result of valid memory errors rather than an attempt by the police officer to deceive the jury. This appears to be the first study to examine the impact of expert testimony specifically in the context of a trial dealing with a police officer who allegedly used excessive force. Thus, the novel finding in this study is that expert testimony related to the impact of stress on police officers during use of force encounters can potentially result in decreased guilty verdicts.

This finding is consistent with previous jury studies (e.g., Neitzel et al., 1999) and the models of jury and juror decision-making discussed in Chapter 3, in that both models predict that expert testimony can impact a juror's verdict (and perceptions of defendant credibility, which in this case may have impacted verdict decisions). Indeed, in line with the Story Model (Pennington \& Hastie, 1986), expert testimony in the current study may have created a plausible alternative to the prosecution's story, thereby impacting the uniqueness of that story. More specifically, rather than overreacting to the incident, the expert may have educated participants that the officer involved in the trial was exposed to lethal threat and severe stress that impacted recall. Plausibility and uniqueness are both 
components of the principle of coherence in the Story Model. Similarly, in Devine's Director's Cut of Juror Decision-making (Devine, 2012), the expert testimony included in this study may have provided extenuation to the story because the expert testimony impacted the scope, credibility, and singularity of the prosecution's film 'cut'. By doing so, the extenuation might have provided an alternative 'cut' to the Crown's story by introducing evidence through the form of the expert testimony that expanded (i.e., extenuated) the story to make the defendant's culpability less certain (similar to the concepts of plausibility and uniqueness of the Story Model).

It is not entirely clear why the other hypotheses related to verdict were not significant. This result was especially surprising given: (1) how these variables are expected to impact verdicts (based on the models described in Chapter 3), and (2) the results of Study 1. Consider the hypothesis that central discrepancies would be associated with more guilty verdicts than peripheral discrepancies. Theoretically, this variable should impact the credibility of the defendant, thus creating consistency with the Crown's story (Devine, 2012; Pennington \& Hastie, 1986), and result in more guilty verdicts. This finding would also be expected based on the Study 1 survey results, which revealed that, when discrepancies were central in nature, people tend to consider these errors to be a sign of officer dishonesty, rather than simple mistakes or memory failures (which was the case for peripheral discrepancies).

The lack of significant results may be related to the specific way in which this variable (and the degree of discrepancies variable) was manipulated. Perhaps the manipulation was not salient enough within the trial transcript, which may have been considered too long by participants. It may be that manipulations of discrepancies (in 
terms of their degree and nature) have to be much more extreme (or made salient in some other way) for these variables to be noticed by participants and have their expected impact. One way to address this in future research would be to have the Crown emphasize this variable in the trial transcript more. This not only has the potential to make the discrepancy manipulation more salient, it would also make the transcript more realistic given that the prosecution would definitely exploit such discrepancies. Also, there may be value in future research to use proportions when presenting the degree of discrepancies to jurors (i.e., $33 \%$ errors vs. $100 \%$ errors) rather than frequencies (i.e., 2 errors vs. 6 errors) to enhance saliency.

Other outcome variables. In line with the two jury decision-making models discussed in Chapter 3, expert testimony also was found in the current study to have a significant impact on increasing mock juror perceptions of the defendant's credibility and persuasiveness. This supported our hypotheses regarding the influence of expert testimony on juror decision-making. Consistent with the Story Model, expert testimony may have resulted in increased plausibility of the defendant's story, resulting in increased perceptions of the defendant's credibility and persuasiveness. These findings are similar to previous research, including the meta-analysis conducted by Neitzel et al. (1999).

Given that the presence of expert testimony significantly predicted verdicts, and perceptions of defendant credibility and persuasiveness, it would stand to reason that the presence of expert testimony might impact the other outcome variables as well, yet this was not the case for severity of punishment or the perceived importance of BWC footage. With respect to punishment severity, perhaps the Story Model or Director's Cut Model do not relate to this issue given that jurors will not weigh in on the appropriateness of 
sanctions in real court cases. Regarding the importance of BWC evidence, it is possible that, since the expert did not speak directly to the BWC evidence, no relationship was found to exist between the two variables. In other words, because the expert's testimony did not contribute to the Story Model's concept of coherence, or the concepts of credibility or singularity in the Director's Cut Model as it related to the BWC evidence, the perceived importance of the BWC evidence was not impacted by the testimony.

Regarding the other two manipulations - degree and nature of discrepancies between officer testimony and BWC footage - none of the hypotheses were supported for any of the outcome variables examined. In fact, the opposite of what was predicted was found in one exception. For example, a higher number of discrepancies was associated with more favourable ratings of defendant credibility, which is contrary to the hypothesis. Before putting too much weight on this finding, however, it would be important to replicate the result with another sample.

As discussed above in relation to verdict decisions, the overall lack of significant findings related to the degree and nature of discrepancies is probably due to the manipulations being too subtle to have their expected impact. This is especially likely considering the length of the Study 2 experiment, and the fact that many participants were clearly not paying close attention to the transcript, as indicated by the number of respondents that failed the attention checks (although it should be kept in mind the trial transcript is shorter than actual real-life trials). If any of these explanations have merit, it is likely that the manipulations would not have influenced the principle of coherence in the Story Model or the errors, credibility, and singularity components that influence juror decision-making according to the Director's Cut Model. Despite the findings, it is 
important to examine these two independent variables in future research as they may be found to have an impact on trial-related variables using a different methodology.

The Role of police legitimacy. Unfortunately, given the psychometric properties that were associated with the scales used in this study, only two scales could be included in the analysis: the Police Legitimacy (PL) scale and the Need for Cognition (NC) Short Form scale. When examining the relationship between these scales and the outcome variables, perceptions of PL appeared to be particularly important. More specifically, perceptions of PL were found to have a significant relationship with verdict decisions, ratings of punishment severity, and perceptions of defendant credibility and persuasiveness.

The strong predictive ability of the PL scale is consistent with previous research on the topic, which has shown that views of PL predict a wide range of outcome variables such as guilty verdicts (Hepburn, 1980), damages awarded in civil lawsuits against the police (Casper, Benedict, \& Perry, 1989), and juror perceptions of legal fairness (Hannaford-Agor \& Hans, 2003). This finding is also consistent with what one might expect based on the models of jury decision-making discussed in Chapter 3. For example, consistent with Devine's Director's Cut Model, a juror's PL bias (characteristic) should influence how credible a police officer is perceived to be by the juror, thus impacting the juror's verdict. Similarly, consistent with Pennington and Hastie's Story Model, juror's perceptions of PL should influence what story they find plausible/credible, thus impacting what story fits best (i.e., goodness-of-fit in the Story Model) with the verdict options. 
What is really new and exciting about this study is that this seems to be the first time that PL has been examined in a mock court case involving a police officer as a defendant in a criminal trial. The findings related to PL highlight the need to incorporate measures of this construct in studies where police officers act as defendants in the trial; the construct can clearly account for how jurors will perceive and treat these defendants. The sub-scale analysis reported above also suggests that perceptions of procedural fairness and lawfulness are particularly important for determining how police officers will be judged when they are on trial.

The overall results associated with NC are inconsistent with previous research findings. For example, a recent meta-analysis on jury studies (Devine \& Caughlin, 2014) found a weak, though statistically significant, correlation between NC and various jury outcomes. Given these findings, further research looking at how NC impacts jury decision-making is warranted. It will be interesting to see if the results found in the current study replicate in future studies.

The Importance of BWC footage. Given the focus on visual evidence in this dissertation, it is important to highlight the findings related to one outcome variable in particular - the importance placed on BWC footage as a piece of evidence in the mock trial. Interestingly, this footage was given the same (approximate) importance rating by participants, regardless of what condition they were assigned to, and regardless of how they scored on the PL or NC scales. In all cases, the strength assigned to this evidence was high (across conditions, mean scores ranged from 6.01 to 6.30 on a 7-point scale).

It is interesting that, across conditions that varied in terms of the number and nature of discrepancies, equal weighting was put on the BWC footage. It is equally 
interesting that this was also true across conditions where an expert either did, or did not, emphasize the degree to which BWC footage was likely to correspond to the defendant's testimony. Perhaps most surprising is the finding that participants who scored higher on the PL scale did not seem to weight the BWC footage as being less important than the defendant's testimony (when compared to participants who scored lower on the PL scale).

It is unclear why the various hypotheses related to the BWC footage were not supported in the current study. It could be that future research will identify variables that impact how BWC footage is perceived. For example, if one were to manipulate how BWC footage was framed, that might impact how the footage is perceived, or if one were to include expert testimony that specifically targets BWC limitations, the importance attached to this evidence may be impacted. This latter variable will be particularly important to explore in our opinion. Additional research of this type will be useful as it will provide further insight into what sorts of variables might come into play when visual evidence is presented to jurors.

\section{Limitations and Future Directions}

Several limitations associated with Study 2 are worthy of discussion. The first limitation relates to sample size (more specifically, why we ended up with a reasonably small sample size). Many of the respondents, all of whom were undergraduate university students, failed the manipulation/attention checks or did not complete the study, which is a matter for concern and consideration. It is possible that the 45 minutes it took to complete the study (on average) fatigued participants. Additionally, due to the study being online, there were no controls to reduce interruptions (phone calls, breaks), 
distractions (watching TV, conversations), or other things that may have interfered with participants paying attention during the study. All this being said, because data was retained only from those students who successfully answered all five manipulation and attention checks, the data quality was protected. This ensured the integrity of the study, but sample size was definitely compromised as a result. In the future, researchers may also want to consider conducting such studies in a face-to-face setting, which may increase attention/focus on the part of the participants.

A second limitation associated with the study is that the participants were undergraduate students, who rarely serve as jurors (Bray \& Kerr, 1982). While previous studies have found that there are no significant differences in verdicts between student participants and community participants (e.g., Finkel \& Duff, 1991; Narby, Cutler \& Moran, 1994; Schuller \& Hastings, 1996), including a recent meta-analysis (Bornstein et al., 2017), the results might be more generalizable to real-world settings if we had focused on a more diverse sample of community members. Certainly, a more diverse sample may have exhibited different results with respect to some of the measures we used (e.g., police legitimacy; Schultheis, Ellingwood, Emeno, \& Bennell, 2017). Future research should focus on collecting data from diverse samples of community members. A third potential limitation of the study relates to the stimuli that was used - a trial transcript presented to participants online. It may have been preferable to use a more realistic approach, such as a video of a mock trial or a live mock trial. This approach would likely make some of the manipulations more salient as well. Logistical and financial constraints prevented taking these approaches in the present study. There is currently a debate about whether these different methodological approaches impact 
results in mock jury trials (e.g., see Bornstein, 1999; Bornstein et al, 2017; Pezdek, AvilaMora, \& Sperry, 2010). Regardless of this debate, the reality of experimental research is that researchers sometimes have to make certain sacrifices with respect to external validity in order to carry out a study and: (1) isolate the conditions the researcher wishes to examine, (2) control for potentially confounding variables, and (3) obtain the sample size necessary to achieve sufficient power for the proposed analyses. These issues factored into the decision to conduct the study in the way it was done, but it would be important to explore different methodologies in future research.

A fourth limitation, also tied to external validity, is that the study focused on individual juror responses without any jury deliberation. It is possible that the process of group deliberation could have altered individual's final responses (e.g., with respect to verdicts), although research suggests otherwise. In fact, previous studies have shown that, generally speaking, individual verdicts tend to be similar to jurors' final verdicts, postdeliberation (e.g., Devine et al., 2009; Devine et al., Wolfe, 2004; MacCoun \& Kerr, 1988). Even if deliberations do not change verdict outcomes (or other trial-related variables), future research based on recorded deliberations may provide greater insights into the decision-making process of jurors (e.g., how the BWC footage was handled by the jurors).

A fifth limitation to this study, which relates to this last point, is that the study was based on a mock trial rather than a real trial. This is a common limitation for most juror and jury research, particularly in Canada, where it is prohibited by law for actual jurors to disclose anything about the trial, including their verdict and decision-making process (Criminal Code, RSC, 1985). In addition to this, it would have been difficult to 
find a real trial that dealt with the range of issues examined in this study, and even if that was possible, it would have been impossible to isolate the effect of the factors examined here. There is little that can be done to deal with this limitation in future research other than to approximate real-world conditions to the extent possible (e.g., presenting participants with a videotaped trial, allowing jurors to deliberate, etc.).

A final limitation relates to my own potential biases. Of course, no research is conducted without it being a product of the researcher's own biases (Nightingale \& Cromby, 1999), and while reflexivity does not tend to be spoken about in quantitative research of the type conducted here, it is important to acknowledge the role that my biases may have played in this research. My interest in policing research comes from my own personal experiences with law enforcement, which have been mixed. Being the member of more than one marginalized group, some personal interactions with police (and those of friends and family) have been negative. However, I have also worked alongside police officers, as has my family, and some of my friends are retired or current law enforcement officers. I have long held concerns with the implementation of any technology when the implementation outpaces evidence-based research and I also am an advocate for the creation of safer spaces, including decreasing discrimination and abuse of power. These personal experiences and predispositions undoubtedly played a part in the measures I chose to use, the way I chose to ask questions, how I framed my dissertation, and the interpretation of results. 


\section{Implications}

Notwithstanding these limitations, the results of Study 2 are potentially important for several reasons. From a practical standpoint, the findings in this study highlight the role that expert testimony can play in educating jurors in court cases involving police use of force (specifically the impact that such incidents can have on officer memory and performance). Also, from a practical standpoint, the findings of the current study highlight the importance, from a police perspective, of working towards improving perceptions of PL on the part of the public. Not only would this positively impact policecommunity relations more generally, the results of Study 2 suggest that perceptions of PL may have specific effects in court cases involving police officers (impacting perceptions of the officer's credibility, for example).

From a theoretical perspective, the findings of the current study appear to support aspects of what is already known in jury decision-making research, while adding new knowledge to existing research. For example, the results of the current study support the importance of including certain variables in studies of jury decision-making, particularly expert testimony. Not only do the results associated with expert testimony in the current study support the previous decision to include this variable in models of juror/jury decision-making, the current research also suggests that the importance of this variable extends to court cases that have rarely been considered in the jury literature (e.g., criminal court cases centred on use of force, cases involving BWC footage, cases where a police officer is the defendant).

Additionally, from a theoretical perspective, the findings of this study also suggest that more research is required to understand how other variables, which should 
relate to decision-making based on existing models of that process, actually impact decision-making. More specifically, while variables like the degree and nature of discrepancies should have impacted components of the Story Model or Director's Cut Model, and thus influence verdict outcomes, they did not in this study. Therefore, it is necessary to determine through future research whether these components are important factors to consider in models of the sort described in Chapter 3 (and simply were not found to be important in the current study due to methodological reasons) or whether such factors really do not have the impact that would be expected based on the models we discussed (i.e., The Story Model and Director's Cut Model). 


\section{Chapter 6: General Discussion and Conclusion}

Police officers are arguably one of most unique communities within Canada. They are the only people in Canada who have the authority to use lethal force if necessary against Canadian citizens. Even the military do not have this power except under special circumstances (e.g., in states of emergency, such as when the government declares martial law). Quite appropriately, the policing profession, and the role that police officers play in our society, is heavily scrutinized due to the power police have and the potential to abuse that power. Not only would such abuses negatively impact public trust in the police, but it could also jeopardize public safety. This is why there is a call-out for the use of BWCs. BWCs are increasingly seen as a method to enhance police accountability and transparency, which should improve the trust between the police and the communities they serve, and allow for more effective (e.g., safer) policing.

There seems to be little doubt that this technology has the potential to accomplish these goals and BWCs are definitely growing in popularity, with more and more police services adopting them on a daily basis. Even other criminal justice sectors (e.g., corrections) are seriously considering whether BWCs should be adopted. While this may turn out to be a good thing, we still know very little about BWCs in the policing context (or any other context for that matter). Indeed, the popularity of this technology has far outpaced the available research, and the research that does exist has focused on a fairly narrow set of issues (e.g., the impact that BWCs have on citizen and officer behaviour). The studies that make up this dissertation represent an attempt to address some of the gaps that currently exist within the literature; specifically, gaps related to our 
understanding of public support for, and knowledge of, BWCs, and our understanding of how BWC footage might be received by jurors if it is presented as evidence in court.

To reiterate, the first study in this dissertation involved a public opinion survey. Generally, the survey was designed to determine: (1) the extent to which Canadians think BWCs are useful and how/when they should be used, (2) whether Canadians are aware of the limitations of BWCs, and (3) how Canadians might view BWC footage when it is presented as evidence in criminal court cases. The survey also captured the demographic characteristics of respondents, which allowed for the examination of how these characteristics relate to various attitudes and beliefs about BWCs (as discussed in detail above, very few significant demographic differences were found). While future research using different methodologies (e.g., focus groups) will allow us to drill down deeper into why Canadians feel the way they do about BWCs and their use, the survey revealed some interesting results, which have some important implications.

Indeed, while serving to inform what Study 2 should look like, many of the findings that emerged from the survey are important in their own right. For example, the reasonably high degree of support for BWCs that was evidenced by the sample suggests that Canadian police services will likely meet little resistance from the public if they decided to adopt BWCs. That being said, it may be that public opinion of BWCs varies by location (e.g., attitudes towards one's local police service may matter). Therefore, it would likely be useful for specific services to survey their communities before deciding to implement BWCs so that they can do so armed with knowledge of what their residents think of the technology. 
The clear lack of awareness of limitations associated with BWC technology, which were highlighted by the survey in Study 1, suggests that the police will likely have to invest in public education if they do decide to adopt BWCs. This will help to ensure that the public (and, importantly, the media) considers BWC footage in an appropriate fashion. I would go so far as to suggest that BWC footage of use of force events should always be released with clearly defined caveats to ensure the least biased interpretation of the footage. These caveats could include information regarding the technical limitations of BWC footage (e.g., cameras do not capture scenes as fast as the human visual system) as well as the conceptual limitations (e.g., that interpretation is often impacted by who controls the narration). Surveys like the one we conducted may be an excellent way to identify specific points of concern that should be addressed.

As mentioned above, beyond gauging the degree of public support for BWCs, and probing the public's knowledge of the technology and its limitations, the survey was also meant to inform decisions related to Study 2, which focused on how mock jurors treat BWC footage in court, especially when the footage contradicts testimony provided by the defendant (a police officer). More specifically, the survey results from Study 1 provided valuable information about how the public interprets situations where discrepancies between officer testimony and BWC footage exist, and this information informed how to conduct Study 2 and what might be found in Study 2. For example, the survey revealed that there was a clear difference in how respondents perceived officer testimony that contradicted BWC footage based on the type of discrepancy; when discrepancies related to relatively unimportant, peripheral details, the respondents saw those discrepancies as resulting from memory errors, but when the discrepancies relate to more important, 
central features of the case, many respondents attributed these to dishonest intentions on the part of the officer.

This finding suggests that variables like the nature of discrepancies or the degree of discrepancies will play an important role in court cases where discrepancies exist between testimony of an event and BWC footage of that event. Combined with the public's lack of knowledge of BWC limitations, these findings also suggest that expert testimony may play an important role in court cases like this. For example, expert witnesses may be able to explain to triers of fact why officer testimony about a use of force incident might contradict BWC footage, and this may have an impact on juror decision-making.

Study 2 was designed to assess these types of factors in a mock court case involving an officer (the defendant) who allegedly used excessive force in an incident that was recorded by a BWC. More specifically, three independent variables were manipulated - the degree of discrepancy between the defendant's testimony and BWC footage of the event, the nature of the discrepancies, and expert testimony about why there may be discrepancies. Interest was in how these variables impacted a range of outcome measures - verdicts, punishment severity, defendant credibility and persuasiveness, and the importance placed on BWC evidence. The three most important findings that merged from Study 2 were: (1) degree and nature of discrepancies did not influence the outcome variables, (2) expert testimony did have a strong and consistent influence on the outcome variables, and (3) perceptions of police legitimacy played an important role in shaping juror decisions and perceptions. 
Due to the survey results, and the fact that the discrepancy variables examined relate to the theoretical models of jury and juror decision-making discussed in Chapter 3, it is believed that further study of the discrepancy variables is warranted. Indeed, before discounting the role that these variables might play in the sort of court case examined here, future researchers are urged to examine them further in studies that address the limitations discussed above (e.g., drawing on a larger sample size, using more realistic stimuli, incorporating a deliberation component, etc.). By addressing some of these limitations, especially the inclusion of jury deliberations, the discrepancy variables manipulated in the current study will likely become more salient and they could have their expected impact on variables like verdict.

Given the consistent finding in the literature that expert testimony can significantly impact mock juror verdicts, this variable also deserves special attention in the future. Clearly, the results suggest that the specific testimony examined in this study impacted the outcome variables, but the type of testimony that was included only scratches the surface of what could be examined. The results of the survey from Study 1 could be used to help determine what sorts of testimony might be useful to examine in the future. For example, future studies may want to include expert testimony related to the technical limitations of BWCs given that there appears to be a clear lack of understanding on the part of the public when it comes to these limitations. In a general way, the hope that the present research highlights the potential value of using surveys like the one conducted in Study 1 to uncover information (e.g., knowledge gaps amongst the public) that can be incorporated into experimental research like the sort that was conducted in 
Study 2 (e.g., as expert testimony in mock trial research, which is designed to fill knowledge gaps among jurors).

On a practical note, police services and police associations (i.e., unions) may want to consider this research when their officers are on trial, especially if the research is replicated in the future. In order for officers to get a fair trial in cases like the one that was examined here (i.e., involving allegations of excessive use of force), Study 2 results suggest it may be necessary for experts to be brought in to educate the courts about the realities of use of force incidents and the impact that operational stress can have on officers, including their memory for events. Without such testimony, it may appear to triers of fact (e.g., jurors) that officers are intentionally lying about their role in an incident, or concealing that information from the court, when in fact discrepancies between their testimony and BWC footage of the incident may be the result of legitimate memory errors (or the officer may in fact be giving a fuller, more accurate account of the event than the BWC was able to capture).

Related to these discussions is the fact that the biases around expert witnesses that were voiced by the Study 1 survey respondents (e.g., that they are simply "hired guns") also need to be factored into peoples' thinking on this issue (although that is arguably an issue that must be tackled by the criminal justice system more generally, not police services specifically). Furthermore, an interesting discrepancy exists between the survey results, which suggest that participants will not put a lot of value on expert testimony (e.g., they simply see them as hired guns) and the Study 2 results, which indicate that the key variable impacting verdict is the presence or absence of expert testimony. This discrepancy could have occurred for a number of reasons. First, the change in context 
between the studies may have played a role. For example, the survey responses were given absent of any context while the transcript in Study 2 provided context for the expert testimony, which may have impacted how participants felt about the expert and their testimony. Second, potential sample differences between the survey and Study 2 may explain the results considering Study 1 involved a community sample while Study 2 participants were undergraduate students. For example, it is possible students are characterized by higher levels of some important variable, such as authoritarianism, which influenced how they perceived the expert in Study 2. Indeed, research has shown that community respondents tend to have significantly more authoritarian predispositions than students who tend to be significantly more egalitarian (Schultheis et al., 2017).

The results of Study 2 also revealed a strong relationship between perceptions of police legitimacy (PL) and most trial outcome variables, including verdict. This is an important finding, as any predispositions that affect verdict could impact a citizen's right to a fair and impartial hearing (a key directive in both section 11 of the Canadian Charter of Rights and Freedoms and the sixth amendment of the US Constitution). Given this finding, PL should be taken into consideration in any research where one of the actors in court - whether witness or defendant - is a police officer. It is argued that such results, especially if replicated in future research, would also need to be considered in real courts of law. This recommendation would certainly be in line with the models of jury and juror decision-making discussed in Chapter 3. To the extent that such considerations could be built into juror selection processes, these results suggest that such a move would potentially be useful (e.g., jurors that score too high or too low on the PL scale may be less likely to render impartial verdicts). 
If PL proves to be extremely predictive in future research, it may also be necessary to assess this sort of construct in any research that centres on attitudes/beliefs/views associated with the police or police-related activities, as this construct may be at the root of how research participants respond in such studies. Take the survey in Study 1, for example. Perceptions of PL may have had a significant impact on how participants responded to the items included in that survey and collecting this information would have allowed the opportunity to develop a better understanding of why certain views on the survey were expressed. As another example, a large body of research is emerging around public perceptions of police officer appearance (e.g., How does public perception differ for officers that are wearing sunglasses vs. no sun glasses?; Simpson, 2017; 2018); without including measures of PL in these sorts of studies, researchers may be unable to fully understand the results that emerge.

\section{Conclusion}

It is hoped that the research described in this dissertation contributes to the ongoing discussions that are taking place around the potential value of BWCs as a way of enhancing police transparency, police accountability, and police effectiveness. The research in Study 1 adds to our growing understanding of opinions about BWCs, especially public opinion about this technology (vs. police officer opinion). The survey results from Study 1 expand the conversations that are taking place around BWCs to include a focus on potential negative aspects of BWCs (e.g., that BWC footage may be interpreted by the public, or triers of fact, without taking into consideration the fact that footage of incidents does not, and it is argued cannot, tell the whole story of what transpired). This moves the conversation beyond the generally positive conversations 
about BWCs that are taking place (e.g., about how BWCs can improve behaviours on the part of the police and the public).

The primary contribution of Study 2 is that the results enhance our understanding of how BWC footage might be received by jurors in court. This is a topic that does not seem to have been studied to-date, despite the fact that such footage is likely to be increasingly brought into the courtroom as BWCs are adopted by more and more police services in North America. The focus on use of force issues in Study 2, and police officers as defendants, is also unusual in the juror literature, even though police officers are able to be charged with serious crimes related to their use of force (indeed, this seems to be happening with increasing frequency, especially in the US). More research of this type is needed, particularly research that is high in external validity. This is especially important because many well-studied and well-accepted ideas in the jury and juror decision-making literature (e.g., the role of authoritarianism in jury and juror decisionmaking) may play a fundamentally different role when the defendant is a representative of the state (i.e., a police officer). 


\section{References}

ABC7 News. (2015, April 21). "Sheriff's Office: San Francisco jail guards will wear body cameras". Retrieved from: http://abc7news.com/news/sheriffs-office-sanfrancisco-jail-guards-will-wear-body-cameras/675790/

Adams, A., \& Cox, A. L. (2008). Questionnaires, in-depth interviews and focus groups. In: Cairns, Paul and Cox, Anna L. eds. Research Methods for Human Computer Interaction. Cambridge, UK: Cambridge University Press, pp. 17-34.

Aronow, E., Weiss, K. A., \& Reznikoff, M. (2013). A practical guide to the Thematic Apperception Test: The TAT in clinical practice. Philadelphia, PA: BrunnerRoutledge.

Artwohl, A. (2008). Perceptual and memory distortions during officer involved shootings. AELE Lethal \& Less Lethal Force Workshop. Retrieved from http://www.aele.org/law/2008FPAUG/wb-19.pdf

Baldwin, S., Hall, C., Blaskovits, B., Bennell, C., Lawrence, C., \& Semple, T. (2018). Excited delirium syndrome (ExDS): Situational factors and risks to officer safety in non-fatal use of force encounters. International journal of law and psychiatry, 60, 26-34.

Beahen, W. (2008). Evolution of use of force by police in a Canadian context. Prepared for the Commission for Public Complaints Against the RCMP. Presented at the CACOLE conference. Retrieved from: http://capg.ca/wpcontent/uploads/2013/05/Evolution-of-Use-of-Force-by-Police-in-the-CanadianContext-W.Beahen_Presentation.pdf 
Beck, C., Lecci, L., \& Myers, B. (2013). Assessing pretrial juror attitudes while controlling for order effects: An examination of effect sizes for the RLAQ, JBS, and PJAQ. American Journal of Forensic Psychology, 31, 41-66.

Beehr, T. A., Ivanitskaya, L., Glaser, K., Erofeev, D., \& Canali, K. (2004). Working in a violent environment: The accuracy of police officers' reports about shooting incidents. Journal of Occupational and Organizational Psychology, 77, 217-235. doi:10.1348/096317904774202153

Berger, J. (Writer). (1972). Ways of seeing [Television series]. London: BBC.

Berman, G. L., Narby, D. J., \& Cutler, B. L. (1995). Effects of inconsistent eyewitness statements on mock-jurors' evaluations of the eyewitness, perceptions of defendant culpability and verdicts. Law and Human Behavior, 19, 79-88. doi:10.1007/BF01499074

Berzonsky, M. D., \& Sullivan, C. (1992). Social-cognitive aspects of identity style: Need for cognition, experiential openness, and introspection. Journal of Adolescent Research, 7(2), 140-155.

Birnbaum, M.H. (Ed.). (2000). Psychological experiments on the Internet. San Diego, CA: Academic Press.

Blaskovits, B. L., Ellingwood, H., Mugford, R., \& Bennell, C. (2015, June). Hollywood myths on the stand: Examining the impact of use of force myths on jury decisionmaking. Poster presented at the 3rd North American Correctional and Criminal Justice Psychology Conference (NACCJPC), Ottawa, ON.

Boehm, V. R. (1968). Mr. Prejudice, Miss Sympathy, and the authoritarian personality: An application of psychological measuring techniques to the problem of jury 
bias. Wisconsin Law Review, 734-750.

Bohm, D. (1964). On the problem of truth and understanding in science. The Critical Approach to Science and Philosophy. In: Bunge, M. (eds). The Critical Approaches to Science and Philosophy. New Jersey: Transaction Publishers, pp. 212-223.

Boivin, R., Gendron, A., Faubert, C., \& Poulin, B. (2017). The body-worn camera perspective bias. Journal of Experimental Criminology, 13(1), 125-142

Bornstein, B. H. (1999). The ecological validity of jury simulations: Is the jury still out?. Law and human Behavior, 23(1), 75-91.

Bornstein, B. H., Golding, J. M., Neuschatz, J., Kimbrough, C., Reed, K., Magyarics, C., \& Luecht, K. (2017). Mock juror sampling issues in jury simulation research: A meta-analysis. Law and Human Behavior, 41(1), 13-28.

Bray, R., \& Kerr, N. L. (1982). Methodological issues in the study of the psychology of the courtroom. In: Kerr, Norbert L. and Bray, R, eds. The psychology of the courtroom. Academic Press, New York.

Brodsky, S. L., Neal, T. M., Cramer, R. J., \& Ziemke, M. H. (2009). Credibility in the courtroom: How likeable should an expert witness be?. Journal of the American Academy of Psychiatry and the Law Online, 37(4), 525-532.

Brown, G. R. (2013). The blue line on thin ice: Police use of force in the era of cameraphones, 'citizen journalism', and YouTube (Master's thesis). Retrieved from https://curve.carleton.ca/d7998649-b8e4-4181-84e6-47e800d58fa3

Bruer, K., \& Pozzulo, J. D. (2014). Influence of eyewitness age and recall error on mock juror decision-making. Legal and Criminological Psychology, 19(2), 332-348. 
Buchanan, T., \& Smith, J.L. (1999). Using the Internet for psychological research: Personality testing on the World-Wide Web. British Journal of Psychology, 90, 125-144. doi:10.1348/000712699161189

Burke, T. M. (1998). The impact of pretrial publicity on jurors: Are there posttrial effects? (Doctoral dissertation). Retrieved from the National Library of Canada Bibliothèque nationale du Canada.

Butler, J. (1993). Endangered/endangering: Schematic racism and white paranoia. In R. Gooding-Williams (Ed.), Reading Rodney King/Reading urban uprising (pp. 1522). New York, NY: Routledge, Inc.

Butler, J., \& Sontag, S. (2007). Torture and the ethics of photography. Environment and Planning D: Society and Space, 25, 951-966. doi:10.1068/d2506jb

Cacioppo, J. T., \& Petty, R. E. (1982). The need for cognition. Journal of Personality and Social Psychology, 42, 116-131. doi:10.1037/0022-3514.42.1.116

Cacioppo, J. T., Petty, R. E., Feinstein, J. A., \& Jarvis, W. B. G. (1996). Dispositional differences in cognitive motivation: The life and times of individuals varying in need for cognition. Psychological Bulletin, 119, 197-253. doi: 10.1037/00332909.119.2.197

Campbell, J. H. (1992). A comparative analysis of the effects of post-shooting trauma on the Special Agents of the Federal Bureau of Investigation (Doctoral dissertation). Available from ProQuest Dissertations and Theses database. (UMI No. 9233863) Canadian Association of Chiefs of Police. (2000). A national use of force framework. Retrieved from 201407181836111492933971_cacpnationaluseofforceframework\%20(5).pdf 
Casper, J. D., Benedict, K., \& Perry, J. L. (1989). Juror decision-making, attitudes, and the hindsight bias. Law and Human Behavior, 13, 291-310. doi:10.1007/BF01067031

Cluett v. The Queen (1985) 2 S.C.R. 216.

Cooper, J., Bennett, E. A., \& Sukel, H. L. (1996). Complex scientific testimony: How do jurors make decisions?. Law and Human Behavior, 20(4), 379-394.

Corey, S., \& Bennell, C. (2008, October). Investigating beliefs related to use-of-force encounters among police officers and jury-eligible members of the public. Poster presented at the annual meeting of the Society for Police and Criminal Psychology, Walnut Creek, CA.

Criminal Code of Canada. RSC, 1985, c. C-46, s. 25

Crow, M. S., Snyder, J. A., Crichlow, V. J., \& Smykla, J. O. (2017). Community perceptions of police body-worn cameras: The impact of views on fairness, fear, performance, and privacy. Criminal justice and behavior, 44(4), 589-610.

David, G. (2010). Camera phone images, videos and live streaming: A contemporary visual trend. Visual Studies, 25, 89-98. doi: 10.1080/14725861003607017

Devine, D. J. (2012). Jury decision-making: The state of the science. New York, NY: New York University Press.

Devine, D. J., Buddenbaum, J., Houp, S., Studebaker, N., \& Stolle, D. P. (2009). Strength of evidence, extraevidentiary influence, and the liberation hypothesis: Data from the field. Law and Human Behavior, 33, 136-148. doi: 10.1007/s10979-008-9144$\mathrm{X}$

Devine, D. J., \& Caughlin, D. E. (2014). Do they matter? A meta-analytic investigation 
of individual characteristics and guilt judgments. Psychology, Public Policy, and Law, 20, 109-134. doi:10.1037/law0000006

Devine, D. J., Olafson, K. M., Jarvis, L. L., Bott, J. P., Clayton, L. D., \& Wolfe, J. M. (2004). Explaining jury verdicts: Is leniency bias for real?. Journal of Applied Social Psychology, 34(10), 2069-2098.

DeWitt, J. S., Richardson, J. T., \& Warner, L. G. (1997). Novel scientific evidence and controversial cases: A social psychological examination. Law \& Psychology Review, 21, 1-23.

Dowler, K., Fleming, T., \& Muzzatti, S. L. (2006). Constructing crime: Media, crime, and popular culture. Canadian Journal of Criminology and Criminal Justice, 48, 837-850.

Doyle, A. (2006). How not to think about crime in the media. Canadian Journal of Criminology and Criminal Justice, 48, 867-885.

Duncan, B. L. (1976). Differential social perception and attribution of intergroup violence: Testing the lower limits of stereotyping of Blacks. Journal of Personality and Social Psychology, 34, 590-598.

*Ellingwood, H., \& *Yamamoto, S. (2014). Body-worn video camera use by law enforcement: A critical review. (RCMP Research User Report). Ottawa, ON: RCMP. ${ }^{*}$ These authors contributed equally to this work.

Ewanation, L., Bennell, C., Blaskovits, B., \& Baldwin, S. (in press). Validating the Police Legitimacy Scale with a Canadian sample. Canadian Journal of Criminology and Criminal Justice.

Farrell, A., Pennington, L., \& Cronin, S. (2013). Juror perceptions of the legitimacy of 
legal authorities and decision-making in criminal cases. Law \& Social Inquiry, 38, 773-802.

Feigenson, N. (2014). The visual in law: Some problems for legal theory. Law, Culture and the Humanities, 10, 13-23.

Ferrara, C., Emeno, K., Ellingwood, H., Bennell, C., \& Schultheis, E. A. (2019, March). Police body-worn cameras: A necessary price to pay for safety and police accountability. Poster presented at the annual meeting of the American Psychology-Law Society, Portland, OR.

Finkel, N. J., \& Duff, K. B. (1991). Felony-murder and community sentiment. Law and Human Behavior, 15(4), 405-429.

Finkel, N. J., Meister, K. H., \& Lightfoot, D. M. (1991). The self-defense defense and community sentiment. Law and Human Behavior, 15, 585-602.

Fiske, J. (1995). Admissible postmodernity: Some remarks on Rodney King, OJ Simpson, and contemporary culture. University of San Francisco Law Review, 30, 917-930.

Fitzgerald, R. T., \& Carrington, P. J. (2011). Disproportionate minority contact in Canada: Police and visible minority youth. Canadian Journal of Criminology and Criminal Justice, 53(4), 449-486.

Force Science Institute. (2010 March 12). Do head cameras always see what you see in a force encounter? Force Science News, 145. Retrieved from http://www.forcescience.org/fsnews/145.html

Gau, J. M., Mosher, C., \& Pratt, T. C. (2010). An inquiry into the impact of suspect race on police use of Tasers. Police Quarterly, 13(1), 27-48. 
Geller, W. A., \& Karales, K. J. (1981). Shootings of and by Chicago Police: Uncommon Crises--Part I: Shootings by Chicago Police. J. Crim. L. \& Criminology, 72, 18131866.

Gelman, A., Fagan, J., \& Kiss, A. (2007). An analysis of the New York City police department's "stop-and-frisk" policy in the context of claims of racial bias. Journal of the American Statistical Association, 102(479), 813-823.

Gilfand v. Planey, No. 07 C 2566, 2011 WL 4036110 (N.D. Ill. Sept. 9, 2011).

Goodan, C. (2014, November 25). Ferguson buildings burn to the ground in most destructive riots since Michael Brown's death. National Post. Retrieved from http://news.nationalpost.com/news/ferguson-protesters-respond-to-grand-jurydecision-with-most-destructive-riots-since-michael-browns-death

Graham v. Connor, 490 U.S. 386 (1989).

Graziano, S. J., Panter, A. T., \& Tanaka, J. S. (1990). Individual differences in information processing strategies and their role in juror decision-making and selection. Forensic Reports, 3, 279-301.

Greene, E., \& Loftus, E. F. (1984). What's new in the news? The influence of wellpublicized news events on psychological research and courtroom trials. Basic and Applied Social Psychology, 5(3), 211-221.

Hall, C., Votova, K., \& Wood, D. (2013). Prospective analysis of police use of force in four Canadian cities. Public Safety Canada.

Hannaford-Agor, P. L., \& Hans, V. P. (2003). Nullification at Work-A Glimpse from the National Center for State Courts Study of Hung Juries. Chi.-Kent L. Rev., 78, 1249-1277. 
Harris, D. A. (1999). Stories, the statistics, and the law: Why "driving while Black" matters. The University of Minnesota Law Review, 84, 265-326.

Hepburn, J. R. (1980). The objective reality of evidence and the utility of systematic jury selection. Law and Human Behavior, 4(1-2), 89-101.

Honig, A. L., \& Roland, J. E. (1998). Shots fired; officer involved. Police Chief, 65, 116120.

Honig, A. L., \& Sultan, S. E. (2004). Reactions and resilience under fire: What an officer can expect. The Police Chief, 71, 54-60. Retrieved from http://www.policechiefmagazine.org/magazine/index.cfm?fuseaction=display\&art icle_id=469\&issue_id $=122004$

Hope, L., Lewinski, W., Dixon, J., Blocksidge, D., \& Gabbert, F. (2012). Witnesses in action: The effect of physical exertion on recall and recognition. Psychological Science, 23, 386-390. doi:10.1177/0956797611431463

Hope, L., Memon, A., \& McGeorge, P. (2004). Understanding pretrial publicity: Predecisional distortion of evidence by mock jurors. Journal of Experimental Psychology: Applied, 10, 111-119.

Hung, V., Babin, S., \& Coberly, J. (2016). A primer on body worn camera technologies. National Institute of Justice. Retrieved from: https://www.ncjrs.gov/pdffiles1/nij/grants/250382.pdf

Jennings, W. G., Fridell, L. A., \& Lynch, M. D. (2014). Cops and cameras: Officer perceptions of the use of body-worn cameras in law enforcement. Journal of Criminal Justice, 42, 549-556.

Johansson, G. (1975). Visual motion perception. Scientific American, 232(6), 76-89. 
Johnson, J. L. (2007). Use of force and the Hollywood factor. Americans for Effective Law Enforcement: Law Journal, 4, 501-515.

Johnson, J. D., Trawalter, S., \& Dovidio, J. F. (2000). Converging interracial consequences of exposure to violent rap music on stereotypical attributions of Blacks. Journal of Experimental Social Psychology, 36, 233-251.

Jones, A. M., Jones, S., \& Penrod, S. (2015). Examining legal authoritarianism in the impact of punishment severity on juror decisions. Psychology, Crime \& Law. Advance online publication. doi:10.1080/1068316X.2015.1077244

Kassin, S. M., Reddy, M. E., \& Tulloch, W. F. (1990). Juror interpretations of ambiguous evidence. Law and Human Behavior, 14, 43-55.

Kassin, S. M., \& Wrightsman, L. S. (1983). The construction and validation of a juror bias scale. Journal of Research in Personality, 17(4), 423-442.

Klettke, B., Graesser, A. C., \& Powell, M. B. (2010). Expert testimony in child sexual abuse cases: The effects of evidence, coherence and credentials on juror decisionmaking. Applied Cognitive Psychology, 24, 481-494.

Klinger, D. A. (2001). Police responses to officer-involved shootings. U.S. Department of Justice. Washington, DC: National Institute of Justice, U.S. Government Printing Office: NCJ 192286.

Klinger, D. A. (2004). Into the kill zone: A cop's eye view of deadly force. San Francisco, CA: Jossey-Bass.

Kochel, T. R., Wilson, D. B., \& Mastrofski, S. D. (2011). Effect of suspect race on officers' arrest decisions. Criminology, 49(2), 473-512.

Kong, S. H., Oh, B. M., Yoon, H., Ahn, H. S., Lee, H. J., Chung, S. G., ... \& Yang, H. K. 
(2010). Comparison of two-and three-dimensional camera systems in laparoscopic performance: a novel 3D system with one camera. Surgical endoscopy, 24(5), 1132-1143.

Korva, N., Yamamoto, S., \& Bennell, C. (2014, September). Use of Force Myths on Trial. Poster presented at the annual Society for Police and Criminal Psychology conference, Las Vegas, NV.

Kramer, G. P., Kerr, N. L., \& Carroll, J. S. (1990). Pretrial publicity, judicial remedies, and jury bias. Law and Human Behavior, 14(5), 409-438.

Kravitz, D. A., Cutler, B. L., \& Brock, P. (1993). Reliability and validity of the original and Revised Legal Attitudes Questionnaire. Law and Human Behavior, 17(6), 661-677.

Lassiter, G. D., Ware, L. J., Ratcliff, J. J., \& Irvin, C. R. (2009). Evidence of the camera perspective bias in authentic videotaped interrogations: Implications for emerging reform in the criminal justice system. Legal and Criminological Psychology, 14(1), 157-170.

Leippe, M. R., Eisenstadt, D., Rauch, S. M., \& Seib, H. M. (2004). Timing of eyewitness expert testimony, jurors' need for cognition, and case strength as determinants of trial verdicts. Journal of Applied Psychology, 89, 524-541.

Lindsay, R. C. L., Lim, R., Marando, L., \& Cully, D. (1986). Mock-juror evaluations of eyewitness testimony: A test of metamemory hypotheses1. Journal of Applied Social Psychology, 16, 447-459.

Luna, K., \& Migueles, M. (2009). Acceptance and confidence of central and peripheral misinformation. The Spanish journal of psychology, 12(2), 405-413. 
Lundrigan, S., Dhami, M. K., \& Mueller-Johnson, K. (2013). Predicting verdicts using pre-trial attitudes and standard of proof. Legal and Criminological Psychology. Advance online publication. doi:10.1111/lcrp.12043

Lupien, S. J., Fiocco, A., Wan, N., Maheu, F., Lord, C., Schramek, T., \& Tu, M. T. (2005). Stress hormones and human memory function across the lifespan. Psychoneuroendocrinology, 30, 225-242.

MacCoun, R. J., \& Kerr, N. L. (1988). Asymmetric influence in mock jury deliberation: Jurors' bias for leniency. Journal of personality and social psychology, 54(1), 2133.

McAuliff, B. D., \& Kovera, M. B. (2008). Juror Need for Cognition and Sensitivity to Methodological Flaws in Expert Evidence1. Journal of Applied Social Psychology, 38, 385-408.

McDowell v. Sherrer, No. 04-6089 (KSH), 2008 WL 4542475, at*1 (D.N.J. Oct. 7, 2008), rev'd in part, 374 F. App'x 288 (3d Cir. 2010).

McKimmie, B. M., Newton, C. J., Terry, D. J., \& Schuller, R. A. (2004). Jurors' responses to expert witness testimony: The effects of gender stereotypes. Group Processes \& Intergroup Relations, 7(2), 131-143.

Memon, A., \& Shuman, D. W. (1998). Juror perception of experts in civil disputes: The role of race and gender. Law \& Psychol. Rev., 22, (179), 1-21.

Mezey, N. (2013). The image cannot speak for itself: Film, summary judgment, and visual literacy. Valparaiso University Law Review, 48, 1-39.

Mnookin, J. L. (1998). Image of Truth: Photographic Evidence and the Power of Analogy, The. Yale JL \& Human, 10, 1-74. 
Mullin, C., Imrich, D. J., \& Linz, D. (1996). The impact of acquaintance rape stories and case-specific pretrial publicity on juror decision making. Communication Research, 23(1), 100-135.

Murray, H. A. (1938). Explorations in personality. Oxford, England: Oxford University Press

Narby, D. J., Cutler, B. L., \& Moran, G. (1993). A meta-analysis of the association between authoritarianism and jurors' perceptions of defendant culpability. Journal of Applied Psychology, 78, 34-42.

Neitzel, M.T., McCarthy, D.M. \& Kerr, N. L. (1999). Juries: The current state of the empirical literature. In R. Roesch, S.D. Hart \& J.R.P. Ogloff (Eds.), Psychology and law: The state of the discipline (pp. 23-52). New York, NY: Kluwer Academic/Plenum.

Nightingale, D., \& Cromby, J. (1999). Social constructionist psychology: A critical analysis of theory and practice. UK: McGraw-Hill Education.

Oakland, T., Douglas, S., \& Kane, H. (2015). Top Ten Standardized Tests Used Internationally with Children and Youth by School Psychologists in 64 Countries A 24-Year Follow-Up Study. Journal of Psychoeducational Assessment, 0734282915595303.

O’Melia, S.J. (1991). The Expert witness. Miller Thompson LLP, Barristers \& Solicitors. Retrieved October, 14, 2011. Retrieved from: http://www.millerthomson.com/assets/files/article_attachments/The_Expert_Witn ess.PDF

Pennington, N., \& Hastie, R. (1986). Evidence evaluation in complex decision- 
making. Journal of Personality and Social Psychology, 51, 242-258.

Pennington, N., \& Hastie, R. (1991). Cognitive theory of juror decision-making: The story model, A. Cardozo L. Rev., 13, 519-557.

Cacioppo, J. T., Petty, R. E., \& Kao, C. F. (1984). The efficient assessment of need for cognition. Journal of Personality Assessment, 48, 306-307.

Pezdek, K., Avila-Mora, E., \& Sperry, K. (2010). Does trial presentation medium matter in jury simulation research? Evaluating the effectiveness of eyewitness expert testimony. Applied Cognitive Psychology, 24(5), 673-690.

Pfeffer, A. (2016, December 10). The cost of accountability: Can Canadian police services afford body cam technology? CBC News. Retrieved from https://www.cbc.ca/news/canada/ottawa/the-cost-of-accountability-can-canadianpolice-services-afford-body-cam-technology-1.3890777

Potter, M. C., Wyble, B., Hagmann, C. E., \& McCourt, E. S. (2014). Detecting meaning in RSVP at 13 ms per picture. Attention, Perception, \& Psychophysics, 76(2), $270-279$.

R. v. Mohan. (1994) 2 S.C.R. 923063

R. v. Nikolovski, (1996) 3 S.C.R. 1197

Ridgeway, G. (2007). Analysis of racial disparities in the New York Police Department's stop, question, and frisk practices. Rand Corporation.

Rivard, J. M., Dietz, P., Martell, D., \& Widawski, M. (2002). Acute dissociative responses in law enforcement officers involved in critical shooting incidents: The clinical and forensic implications. Journal of Forensic Sciences, 47, 1093-1100.

Roozendaal, B., McEwen, B. S., \& Chattarji, S. (2009). Stress, memory and the 
amygdala. Nature Reviews Neuroscience, 10, 423-433.

Rosenbaum, D. P., Schuck, A. M., Costello, S. K., Hawkins, D. F., \& Ring, M. K. (2005). Attitudes toward the police: The effects of direct and vicarious experience. Police quarterly, 8, 343-365.

Rossi, P. H., Freeman, H. E., \& Lipsey, M. (2004). Evaluation a systematic approach. (6th ed.). Thousand Oaks, California: Sage Publications, Inc.

Ruva, C. L., \& LeVasseur, M. A. (2012). Behind closed doors: the effect of pretrial publicity on jury deliberations. Psychology, Crime \& Law, 18, 431-452.

Ruva, C. L., \& McEvoy, C. (2008). Negative and positive pretrial publicity affect juror memory and decision-making. Journal of Experimental Psychology: Applied, 14(3), 226-235. Doi: http://dx.doi.org/10.1037/1076-898X.14.3.226

Sagar, H. A. \& Schofield, J. W. (1980). Racial and behavioral cues in Black and White children's perceptions of ambiguously aggressive acts. Journal of Personality and Social Psychology, 39, 590-598.

Schuller, R. A., \& Cripps, J. (1998). Expert evidence pertaining to battered women: The impact of gender of expert and timing of testimony. Law and Human Behavior, 22(1), 17-31.

Schuller, R. A., \& Hastings, P. A. (1996). Trials of battered women who kill: The impact of alternative forms of expert testimony. Law and Human Behavior, 2, 167-188.

Schuller, R. A., Terry, D., \& McKimmie, B. (2005). The Impact of Expert Testimony on Jurors' Decisions: Gender of the Expert and Testimony Complexity 1. Journal of Applied Social Psychology, 35(6), 1266-1280.

Schultheis, E., Ellingwood, H., Emeno, K. \& Bennell, C. (2017, September). Perceptions 
of Police Legitimacy and Legal Authoritarianism in Community and Student Samples. Poster presented at the $43^{\text {rd }}$ Annual Conference for the Society for Police and Criminal Psychology, San Diego, CA.

Schwartz, M. A., Silbey, J., Ryan, J., \& Donoghue, G. (2009). Analysis of Videotape Evidence in Police Misconduct Cases. Touro Law Review, 25, 857-907.

Scott v. Harris, 550 U.S. 372, 127 S. Ct. 1769, 167 L. Ed. 2d 686 (2007) [2007 BL 12373]

Semmler, C., \& Brewer, N. (2002). Effects of mood and emotion on juror processing and judgments. Behavioral Sciences \& the Law, 20, 423-436.

Serfass, D. G., \& Sherman, R. A. (2013). Personality and perceptions of situations from the Thematic Apperception Test. Journal of Research in Personality, 47, 708-718.

Sharps, M. J. (2009). Processing under pressure: Stress, memory, and decision-making in law enforcement. Flushing, NY: Looseleaf Law Publications, Inc.

Simons, H. W. (1976). Persuasion: Understanding, practice, and analysis. Reading, MA: Addison-Wesley Publishing Company.

Simpson, R. (2017). The Police Officer Perception Project (POPP): An experimental evaluation of factors that impact perceptions of the police. Journal of Experimental Criminology, 13(3), 393-415.

Simpson, R. (2018). Officer appearance and perceptions of police: accoutrements as signals of intent. Policing: A Journal of Policy and Practice. https://doi.org/10.1093/police/pay015

Sink, J. (2014, December 1). Obama to provide funding for 50,000 police body cameras. The Hill. Retrieved from http://thehill.com/homenews/administration/225583- 
obamato-provide-funding-for-50000-police-body-cameras

Skogan, W. G., \& Frydl, K. (2004). Fairness and Effectiveness in Policing: The Evidence. Washington, D.C.: National Academies Press.

Smith, P. E., \& Hawkins, R. O. (1973). Victimization, types of citizen-police contacts, and attitudes toward the police. Law and Society Review, 8, 135-152

Solomon, R.M., \& Horn, J.M. (1986) Post-shooting traumatic reactions: A pilot study. In J. T. Reese \& H. A. Goldstein (Eds.), Psychological services for law enforcement (pp. 383-393). Washington, DC: U.S. Government Printing Office

Sontag, S. (1978). On photography 5. MacMillan.

Sousa, W. H., Miethe, T. D., \& Sakiyama, M. (2015). Body-worn cameras on police: Results from a national survey of public attitudes. University of Nevada Las Vegas: Center for Crime and Justice Policy. Retrieved from: https://jobs.unlv.edu/sites/default/files/page_files/27/BodyWornCameras.pdf

Steblay, N. M., Besirevic, J., Fulero, S. M., \& Jimenez-Lorente, B. (1999). The effects of pretrial publicity on juror verdicts: A meta-analytic review. Law and Human Behavior, 23, 219-235.

Suziedelis, A., \& Lorr, M. (1973). Conservative attitudes and authoritarian values. The Journal of Psychology, 83, 287-294.

Tang, C. M., \& Nunez, N. (2003). Effects of defendant age and juror bias on judgment of culpability: What happens when a juvenile is tried as an adult? American Journal of Criminal Justice, 28, 37-52.

Tankebe, J., Reisig, M. D., \& Wang, X. (2016). A multidimensional model of police legitimacy: A cross-cultural assessment. Law and Human Behavior, 40(1), 11-22. 
Tenney, E. R., MacCoun, R. J., Spellman, B. A., \& Hastie, R. (2007). Calibration trumps confidence as a basis for witness credibility. Psychological Science, 18(1), 46-50.

Thorpe, S., Fize, D., \& Marlot, C. (1996). Speed of processing in the human visual system. nature, 381(6582), 520-522.

Tinsley, J. N., Molodtsov, M. I., Prevedel, R., Wartmann, D., Espigulé-Pons, J., Lauwers, M., \& Vaziri, A. (2016). Direct detection of a single photon by humans. Nature communications, 7, 12172.

Todd, H. E. M. (2015). The effects of citizen monitoring on the police: an examination of citizen monitoring and police use of justified force (Doctoral dissertation, Arts \& Social Sciences).

Valiante, G. (2019, February 10). Montreal rules out body cameras for police, saying cost not worth results. The Canadian Press. Retrieved from https://www.ctvnews.ca/canada/montreal-rules-out-body-cameras-for-policesaying-cost-not-worth-results-1.4290330

Van Dijck, J. (2011). Flickr and the culture of connectivity: Sharing views, experiences, memories. Memory Studies, 4, 401-415. doi: 10.1177/1750698010385215

Verplanken, B., Hazenberg, P. T., \& Palenewen, G. R. (1992). Need for cognition and external information search effort. Journal of Research in Personality, 26(2), 128136.

Voss, J. F., Wiley, J., \& Sandak, R. (1999). On the use of narrative as an argument. In S. Goldman, A. Graesser, \& P. van den Broek (Eds.), Narrative comprehension, causality, and coherence: Essays in honor of Tom Trabasso (pp. 235-252). Mahwah, NJ: Lawrence Erlbaum. 
Walker, D. B., \& Kratcoski, P. C. (1985). A cross cultural perspective on police values and police-community relations. Criminal Justice Review, 10, 17-24. doi:10.1177/073401688501000103

Warling, D., \& Peterson-Badali, M. (2003). The verdict on jury trials for juveniles: The effects of defendant's age on trial outcomes. Behavioral Sciences \& the Law, 21, 63-82. doi:10.1002/bs1.517

Wasserman, H.M. (2008). Video evidence and summary judgement: The procedure of Scott v. Harris. Judicature, 91, 180-184.

White, M. D. (2014). Police officer body-worn cameras: Assessing the evidence. Washington, DC: Office of Community Oriented Policing Services.

White, D., \& Knowles, A. (2013). Predictors and classification of attitudes to differing sentencing goals in an Australian sample. Psychiatry, Psychology and Law, 20(2), 157-167.

Worrall, J. L., Bishopp, S. A., Zinser, S. C., Wheeler, A. P., \& Phillips, S. W. (2018). Exploring bias in police shooting decisions with real shoot/don't shoot cases. Crime \& Delinquency, 64(9), 1171-1192.

Wortley, S., \& Owusu-Bempah, A. (2011). The usual suspects: Police stop and search practices in Canada. Policing and Society, 21(4), 395-407.

Wortley, S., \& Roswell, T. (2006). Police Use of force in Ontario: An examination of data from the Special Investigations Unit. (Final Report). Ipperwash Inquiry. Ontario: Canada.

Wright, D. B., \& Stroud, J. N. (1998). Memory quality and misinformation for peripheral and central objects. Legal and Criminological Psychology, 3(2), 273-286. 
Zamble, E., \& Annesley, P. (1987). Some determinants of public attitudes toward the police. Journal of Police Science \& Administration, 15, 285-290. 


\section{Appendix A}

\section{Informed Consent Form}

The purpose of an informed consent form is to ensure that you understand the purpose of the study and the nature of your involvement. An informed consent form must provide sufficient information such that you have the opportunity to determine whether or not you wish to participate in the study.

Present study: Is Seeing Believing? Public Perception on the Use of Body-worn Video by Police

Research personnel: The following people will be involved in this research project and may be contacted at any time: Holly Ellingwood (Doctoral Student, Principal Investigator, HollyEllingwood@cmail.carleton.ca, Lab 613-520-1728) or Dr. Craig Bennell (Faculty Advisor, Craig.Bennell@carleton.ca, 613-520-2600, ext. 1769).

Concerns: If you should have any ethical concerns about this study please contact, Dr. Shelley Brown (Chair, Carleton University Research Ethics Board - B, ethics@carleton.ca,613-520-2517).

Purpose: The purpose of this study is to engage community members in a preliminary examination of their beliefs, opinions, and concerns surrounding the use of body-worn video by members of police services.

Task requirements: You will be asked to read and answer a series of questions about police use of body-worn video and camera-based evidence in general. You will also be asked to complete some questionnaires requesting your demographic information.

Duration and locale: This study will be completed online in one testing session that will last approximately 25 minutes.

Remuneration: Any incentive you will receive for completing this survey will be in the amount of $\$ 1.00$ and provided to you in accordance with the terms and conditions of your membership in the survey panel through which you have received the invitation to participate. Qualtrics Panel's terms and conditions are that if a participant does not meet the criteria to participate in this study (at least 18 years old and a Canadian citizen) or withdraws without completing the survey, the participant will receive no remuneration (i.e., will not be paid $\$ 1.00$ ).

Potential risk/discomfort: There are no potential physical risks involved in this experiment. There is a minimal risk for discomfort when thinking about our culture's level of exposure to being recorded. Should you experience any unease, you have the right to withdraw from the study at any time, in accordance with the terms and conditions of your membership in the survey panel through which you have received the invitation to participate. 
Anonymity/Confidentiality: The data collected in this experiment are strictly confidential. All data are coded such that your name is not associated with the responses you provide. Any identifying information associated with your code will be confined to a single page that will be separated from your questionnaire, and kept in a separate, secured file by the research investigators, who will keep this information confidential. Only members of the Police Research Laboratory will have access to the data. We collect data through the software Qualtrics, which uses servers with multiple layers of security to protect the privacy of the data (e.g., encrypted websites and pass-word protected storage). Please note that Qualtrics is hosted by a server located in the USA. The United States Patriot Act permits U.S. law enforcement officials, for the purpose of an anti-terrorism investigation, to seek a court order that allows access to the personal records of any person without that person's knowledge. In view of this we cannot absolutely guarantee the full confidentiality and anonymity of your data. With your consent to participate in this study you acknowledge this. Your data will be kept for a period of 5 years at which time it will be destroyed. All of your data will be stored on password protected computers, which are accessible by the research team. All the information you provide will be strictly confidential and these data will only be used for research and teaching purposes. Your personal information will not appear in any presentations, reports, or other publications prepared using data collected from this study.

Right to withdraw: You may refrain from answering any questions on the questionnaire if you are uncomfortable doing so or otherwise do not want to. At any point in the study, you may withdraw in accordance with the terms and conditions of your membership in the survey panel through which you have received the invitation to participate. The terms and conditions of Qualtrics Panels are that you will not receive your \$1 remuneration if you withdraw from the study before it is complete.

This study has received clearance by the Carleton University Psychology Research Ethics Board (15-109).

I have read the above form and understand the conditions of my participation. My participation in this study is voluntary, and I understand that if at any time I wish to leave the study, I may do so without having to give an explanation. I also understand that if I withdraw from the study before it is complete that I will not receive the \$1 remuneration. Furthermore, I am also aware that the data gathered in this study are confidential and anonymous with respect to my personal identity. By checking this box, I'm indicating that I agree to participate in this study. 


\section{Appendix B}

\section{Demographics Measure}

[Note: Questions 1 and 2 are the inclusion criteria questions. Participants must meet the criteria to move onto the remainder of the questionnaire and be able to complete the survey. This notation will not be included in the questionnaire, that is, participants will not read this statement.]

Please answer the following questions by checking the appropriate box or writing your answer in the space provided.

1. Are you 18 years or older?

$\square$ Yes

$\square \mathrm{No}$

2. Are you a Canadian Citizen?

$\square$ Yes

$\square$ No

3. What is your age? (years)

4. What is your gender?

5. What is your ethnic background?

$\square$ Caucasian/White

African Canadian/Black

$\square$ First Nations/Aboriginal Canadian/Native Canadian

Asian

$\neg$ East Indian

$\checkmark$ Hispanic/Latino

$\square$ Middle Eastern 
$\square$ Other (please specify):

6. Please indicate the type of area where you live:

$\square$ Rural

ᄀ Urban

7. Please indicate your political affiliation:

$\square$ Conservative Party

$\square$ Liberal Party

$\square$ New Democratic Party

$\square$ Green Party

$\square$ Le Bloc Quebecois

$\square$ I have no political affiliation

$\square$ Other (please specify):

8. Please indicate your level of education:

$\square$ some high school

$\square$ graduated high school

$\square$ some college/university

$\square$ graduated college/university bachelors

$\square$ graduated with a graduate degree (Master's, Ph.D.)

$\square$ medical degree

$\square$ Other: Please specify

9. Are you, or have you ever been, a law enforcement officer, a correctional worker, or a 
security guard?

$\square$ Yes (please specify):

$\square$ No

10. Have you ever read any reports about body-worn cameras and their potential strengths and/or limitations?

\section{$\square$ Yes}

$\square$ No

11. Are you familiar with what happened in the police shooting in Ferguson, Missouri?

$\square$ Yes

$\square$ No

12. Have you seen any depictions of police use of force captured on video in the news or in social media (e.g., Facebook, YouTube, Instagram, etc.)?

$\square$ Yes

$\square$ No

If yes, have you seen:

$\square$ A lot

$\square$ Only a little

13. Have you seen any police body-worn camera video footage depicting a use of force incident in the news or in social media (e.g., Facebook, YouTube, Instagram, etc.)?

$\square$ Yes

$\square$ No

$\square$ Don't know 
If yes, have you seen:

$\square \mathrm{A}$ lot

$\square$ Only a little 


\section{Appendix C}

\section{Questionnaire}

\section{Section A: Attitudes Toward Body-worn Cameras}

Please answer the following questions:

1. Has a member of the public (not a media photographer or videographer) ever recorded you (using some sort of handheld camera) while you were out in public?

$\square$ Yes

$\square$ No

If yes, has it happened more than once?

$\square$ Yes

$\square$ No

2. On a scale from 1 to 7 , with 1 representing not at all concerned and 7 representing extremely concerned, how concerned are you with being video-recorded (including surreptitiously) by other people?

3. On a scale from 1 to 7 , with 1 representing not at all concerned and 7 representing extremely concerned, how concerned are you with police officers wearing a device that would video-record their conduct while performing their duties in public?

Please indicate for each statement whether you strongly agree, agree, somewhat agree, are neutral, somewhat disagree, disagree, strongly disagree.

4. Police officers wearing a body-worn camera would improve officer behaviour while on duty.

5. Police officers wearing a body-worn camera would improve citizen behaviour while on duty. 
6. If police wore body-worn cameras, I would feel safer.

7. If police wore body-worn cameras, officers would be safer.

8. Police should alert people before they record them with a body-worn camera.

9. Body-worn cameras should be recording at all times when police are on duty.

10. Body-worn cameras should only record when police are approaching a possible incident/potential suspect.

11. Officers should be able to control when a body-worn camera records.

12. Should police recordings be turned off when:

a. Police are on break.

b. Police are interviewing an informant.

c. Children are present.

d. A member of the public requests to not be recorded.

e. Police are in a person's residence.

f. Police are attending community events such as parades.

g. Police are investigating a sexual assault.

h. Police are investigating a domestic dispute.

i. Police are involved in everyday interactions with the public.

13. The use of body-worn cameras by police will make police more accountable for any misconduct.

14. The use of body-worn cameras by police will reduce false misconduct reports against the police by the public.

15. The use of body-worn cameras by police will improve investigations by providing much needed evidence (i.e., caught in the act on video). 
16. The use of body-worn cameras by police violates my right to privacy.

17. The use of body-worn cameras by police will increase public trust in the police.

18. Please check off the option you think is most appropriate: Body-worn video recordings captured by the police should be kept for:

a. Destroyed immediately following the recorded event

b. 3 months

c. 6 months

d. 1 year

e. 3 years

f. 5 years

g. 10 years

h. Forever

Please indicate for the following statement whether you strongly agree, agree, somewhat agree, are neutral, somewhat disagree, disagree, strongly disagree.

19. I would be willing to pay slightly higher taxes to ensure my local police service is equipped with body-worn cameras.

\section{Section B: Beliefs Regarding Visual Evidence}

Please indicate for each statement whether you strongly agree, agree, somewhat agree, are neutral, somewhat disagree, disagree, strongly disagree.

1. A photograph tells the truth by providing an image.

Please explain why:

2. A video recording tells the truth about the recorded event.

Please explain why: 
3. A photograph can be altered/manipulated after the photo has been taken.

4. A video can be altered/manipulated after the video was recorded.

5. In court, I would view a video recording from a police officer (via a body-worn camera) as more credible than a video recording from a bystander (via a cell phone or handheld camera).

Please explain why:

6. In court, I would view video evidence of a potential crime presented by the prosecution as more credible than video evidence presented by the defence (the lawyer representing the accused)?

Please explain why:

7. In court, I would view video evidence of a potential crime introduced by the judge to be more credible than video evidence presented by the prosecution or the defence.

Please explain why:

8. A photograph of an incident gives a more accurate account than eyewitness testimony of the same incident.

Please explain why:

9. A video of an incident from a police issued body-worn camera gives a more accurate account than eyewitness testimony of the same incident.

Please explain why:

Please indicate for each statement whether you strongly agree, agree, somewhat agree, are neutral, somewhat disagree, disagree, strongly disagree.

10. During an incident where a police officer had to use force on a suspect, the officer said they turned on their body-worn camera, but it did not record. If you were to hear this 
explanation in a court case involving allegations of excessive use of force by the police officer, would your tendency be to view this officer as:

$\square$ Being dishonest

$\square$ Telling the truth

$\square$ Other. Please explain

11. Video produced from body-worn cameras is consistently of very high visual quality.

12. Can a camera capture depth perception?

$\square$ Yes

$\square$ No

$\square$ Don't know

134. Can a video recorder capture depth perception?

$\square$ Yes

$\square$ No

$\square$ Don't know

14. Can a camera capture a scene in poor lighting or darkness better than the human eye can see?

$\square$ Yes

$\square$ No

\section{$\square$ Don't know}

15. Can a video recorder record a scene in poor lighting or darkness better than the human eye can see?

$\square$ Yes 
$\square$ No

$\square$ Don't know

16. Can a video recorder record a scene as fast as the human visual system can process that scene?

$\square$ Yes

$\square$ No

$\square$ Don't know

17. Can a video recorder pick up on subtle threat cues (for example, tensing of a suspect's body, flash of metal), the same as the human visual system can?

$\square$ Yes

$\square$ No

\section{$\square$ Don’t know}

18. An officer testifies in a use of force court case that he was standing beside a bush, but a video of the incident shows it was a mailbox. Would your tendency be to view this officer as:

\section{$\square$ Dishonest}

$\square$ Mistaken (i.e., did not remember the detail correctly)

\section{$\square$ Not sure}

$\square$ Other. Please explain

19. An officer testifies in a use of force court case that the suspect was lunging at him with a bat, but the video shows the suspect was walking with a bat. Would your tendency be to view this officer as: 
$\square$ Dishonest

$\square$ Mistaken (i.e., did not remember the detail correctly)

$\square$ Not sure

$\square$ Other. Please explain

\section{Section C: General Opinions about the Police and the Justice System}

Please indicate for each statement whether you strongly agree, agree, somewhat agree, are neutral, somewhat disagree, disagree, strongly disagree.

1. Stress of a use of force event can cause problems with respect to an officer's memory of the event?

2. Expert witnesses for the defence are only hired guns that are there to help get accused acquitted, even when the evidence suggests they may be guilty.

3. Experts hired by the Defence or Prosecution only report what the side that hired them wants to hear. 


\section{Appendix D}

\section{Contact Form}

Thank you for your participation in the present study: Is Seeing Believing? Public Perception on the Use of Body-worn Video by Police. To reiterate, the purpose of this study was to engage community members in a preliminary examination of their beliefs, opinions, and concerns surrounding the use of body-worn video by members of police services.

Research personnel: The following people are involved in this research project and may be contacted at any time: Holly Ellingwood (Doctoral Student, Principal Investigator, HollyEllingwood@cmail.carleton.ca, Lab 613-520-1728) or Dr. Craig Bennell (Faculty Advisor, Craig.Bennell@carleton.ca, 613-520-2600, ext. 1769).

Concerns: If you should have any ethical concerns about this study please contact, Dr. Shelley Brown (Chair, Carleton University Research Ethics Board - B, ethics@carleton.ca, 613-520-2517).

Thank you for your time. 


\section{Appendix E}

\section{Police Legitimacy Scales}

Police Legitimacy Scale (Tankebe et al. 2016)

Please Rate the statements below on the following scale.

Strongly Disagree

1
Disagree

2
Agree

3
Strongly Agree 4

1. When the police deal with people, they always behave according to the law.

2. If I were to talk to police officers in my community, I would find their values to be very similar to my own.

3. The police act in ways that are consistent with my own moral values.

4. The police treat citizens with respect.

5. The police take time to listen to people.

6. The police treat people fairly.

7. The police respect citizens' rights.

8. The police are courteous to citizens they come into contact with.

9. The police treat everyone with dignity.

10. The police make decisions based on the facts.

11. The police provide the same quality of service to all citizens.

12. The police enforce the law consistently when dealing with people.

13. The police make sure citizens receive the outcomes they deserve under the law.

14. Crime levels in my neighbourhood have changed for the better in the last year. 
15. There are not many instances of crime in my neighbourhood.

16. I feel safe walking in my neighbourhood.

To what extent are your views expressed above a result of exposure to the police through:

1. The media (television coverage, newspaper, radio, etc.):

\begin{tabular}{cccccccc}
\hline 1 & 2 & 3 & 4 & 5 & & 6 & 7 \\
Not at all & a little & somewhat & a lot & extremely
\end{tabular}

2. Direct personal experience with the police:

\begin{tabular}{cccccccc}
\hline 1 & 2 & 3 & 4 & 5 & & 6 & 7 \\
Not at all & a little & somewhat & a lot & extremely
\end{tabular}

3. Hearing about how others have been treated by the police:

\begin{tabular}{cccccccc}
\hline 1 & 2 & 3 & 4 & 5 & & 6 & 7 \\
Not at all & a little & somewhat & a lot & & extremely
\end{tabular}




\section{Appendix F}

\section{Juror Bias Scale}

This questionnaire is designed to assess people's opinions and attitudes on various legal issues.

Please read each item carefully and give as true a picture as possible of your own beliefs by writing in the number $1,2,3,4$, or 5 , as appropriate.

\section{Strongly Agree}

2. Somewhat Agree

3. Agree \& Disagree Equally

4. Somewhat Disagree

\section{Strongly Disagree}

1. Appointed judges are more competent then elected judges.

2. If a suspect runs from the police, then he probably committed the crime. (PC)

3. A defendant should be found guilty if 11 out of 12 jurors vote guilty. (RD)

4. Most politicians are really as honest as humanly possible.

5. Too often jurors hesitate to convict someone who is guilty out of pure sympathy. (RD)

6. In most cases, where the accused presents a strong defense, it is only because of a good lawyer. (PC)

7. In general, children should be excused for their misbehavior.

8. The death penalty is cruel and inhumane. (RD)

9. Out of every 100 people brought to trial, at least 75 are guilty of the crime with which they are charged. (PC)

10. For serious crimes like murder, a defendant should be found guilty so long as there is a $90 \%$ chance that he committed the crime. (RD) 
11. Defense lawyers don't really care about guilt or innocence, they are just in business to make money. (PC)

12. Generally, the police make an arrest only when they are sure about who committed the crime. (PC)

13. Circumstantial evidence is too weak to use in court. (PC)

14. Many accident claims filed against insurance companies are phony. (PC)

15. The defendant is often a victim of his own bad reputation. (PC)

16. If the grand jury recommends that a person be brought to trial, then he probably committed the crime. (PC)

17. Extenuating circumstances should not be considered - if a person commits a crime, then that person should be punished. (RD)

18. Hypocrisy is on the increase in society.

19. Too many innocent people are wrongfully imprisoned. (RD)

20. If a majority of the evidence - but not all of it - suggests that the defendant committed the crime, the jury should vote not guilty. (RD)

21. If the defendant committed a victimless crime like gambling or possession of marijuana, he should never be convicted. (RD)

22. Some laws are made to be broken.

Note. $\mathrm{PC}=$ Probable culpability (pro-prosecution bias); $\mathrm{RD}=$ reasonable doubt (prodefence bias)

\section{Scoring Key:}

Defense-biased statements are scored at face value; prosecution-biased statements are reverse scored $(1=5,2=4,3=3,4=2,5=1)$.

$\mathbf{P C}=$ Items $2+6+9+11+12+13+14+15+16$

$\mathbf{R D}=$ Items $3+5+8+10+17+19+20+21$

Total Score $=\mathrm{PC}+\mathrm{RD}$ 


\section{Appendix G}

\section{Items of the Revised Legal Attitudes Questionnaire}

Please read each item carefully and give as true a picture as possible of your own beliefs by writing in the number $1,2,3,4,5$ or 6 as appropriate.

\section{Strongly Disagree}

2. Moderately Disagree

3. Slightly Disagree

4. Slightly Agree

5. Moderately Agree

6. Strongly Agree

1. Unfair treatment of underprivileged groups and classes is the chief cause of crime. $(\mathrm{AA}, \mathrm{R})$

2. Too many obviously guilty persons escape punishment because of legal technicalities. (A)

4. Evidence illegally obtained should be admissible in court if such evidence is the only way of obtaining a conviction. (A)

6. Search warrants should clearly specify the person or things to be seized. (E, R)

7. No one should be convicted of a crime on the basis of circumstantial evidence, no matter how strong such evidence is. (AA, R)

8. There is no need in a criminal case for the accused to prove his innocence beyond a reasonable doubt. $(\mathrm{E}, \mathrm{R})$

9. Any person who resists arrest commits a crime. (A)

10. When determining a person's guilt or innocence, the existence of a prior arrest record should not be considered. (E, R)

11. Wiretapping by anyone and for any reason should be completely illegal. (AA, R)

14. Defendants in a criminal case should be required to take the witness stand. (A)

15. All too often, minority group members do not get fair trials. (E, R) 
16. Because of the oppression and persecution minority group members suffer, they deserve leniency and special treatment in the courts. (AA, R)

17. Citizens need to be protected against excess police power as well as against criminals. $(\mathrm{E}, \mathrm{R})$

19. It is better for society that several guilty men be freed than one innocent one wrongfully imprisoned. (E, R)

20. Accused persons should be required to take lie-detector tests. (A)

21. When there is a "hung" jury in a criminal case, the defendant should always be freed and the indictment dismissed. (AA, R)

22. A society with true freedom and equality for all would have very little crime. (AA, R)

23. It is moral and ethical for a lawyer to represent a defendant in a criminal case even when he believes his client is guilty. $(\mathrm{E}, \mathrm{R})$

24. Police should be allowed to arrest and question suspicious looking persons to determine whether they have been up to something illegal. (A)

25. The law coddles criminals to the detriment of society. (A)

27. The freedom of society is endangered as much by overzealous law enforcement as by the acts of individual criminals. (E, R)

29. In the long run, liberty is more important than order. (E, R)

30. Upstanding citizens have nothing to fear from the police. (A)

Note. Identification of subscales Authoritarianism (A), Antiauthoritarianism (AA) and Equalitarianism (E) is given immediately following each item. Items that are reversecoded on the overall RLAQ scale are indicated with an R following the subscale identification. 


\section{Appendix $\mathbf{H}$}

\section{Short Form of the Need for Cognition Scale}

Instructions: For each of the statements below, please indicate to what extent the statement is characteristic of you. If the statement is extremely uncharacteristic of you (not at all like you) please write a " 1 " to the left of the question; if the statement is extremely characteristic of you (very much like you) please write a " 5 " next to the question. Of course, a statement may be neither extremely uncharacteristic nor extremely characteristic of you; if so, please use the number in the middle of the scale that describes the best fit. Please keep the following scale in mind as you rate each of the statements below: $1=$ extremely uncharacteristic; $2=$ somewhat uncharacteristic; $3=$ uncertain; $4=$ somewhat characteristic; 5 = extremely characteristic.

\begin{tabular}{|c|c|}
\hline Item number & Item Wording \\
\hline 1. & I would prefer complex to simple problems. \\
\hline 2. & $\begin{array}{l}\text { I like to have the responsibility of handling a situation that requires a lot of } \\
\text { thinking. }\end{array}$ \\
\hline 3. & Thinking is not my idea of fun. ${ }^{\mathrm{a}}$ \\
\hline 4. & $\begin{array}{l}\text { I would rather do something that requires little thought than something that is } \\
\text { sure to challenge my thinking abilities. }{ }^{\text {a }}\end{array}$ \\
\hline 5. & $\begin{array}{l}\text { I try to anticipate and avoid situations where there is a likely chance I will have } \\
\text { to think in depth about something. }\end{array}$ \\
\hline 6. & I find satisfaction in deliberating hard and for long hours. \\
\hline 7. & I only think as hard as 1 have to. ${ }^{\text {a }}$ \\
\hline 8. & I prefer to think about small, daily projects to long-term ones. ${ }^{\text {a }}$ \\
\hline 9. & I like tasks that require little thought once I've learned them. ${ }^{a}$ \\
\hline 10. & The idea of relying on thought to make my way to the top appeals to me. \\
\hline 11. & I really enjoy a task that involves coming up with new solutions to problems. \\
\hline 12. & Learning new ways to think doesn't excite me very much. ${ }^{\text {a }}$ \\
\hline 13. & I prefer my life to be filled with puzzles that I must solve. \\
\hline 14. & The notion of thinking abstractly is appealing to me. \\
\hline 15. & $\begin{array}{l}\text { I would prefer a task that is intellectual, difficult, and important to one that is } \\
\text { somewhat important but does not require much thought. }\end{array}$ \\
\hline 16. & $\begin{array}{l}1 \text { feel relief rather than satisfaction after completing a task that required a lot of } \\
\text { mental effort. }{ }^{\text {a }}\end{array}$ \\
\hline 17. & $\begin{array}{l}\text { It's enough for me that something gets the job done; I don't care how or why it } \\
\text { works. }^{\text {a }}\end{array}$ \\
\hline 18. & $\begin{array}{l}\text { I usually end up deliberating about issues even when they do not affect me } \\
\text { personally. }\end{array}$ \\
\hline
\end{tabular}

Note. From "'The Efficient Assessment of Need for Cognition," by J. T. Cacioppo, R. E. Petty, and C. F. Kao, 1984, Journal of Personality Assessment, 48, pp. 306-307. Copyright 1984 by Lawrence Erlbaum. Adapted by permission. The number of response options on the scales used across studies has typically ranged from five to nine, and the labels for these response options have varied from agreement--disagreement to extremely uncharacteristic-extremely characteristic. Although these variations across studies may influence the total scores obtained, they have not had dramatic effects on the relationships 
between inter-individual variations in need for cognition and other variables in a given study.

${ }^{\text {a }}$ Reverse scored. 


\section{Appendix I}

\section{Consent Form for Pilot for Study 2}

The purpose of an informed consent form is to make sure that you understand the purpose of the study and your involvement as a participant. The informed consent form must include enough information regarding the study for you to be able to make a wellinformed decision regarding whether or not you would like to partake in the study.

Present Study: To Shoot or Not to Shoot: Decision-making in Police Use of Force Trials

Research Personnel: The following people will be involved in this research project and may be contacted at any time: Holly Ellingwood (Doctoral Student, Principal Investigator, HollyEllingwood@cmail.carleton.ca, Lab 613-520-1728), or Dr. Craig Bennell (Faculty Advisor, Craig.Bennell@carleton.ca, 613-520-2600, ext. 1769).

Concerns: If you have any ethical concerns with the study, please contact Dr. Andy Adler, Chair, Carleton University Research Ethics Board-B (by phone at 613-520-2600 ext. 4085 or via email at ethics@carleton.ca).

Purpose: This is a study to evaluate how people process trial information.

Task Requirements: During this study you will be asked to complete a brief demographic questionnaire. Following this, you will read a mock trial transcript that describes a police use of force incident that involves a criminal charge. You will be asked to watch a video of a real event that was captured by the police officer's body-worn camera. You will be asked to read the entire fictitious transcript based on the real event and then answer questions, including some questionnaires. This study will take you approximately 45 minutes to complete. You will be compensated by being given $0.5 \%$ credits towards your final grade in either PSYC 1001, PSYC 1002, PSYC 2001, PSYC 2002, NEUR 2001, or NEUR 2002 for participating in this research. Participation is completely voluntary.

Potential Risk/Discomfort: You will be asked to read about a real incident where an officer was involved in a use of force event where he ended up using lethal force. Some of you will be asked to view the footage of the incident. Participants may find aspects of the study distressing. If you anticipate that reading or seeing such material and/or providing judgements about the case may cause you discomfort or anxiety, you may choose not to participate. If you do decide to participate, but at any point during the study you feel discomfort or anxiety, you can withdraw.

Anonymity/Confidentiality: The data collected in this experiment are strictly anonymous. All data are coded such that your name is not associated with the responses you provide. The online data we will collect with be through online SONA system using the software program Qualtrics. Qualtrics uses servers with multiple layers of security to protect the privacy of the data (e.g., encrypted websites and pass-word protected storage). 
Participant data will be stored and protected on a server in Toronto. Please note that the data may be disclosed via a court order or data breach, but such instances are very unlikely. In view of this we cannot absolutely guarantee the full confidentiality and anonymity of your data. With your consent to participate in this study you acknowledge this.

The database that holds your data will be kept for five years, and then destroyed. The information in this database cannot be matched to your responses. These data will be used for research purposes at Carleton University. The data could also potentially be used for teaching purposes and will likely be published in peer reviewed journals and presented at conferences. Only aggregate data will be presented and/or published.

Right to withdraw data: You may refrain from answering any questions on the questionnaire if they make you uncomfortable or you otherwise do not want to answer a question. At any point in the study, you may withdraw. Participants may withdraw by selecting the withdraw button at the bottom of each survey page. Once you complete the survey, you are no longer able to withdraw your data.

This research has been cleared by Carleton University Research Ethics Board-B (Clearance \# 108721).

By checking this box, I'm indicating that I agree to participate in this study. 


\section{Appendix J}

\section{Consent Form for Study 2}

The purpose of an informed consent form is to make sure that you understand the purpose of the study and your involvement as a participant. The informed consent form must include enough information regarding the study for you to be able to make a wellinformed decision regarding whether or not you would like to partake in the study.

Present Study: To Shoot or Not to Shoot: Decision-making in Police Use of Force Trials

Research Personnel: The following people will be involved in this research project and may be contacted at any time: Holly Ellingwood (Doctoral Student, Principal Investigator, HollyEllingwood@cmail.carleton.ca, Lab 613-520-1728), or Dr. Craig Bennell (Faculty Advisor, Craig.Bennell@carleton.ca, 613-520-2600, ext. 1769).

Concerns: If you have any ethical concerns with the study, please contact Dr. Andy Adler, Chair, Carleton University Research Ethics Board-B (by phone at 613-520-2600 ext. 4085 or via email at ethics@carleton.ca).

Purpose: This is a study to evaluate how people process trial information.

Task Requirements: During this study you will be asked to complete a brief demographic questionnaire. Following this, you will read a mock trial transcript that describes a police use of force incident that involves a criminal charge. You will be asked to watch a video of a real event that was captured by the police officer's body-worn camera. You will be asked to read the entire fictitious transcript based on the real event and then answer questions, including some questionnaires. This study will take you approximately 45 minutes to complete.

Potential Risk/Discomfort: You will be asked to read about a real incident where an officer was involved in a use of force event where he ended up using lethal force. Some of you will be asked to view the footage of the incident. Participants may find aspects of the study distressing. If you anticipate that reading or seeing such material and/or providing judgements about the case may cause you discomfort or anxiety, you may choose not to participate. If you do decide to participate, but at any point during the study you feel discomfort or anxiety, you can withdraw.

Anonymity/Confidentiality: The data collected in this experiment are strictly anonymous. All data are coded such that your name is not associated with the responses you provide. The online data we will collect with be through online SONA system using the software program Qualtrics. Qualtrics uses servers with multiple layers of security to protect the privacy of the data (e.g., encrypted websites and pass-word protected storage). Participant data will be stored and protected on a server in Toronto. Please note that the data may be disclosed via a court order or data breach, but such instances are very unlikely. In view of this we cannot absolutely guarantee the full confidentiality and 
anonymity of your data. With your consent to participate in this study you acknowledge this. You will be compensated by being given $0.5 \%$ credits towards your final grade in either PSYC 1001, PSYC 1002, PSYC 2001, or PSYC 2002 for participating in this research. Participation is completely voluntary.

The database that holds your data will be kept for five years, and then destroyed. The information in this database cannot be matched to your responses. These data will be used for research purposes at Carleton University. The data could also potentially be used for teaching purposes and will likely be published in peer reviewed journals and presented at conferences. Only aggregate data will be presented and/or published.

Right to withdraw data: You may refrain from answering any questions on the questionnaire if they make you uncomfortable or you otherwise do not want to answer a question. At any point in the study, you may withdraw. Participants may withdraw by selecting the withdraw button at the bottom of each survey page. Once you complete the survey, you are no longer able to withdraw your data.

This research has been cleared by Carleton University Research Ethics Board-B (Clearance \# 108721). 


\section{Appendix K}

\section{Study 2: Trial Transcript}

BOLD in blue colour: denotes peripheral/irrelevant discrepancies

ITALICS in orange colour: denote central/relevant discrepancies

[Note: The discrepancies will be alternated between 2 details for minimal and 6 for large discrepancies (degree of discrepancies) and alternated whether they are central or peripheral (nature of discrepancies). The 2 peripheral and 2 central details that will be included in the low degree condition will be selected based on spatial and thematic proximity to the action central to the issue at trial]

Please read the following transcript carefully and answer the questions that follow:

\section{Background Information:}

Alleged Crime: Second Degree Murder

Victim: Scott Secord

Defendant: Officer James Mitchell

\section{[Opening remarks]}

Judge: Officer James Mitchell has been charged with Section 231 of the Canadian Criminal Code: Second Degree Murder. He has pleaded not guilty to this charge. The first and most important principle of law applicable to every criminal case is the presumption of innocence. Officer James Mitchell enters the proceedings presumed to be innocent, and the presumption of innocence remains throughout the case unless the Crown, on the evidence put before you, satisfies you beyond a reasonable doubt that he is guilty.

Two rules flow from the presumption of innocence. One is that the Crown bears the burden of proving guilt. The other is that guilt must be proved beyond a reasonable doubt. These rules are inextricably linked with the presumption of innocence to ensure that no innocent person is convicted.

The burden of proof rests with the Crown and never shifts. There is no burden on Officer James Mitchell to prove that he is innocent. he does not have to prove anything.

Now what does the expression "beyond a reasonable doubt" mean? A reasonable doubt is not an imaginary or frivolous doubt. It is not based on sympathy for or prejudice against anyone involved in the proceedings. Rather, it is based on reason and common sense. It is a doubt that arises logically from the evidence or from an absence of evidence.

Even if you believe the accused is probably guilty or likely guilty, this is not sufficient. 
In those circumstances, you must give the benefit of the doubt to the accused and acquit because the Crown has failed to satisfy you of the guilt of the accused beyond a reasonable doubt. On the other hand, you must remember that it is virtually impossible to prove anything to an absolute certainty and the Crown is not required to do so. Such a standard of proof is impossibly high. In short if, based on the evidence before the court, you are sure that the accused committed the offence you should convict since this demonstrates that you are satisfied of his guilt beyond a reasonable doubt.

To make your decision, you must consider carefully, and with an open mind, all the evidence presented during the trial. You must consider the evidence and make your decision without sympathy, prejudice or fear. You must not be influenced by public opinion. Your duty as jurors is to assess the evidence impartially. At the end of the trial, you will be given specific and detailed instructions about the rules of law that apply to this case.

Crown Opening Statement: The Crown will prove that, in a confrontation with Scott Secord, Officer James Mitchell shot Mr. Secord while he was on the ground prone while the first officer on the scene, Officer David Duford, had punched and pushed Mr. Secord to the ground. Although Mr. Secord was in possession of a $9 \mathrm{~mm}$ Beretta, he was fleeing from the officers and had in no way moved for his gun when he was shot. The Defence will try to tell you a convenient and impossible story to explain away Officer Mitchell's actions, all to protect him from taking responsibility for them. However, this was not an appropriate use of force. Officer Mitchell saw an opportunity to take down Mr. Secord the easy way, when Mr. Secord had no chance to resist. He shot a man who was scared, confused, and in no way a threat to the officer. Officer Mitchell's actions were excessive, unreasonable, and unnecessary. We will prove beyond a reasonable doubt that James Mitchell is guilty of second degree murder, and we will ask you to return a verdict of guilty.

Defence's Opening Statement: Ladies and gentlemen, the Crown wants you to ignore some very compelling facts. You will hear from the defendant, an upstanding officer with many years' experience, that Scott Secord posed a lethal threat. You will hear testimony confirming that Mr. Secord had been acting suspiciously outside a gas station convenience store, the very same store he had been warned to stay away from due to previous loitering and suspicious behaviour. He was outside that store acting suspiciously with his car in the parking lot running at the time the two officers approached him. Scott Secord refused to comply with Officers Duford and Mitchell when asked to come to the officers so that he could be questioned. When Secord accidentally revealed he had a handgun in his waistband, he defied the officer's commands to put his hands up and instead he ran, moving his hand towards his gun. While Officer Duford struggled with Mr. Secord, Officer Mitchell saw the struggle on the ground for the handgun and at one point saw the handgun pointed at his fellow officer's head. He did the only thing he could do; Officer Mitchell shot Mr. Secord to protect the life of his partner and everyone at that gas station. Officer Mitchell did what he was trained to do. He protected himself, his 
fellow officer, and the innocent bystanders at the scene. Consistent with his training, Officer Mitchell continued shooting the subject until the threat was eliminated. His actions that night were reasonable and necessary to preserve his life and the lives of others. It will become obvious to you, ladies and gentlemen, that had Officer Mitchell not acted in self-defence, the officers or innocent bystanders might now be dead; this is not a stretch of the imagination, as the Crown will try to make you believe. You will find there is plenty of room for reasonable doubt regarding the Crown's unfair and inaccurate portrayal of the incident. Don't send a good officer to jail for the Crown's poor understanding of police shootings. Return a verdict of not guilty due to the fact that the officer made a reasonable and necessary use of force decision in the line of duty to protect life.

[The Crown calls their first witness, Steve Coleman, to take the stand]

\section{Crown Witness, Steve Coleman}

Crown: Could you please introduce yourself to the jury, and tell them why you are here testifying today?

Coleman: My name is Steve Coleman. I was outside having a drink and a smoke when the police came up to talk to a guy standing outside.

Crown: Please take a look at this photo? Was this the man you were speaking to?

Coleman: Yeah, that was him.

Crown: Let the records show that the witness has identified Scott Secord.

Crown: Did you know Scott Secord?

Coleman: No. We were just chatting outside of the store. I only know his name because of what happened afterwards.

Crown: What did you see happen?

Coleman: I was just chatting to this guy when a cop drove up, got out of the car and started to talk to him. Then a second cop showed up and I decided to go back into the store. From there I suddenly heard shouting like "Stop! Stop!" and stuff like that. I saw outside the window one of the cops wrestling with the guy on the ground and the next instant I heard a gunshot, a pause and then I heard a ton of gunshots while the guy was lying on the ground. The second officer had shot him several times. After that more cops came and an ambulance, but the guy was dead.

Crown: Thank you, Mr. Coleman. Those are all the questions I have for you at this time. Defence Cross-Examination:

Defence: Mr. Coleman, it must have been very traumatic for you to see that altercation between Mr. Secord and the police. 
Coleman: It was. I never saw anyone shot before, not for real.

Defence: You had gone into the store before the physical altercation occurred, correct? Coleman: Yes.

Defence: How clear was your vantage point from the store? Were there things, obstructions, in your vision, like items on shelves or signs in the window?

Coleman: Couldn't see great I guess. There were a couple of stickers on the window and some stuff on shelves but I could see that the guy was on the ground doing nothing when the cop shot him a whole bunch.

Defence: You confirmed your field of vision was obstructed. Did you see the gun Mr. Secord had in his waistband?

Coleman: No. But it all happened so fast.

Defence: Could you tell from your obstructed view inside the store whether Officer Duford and Mr. Secord had gone to the ground grappling over control of Mr. Secord's illegal firearm?

Coleman: No, it happened too fast.

Defence: Thank you Mr. Coleman. That will be all.

[The Crown calls their second witness, Eric Lalonde, to take the stand]

\section{Crown Witness, Eric Lalonde}

Crown: Could you please state your name, occupation, and where you were during the incident that took place April $12^{\text {th }}$ for the court?

Lalonde: My name is Eric Lalonde; I work at the Hop and Shop convenience store. I had called the police when I noticed Mr. Secord hanging around acting suspicious.

Crown: Can you describe what you mean by 'acting suspicious'?

Lalonde: Certainly. He never came in the store, just kept hanging out outside talking occasionally to people and he kept his car running the whole time.

Crown: Had you any other reason to be suspicious of Mr. Secord other than his behaviour at the time?

Lalonde: Yes, I have a photo of him by the cash so that anyone who works there and sees him knows to call the police. I had warned him before not to keep coming by and loitering. You're not allowed to loiter and he was doing it a lot. I saw him at least five times in the past month just hanging around and never buying anything.

Crown: What about the night in question, Mr. Lalonde, what did you see then?

Lalonde: I saw him, Secord, talking to a couple of customers who were standing outside when an officer came up to speak to him. Not two seconds later a second officer was there hanging back a bit. They kept asking him to come over and talk to them and he kept 
not going near them. Then he did something with his clothes, pulling up his shirt it seemed, and suddenly the police were yelling, he ran and they chased and caught up to him in like 2 seconds. One cop was wrestling with him on the ground and the other was standing off to the side with his gun out. The next thing I know there were several gun shots with the guy on the ground.

Crown: During the time before the gun shots, before he ran, did you witness Mr. Secord acting aggressively in any way?

Lalonde: No, he never swore or said anything bad. He was asking why they wanted to speak to him.

Crown: You mentioned several shots. Was Mr. Secord on the ground before or after you heard the first shot?

Lalonde: He was on the ground before the first shot and the officer that had been wrestling with him had moved away from him. Then I heard several shots.

Crown: How many shots did you hear fired?

Lalonde: It was a lot. Way more than 10, maybe 20.

Crown: Did you see Mr. Secord holding a gun at the time he was shot?

Lalonde: No, I didn't see any gun.

Crown: Thank you, Mr. Lalonde. I have no further questions for you at this time.

\section{Defence Cross-examination}

Defence: You mentioned that Mr. Secord did not act aggressively towards the police. But did he comply with the officer's request to come over and talk to the officers?

Lalonde: No, he didn't. In fact, he started to run when the first cop approached him.

Defence: Thank you, Mr. Lalonde.

[The Defence calls their first witness, James Mitchell, to take the stand]

\section{Defence Witness, Officer James Mitchell}

Defence: Can you please introduce yourself to the court?

Mitchell: My name is James Mitchell. I am a Sergeant with the Samton Police Service. I have been an officer for 5 years.

Defence: I'd like you to think back to the evening of April $12^{\text {th }}, 2014$. Would you please tell the court what happened?

Mitchell: I had received a call about a possible armed suspect hanging outside of the 
Hop and Shop on McCarthy Street. I was given his description and told he had been loitering and acting suspiciously with a car running in the parking lot. He had been identified as Mr. Scott Secord. I knew we had to proceed with caution as he was known to us from a previous encounter that had turned violent and he had been armed. I was told to locate Mr. Secord, back up the other officer arriving at the scene, search him for a weapon, and bring him in for questioning.

Defence: Why did you think Mr. Secord was armed?

Mitchell: I didn't know for sure, but due to the content of the dispatch message, I believe it was a concern that he might be considering robbing the store and therefore might be armed. We're trained as officers to be prepared for the worst. I saw him in the parking lot, stopped my cruiser, got out of it and approached him.

Defence: What happened next? If you could please read based on your incident report which you had to file after the incident?

Mitchell: Based on what I had written in my report, Mr. Secord had been standing outside the store in a parking lot that had 3 cars. He was standing by a trashcan/bicycle rack talking to two men/one person by a black/silver car while Officer Duford, who was the first officer on the scene, told Mr. Secord to come talk to us, where we were standing. The bystander by the door said something unclear, about guessing someone had called the cops. Secord kept asking what he had done, insisting he was doing nothing. The bystander by the door went inside the store saying " ${ }^{6}$ 'm not getting in the middle of this". Secord seemed agitated, on edge. He was asked again by Officer Duford to come speak to us and we told him we needed to search him. He did not comply. I then saw him put his hand in his pocket and I warned him to keep his hands out of his pocket. It was then that he insisted again he was up to nothing and he pulled up his black hoodie to show he was not a threat. That's when I saw the handgun in his waistband of his jeans and what looked like an extra ammo clip for his gun. I told him he had to put his hands up, to stop. We both warned him to not go near the gun. Then Officer Duford approached him and Secord took a step towards him. I saw Secord's right hand form a fist while his left hand moved towards his gun and he turned and ran. I drew my gun, ran to offer back up to my fellow officer yelling at Mr. Secord to “stop, drop the gun, or I'll shoot." I ran to cover my fellow officer. I heard car tires squeal in the background. Officer Duford and Mr. Secord fell to the ground during the altercation and I saw them wrestling for control of Secord's gun. At one point I saw the barrel of the gun pointed towards Officer Duford's face. I saw a clear shot, fired once, and when Officer Duford was clear, continued to fire until the suspect was no longer a threat.

Defence: What was your thought process at that time?

Mitchell: That Mr. Secord could shoot Officer Duford, me or someone in the parking lot or along the road. I had to shoot. I couldn't take the risk of letting him get off a shot and possibly kill someone.

Defence: How many times did you fire?

Mitchell: Nine times/Fifteen times. 
Defence: What happened then?

Mitchell: He stopped moving. I approached him, weapon still drawn, telling him not to move, as did my fellow officer. We handcuffed him, searched him for any other weapons and called in paramedics and more officers to come in to attend the downed suspect and secure the scene.

Defence: What happened next?

Mitchell: I maintained a secure scene until the other officers arrived. The paramedics arrived at the same time. I relinquished the scene to the other officers and gave them my statement.

Defence: Just so we are all clear, was Mr. Secord posing a threat at the time you decided to fire your weapon?

Mitchell: Yes. When I made the decision to fire, the suspect had his gun facing my partner, Officer Duford, and was presenting a full-front threat.

Defence: How do you account for the several shots fired after Officer Duford had disarmed Mr. Secord?

Mitchell: Between the time that Mr. Secord had the gun and the time I pulled the trigger of my gun, he could have shot his gun. It only takes a split-second for everything to change - for him to have aimed that gun at Officer Duford, me or someone in the parking lot and take a shot. He could have had another weapon on him. We had no way of knowing so I continued to fire my weapon. Consistent with my training, I made the decision to fire my weapon and continue to fire my weapon because if he fired his first or had another weapon on him, he could have seriously injured or killed my partner, me or another person.

Defence: After the incident, what did you learn in the course of the investigation that followed about Scott Secord?

Mitchell: The investigation team found 18 illegal firearms in his apartment.

Defence: Thank you officer Mitchell. Those are all the questions I have at this time.

Defence: I would like at this time to enter into evidence Exhibit A, the video footage of the incident from the body-worn video camera Office Mitchell wore that day which clearly backs up Officer Mitchell's testimony that Mr. Secord was not compliant, had a weapon and entered in a deadly match for control of said weapon, resulting in shots fired to stop Secord, protect his fellow officer and everyone at that store and gas station that night.

\section{[VIDEO CLIP PLAYS]}

\section{Crown Cross-examination}

Crown: Officer Mitchell, can you confirm that what we just saw was the video footage from your police issued body-worn video camera? 
Mitchell: Yes.

Crown: Your account of the incident seems awfully self-serving.

Mitchell: I don't see any of what's happened as self-serving. I had to fire my weapon to protect my partner and myself. My account of the incident is exactly how I remember it.

Crown: So, even though Mr. Secord had turned to run and had never aimed at you directly, you still maintain that he could have shot you or someone else?

Mitchell: I don't know. I just know that I saw a threat, and I feared for my life. When I fired the shot, Mr. Secord was pointing the gun at Officer Duford.

Crown: Maybe you just want to remember it that way?

Mitchell: That is what happened.

Crown: And what about the amount of times you shot him? Was that not excessive?

Mitchell: No, it was not. I followed my training. When there is a lethal threat then it is reasonable in that situation to use deadly force to stop the threat.

Crown: You say he did not aim directly at you but you shot him fifteen times. Fifteen times, Officer Mitchell. Could you not have used your training to wound and disarm the young man?

Mitchell: We are trained to shoot at a person's core, their centre of mass. We are more likely to hit the target and there is a smaller chance of stray bullets that might harm others. It is important to stop the threat.

Crown: Was yours the only gun that fired?

Mitchell: No, Officer Duford had taken the gun from Secord and shot him twice with it.

Crown: And those two shots were after you had shot Secord 15 times?

Mitchell: Yes, right at the end.

Crown: Were you aware that the Coroner's report confirmed that it was your shots that killed Mr. Secord, an unarmed man that was not a threat to anyone?

Mitchell: I was informed about the report. We didn't know he didn't have another gun. I had to deal with the threat he presented.

Crown: What threat did Mr. Secord continue to pose when your partner had successfully disarmed him? You stated that you continued to shoot as he might have had another weapon on him. Did he have a weapon in his hand after the other officer had taken Mr. Secord's gun?

Mitchell: No, he did not, but he could have pulled one at any moment.

Crown: But he didn't pull a second weapon, did he, Officer Mitchell? Mitchell: No, he did not.

Crown: In fact, your search, after having shot Mr. Secord 15 times, revealed that he had 
no other weapons on him, only the one handgun which Officer Duford had taken possession of during the altercation, is that not correct?

Mitchell: That is correct.

Crown: But you say this man was a threat even though his gun was taken?

Mitchell: He had a gun and posed a serious, lethal threat. Officer Duford had taken possession of the gun only after I had shot my gun.

Crown: But you kept shooting even after he was disarmed?

Mitchell: It happened very quickly and as I stated, there was no way for us to know that he didn't have another weapon on him so he remained a threat.

Crown: That supposed threat was a 35-year-old man with a life and a future that you took away from him, Officer Mitchell. Tell me, did you give a full statement at the time immediately following the incident?

Mitchell: No. I gave a partial statement and then later at the station gave a full one. A few hours had passed between the initial and the full statement.

Crown: You needed time to think up a good story?

Mitchell: No, I was very stressed after the event. I wasn't in a place to be making a formal statement. I needed time to recover first.

Crown: Again, very convenient.

Crown: I have no more questions at this time.

[Rebuttal - Defence]

Defence: Officer Mitchell, you mentioned that Scott Secord presented a threat to your fellow officer. Did he present a threat to the public?

Mitchell: Yes, we were in the parking lot of a convenience store by a gas station. Anyone could be walking by or driving by at any moment and anyone in the store.

Defence: Thank you Officer Mitchell. That will be all.

[The Defence calls their second witness, David Duford, to take the stand]

\section{Defence Witness, Officer David Duford}

Defence: Could you please introduce yourself to the court?

Duford: My name is David Duford.

Defence: Could you please tell the court your profession and how long you have served in that profession?

Duford: I am a sergeant with Samton Police Service and have been an officer for 8 years. 
Defence: Could you tell us what happened that evening?

Duford: I received a call from dispatch about a suspicious person at the Hop and Shop. I arrived there at 10:04 pm. My backup, Officer Mitchell, arrived a few moments later. I asked the man fitting the description provided to us by dispatch to come over and speak to us, he kept not complying. When he put a hand in his pocket, Officer Mitchell told him to keep his hands out of his pocket, but then he flipped up his hoodie to show he had nothing to hide, which is when we both saw the handgun in his waistband. Officer Mitchell told him not to touch the gun. I saw the suspect edging to run and moved to intercept. He turned and ran and I tackled him. Punches were exchanged, we fell to the ground and he had his gun out. I grabbed his hands and the gun to stop him. At one point the gun was turned towards me. I was able to wrest the gun away from him and started to stand back when the first shot rang out and as I backed away from the suspect, Officer Mitchell continued to shoot and I shot the gun in my hand, Mr. Secord's gun, shooting twice at him, before discarding it and pulling out my own handgun.

Defence: You shot Mr. Secord with his own gun?

Duford: Yes, I did.

Defence: You had disarmed him, so why did you shoot?

Duford: We are trained for worst case scenarios. He had not complied to a search, he had pointed his gun at me to shoot, and we had no way of knowing if he had another weapon concealed on him. We had to act in the best interest of public safety.

Defence: Thank you Officer Duford. Those are all the questions I have for now.

\section{Crown Cross-examination}

Crown: You say Mr. Secord could have had another weapon, but the reality is that he had no such weapon on him, did he?

Duford: After the search, we found out that he had no other weapon on his person.

Crown: In fact, he had no weapon pointed at you, Officer Mitchell or anyone else at the time he was shot by Officer Mitchell, correct?

Duford: These situations can go wrong very quickly in terms of loss of life so we had to act on the worst case scenario that he may have had another weapon. He had already threatened my life by pointing his weapon at me. If was Officer Mitchell's quick actions that helped save my life.

Crown: But we have no proof of that, now do we Officer Duford? You have no proof except the accused's testimony that he saw the gun pointed at you during the altercation you yourself had instigated. Then Mitchell followed your lead and shot a man who had not acted as a threat in any way to you or anyone else that night.

Duford: I don't know what you're talking about. I responded to the threat Mr. Secord represented and Officer Mitchell did the same. 
Crown: That will be all, Officer Duford.

\title{
Manipulation
}

\section{(Half of the participants will be exposed to an expert and half will not)}

\author{
[The Defence calls their third witness, Carl Hudson, to take the stand]
}

\section{Defence Witness, Dr. Carl Hudson}

Defence: Could you please state your name and credentials for the jury?

Hudson: Certainly. My name is Dr. Carl Hudson. I have a Ph.D. in Psychology, specializing in Police Psychology. I have been studying lethal force encounters, action/reaction parameters, perception, and memory for over 25 years. My work has been published in several peer-reviewed journals.

Defence: Dr. Hudson, has your research dealt specifically with officer involved shootings?

\section{Hudson: Yes.}

Defence: What is the overall goal of this research?

Hudson: To ensure the availability of scientific principles to better and more accurately understand officer involved shootings. It is very important not to jump to conclusions without this kind of information. My research has uncovered several types of incidents that seem straightforward at first blush, but that scientific experiments have revealed to be much more complex.

Defence: So, to be clear. You're not saying that every incident has an innocent explanation behind it.

Hudson: That's right; I am not saying that every officer related shooting is excusable. I'm only saying that we need to consider the full range of facts, and that my research helps to uncover that.

Defence: Could you briefly summarize the findings of your research?

Hudson: Yes. My research has shown that for an average officer, split-second decisionmaking in use of force incidents causes extreme stress that can affect an officer's ability to perform effectively or recall events accurately.

Defence: The officer in this case shot 15 times before the suspect had a chance to shoot. Is that a normal or average reaction by an officer?

Hudson: It is my understanding that officers are trained to shoot a certain amount of times during their formal training. This training carries over into the field. In other words, when an officer is confronted with a life or death scenario - such as facing a suspect with a gun - the officer might regress to being on automatic pilot. This is a very real condition officers and soldiers suffer from in dangerous use of force encounters, where they revert to training no matter if it is appropriate or not to the circumstances. 
Defence: You study the impact of dangerous use of force encounters faced by police. What does your research suggest happens to officers when faced with potentially lethal situations in the line of duty?

Hudson: Based on my research, an officer's physiology is put under immense stress in a use of force encounter. This stress can have severe ramifications on the prefrontal cortex, which is our thinking/reasoning area of the brain. In short, when we are faced with a stressful and life threatening situation, our brain can be, in layman's terms, short circuited by our physiological reaction, such as adrenal and cortisol levels rising, elevated heart rate, all of which can circumvent our reasoning areas of the brain and cause distortions. These distortions can include audio hallucinations such as hearing sounds that did not occur and tunnel vision, which results in the officer only seeing the immediate threat and not being able to see what else is going on around them. Also memory lapses such as not remembering some things, misremembering others, or recalling things out of sequence are not uncommon for police officers when they have been involved in a potentially lethal encounter. These are only a few of distortions officers might experience in dangerous use of force scenarios and they have been extensively documented in research involving police officers and soldiers.

Defence: So errors in an officer's testimony are not uncommon?

Hudson: In all my years of research with police officers, I have yet to see a single report that does not contain some memory error, however small. It is important to remember that police officers are human beings, not machines. No one's memory is perfect, but more importantly, under extreme stress, the brain can be greatly impacted leading to such errors. In such situations, there is no time to second guess or take time to commit every detail to memory.

Defence: Do other researchers' findings support your conclusions?

Hudson: Yes. My research is consistent with what has previously been demonstrated regarding officer memory in use of force incidents. Their conclusions were the same: once an officer perceives a threat, even under training circumstances, adrenaline, elevated heart rate, and brain reaction interferes with higher thinking areas of the brain, negatively impacting memory and increasing the chance of perceptual distortions.

Defence: Thank you, Dr. Hudson.

\section{Crown Cross-examination:}

Crown: Your research comes in awfully handy for police officers who have broken the law, wouldn't you say?

Hudson: My research has been conducted in an unbiased way, and has been through a rigorous peer review process. The science speaks for itself.

Crown: The science? Don't you start out with something you want to prove, and then just do whatever is needed to show that your prediction is right? 
Hudson: Well I wouldn't say we ever really 'prove' anything, nor are we trying to. All we're doing is conducting scientific experiments that are based on probabilities. They are a best guess as to what's going on in the real world, but in a controlled setting.

Crown: So each researcher 'controls' their own experiment, then?

Hudson: We employ both experimental and statistical controls. Again, we try to do this without any biases. We are simply testing a set of hypotheses that are informed by other research in the field.

Crown: So, unlike the hard sciences, your experiment is quite subjective?

Hudson: Like any other science, we test hypotheses based on sound theory.

Crown: Is there a lot of consensus about your findings?

Hudson: Yes, other researchers have reported findings that are similar to what I've found in my research.

Crown: Have your findings ever been contested?

Hudson: As I said, my work has been through a strict peer review process, which means that other researchers have evaluated it in terms of the experimental design, rationale, and its contribution to the field.

Crown: Have you testified in this type of case before?

Hudson: Yes. I have given testimony in other cases involving controversial shootings.

Crown: But, have you ever testified for the Crown?

Hudson: No, I have not. I primarily work with police officers who are accused of excessive use of force.

Crown: Some might even think of you as a professional witness. Didn't you say, earlier, that your research is unbiased?

Hudson: Yes, my research is unbiased. I am not a professional witness. I would never suggest that all officers are innocent of wrongdoing in fatal shootings. Just as there are some bad officers, there are some bad shootings. But part of our goal is to help investigators and prosecutors understand that what appears controversial often is not, when judged in light of scientific principles.

Crown: So you wouldn't say that your opinion is for sale?

Hudson: No. All I want to do is allow for a better understanding of use of force situations. Some shooting situations are simply unavoidable. Also, in many situations, cover just isn't available and deadly force is the only option.

Crown: One last question Dr. Hudson. You mentioned all types of brain interference and memory lapses that an officer can have. However, in the face of an officer's testimony being inaccurate, is it not also a possibility that the officer is lying? Covering their tracks? In other words, is memory lapse due to the brain 'short circuiting' as you mentioned, the only possible explanation for an officer having inconsistent testimony compared to hard 
evidence?

Hudson: I can only speak to my area of research, which is police stress in use of force incidents. In these types of incidents, the stress can impact cognitive and physiological functions, which can influence memory.

Crown: I have no further questions. 


\section{[Note: bold denotes sentence that will only be in expert condition/manipulation.]}

\section{[Closing Remarks]}

Crown Closing Statement: The rule of law prohibits any officer from shooting a fleeing suspect unnecessarily. The law is clear on this point, ladies and gentlemen. You have heard testimony from the two witnesses that Scott Secord did not pose a threat and was shot excessively when he could have been wounded instead and alive today. Did he have a weapon in his possession that was restricted? Yes. Did he use it? No. The Defence wants you to believe that the victim posed a terrible threat to a fellow officer who has no real evidence to back up their claim that he threatened anyone. Scott Secord has been an upstanding citizen with a job, an education, trying to turn his life around. He had a weapon that he never used, never touched when the officers attacked him. He did not deserve to be shot, let alone shot fifteen times. He did not deserve to die there in that parking lot without having acted in a hostile way to anyone, let alone posing a threat in any way that would have called for such an excessive lethal action on the part of Officer Mitchell. There is just no way. On top of that, Officer Mitchell lied during his testimony. You saw the video evidence from his own police issued video camera, which contradicted parts of his testimony. He made statements about what happened and those were lies. The simplest explanation here is that Officer Mitchell shot down a person of interest unreasonably and unnecessarily. You heard testimony from two witnesses that can attest to that. And then Officer Mitchell lied about aspects of it. Show this officer that it is not okay to abuse his power like that, and that officers are not above the law. Do not let another officer get away with unnecessary force. Return a verdict of guilty.

Defence's Closing Statement: Despite what the Crown would have you believe, this is not a blanket excuse for police shooting innocent people who are fleeing. The fact is that officers put their life on the line for us every day. They are trained to react to things differently than you or I. In a life-threatening situation, they sometimes have no choice but to act with lethal force. Officer Mitchell's account of the event has been consistent. He has told the court in detail about the incident, and there is no reason to dispute what he has said. He had to take down a dangerous suspect who did not comply with his and his fellow officer's instructions. You heard testimony that he warned Mr. Secord to not touch the gun. Instead of listening, Mr. Secord attempted to flee with his hand moving toward the gun. This ended up in a dangerous close up use of force situation with Officer Duford wrestling Mr. Secord to gain control of the gun to save his own life, let alone that of everyone there. Mr. Secord pointed his gun at Officer Duford, and on seeing that, Officer Mitchell took actions that were necessary and within reason. Any discrepancies between the officer and the video footage are simply a matter of imperfect memory under severe life or death stress in a lethal shooting incident, which you heard is possible from an expert in the field of police psychology. Officer Mitchell followed his training and used the amount of force that was necessary to protect himself and others and stop Scott Secord from using his gun to shoot Officer Duford or anyone else. Officer Mitchell did his job and saved lives because of his actions that day; do not punish him for that. Return a verdict of not guilty. 
Crown Rebuttal: Nobody is saying Officer Mitchell went into work that day planning to shoot someone. However, he violated his own rules. This is just another example of an officer using excessive force when the situation did not warrant it. Yes, the police put their lives on the line, and have great responsibility. Therefore, we need to hold their behaviour to a very high standard. You can hold Officer Mitchell accountable for his actions, by returning a verdict of guilty.

\section{[Reading of the law]}

Judge: Members of the jury, you have heard the testimony from a number of witnesses. It is now my responsibility to provide you with the law.

\section{Presumption of Innocence:}

[1] Every person charged with an offence is presumed to be innocent, unless and until the Crown has proved his/her guilt beyond a reasonable doubt.

[2] The indictment tells you and James Mitchell what offence the Crown alleges against James Mitchell. The charge is not evidence. It is not proof of guilt.

[3] The presumption of innocence lasts throughout the trial. This presumption only ceases to apply if, at the end of the case and on the whole of the evidence, the Crown has proved beyond a reasonable doubt that James Mitchell is guilty of the crime charged.

\section{Burden of Proof:}

[1] The person charged does not have to present evidence or prove anything in this case, in particular, that he is innocent of the offence charged.

[2] From start to finish, it is the Crown who must prove the guilt of James Mitchell beyond a reasonable doubt. You must find James Mitchell not guilty of the offence unless the Crown proves beyond a reasonable doubt that he is guilty of it.

Judge: I will remind you that Officer Mitchell is charged with second degree murder.

\section{Culpable homicide is murder}

(a) where the person who causes the death of a human being

(i) means to cause his death, or

(ii) means to cause him bodily harm that he knows is likely to cause his death, and is reckless whether death ensues or not;

(b) where a person, meaning to cause death to a human being or meaning to cause him bodily harm that he knows is likely to cause his death, and being reckless whether death ensues or not, by accident or mistake causes death to another human being, notwithstanding that he does not mean to cause death or bodily harm to that human being; or

(c) where a person, for an unlawful object, does anything that he knows or ought to know is likely to cause death, and thereby causes death to a human being, 
notwithstanding that he desires to effect his object without causing death or bodily harm to any human being.

231. (1) Murder is first degree murder or second degree murder.

(2) Murder is first degree murder when it is planned and deliberate.

(7) All murder that is not first degree murder is second degree murder.

\section{Punishment:}

235. (1) Everyone who commits first degree murder or second degree murder is guilty of an indictable offence and shall be sentenced to imprisonment for life.

Judge: What you must decide is if Officer Mitchell is not guilty of second degree murder due to using reasonable use of force. Reasonable use of force under the law is described as the following:

25. (1) Everyone who is required or authorized by law to do anything in the administration or enforcement of the law

- (a) as a private person,

- (b) as a peace officer or public officer,

- (c) in aid of a peace officer or public officer, or

- (d) by virtue of his office,

is, if he acts on reasonable grounds, justified in doing what he is required or authorized to do and in using as much force as is necessary for that purpose.

(3) Subject to subsections (4) and (5), a person is not justified for the purposes of subsection (1) in using force that is intended or is likely to cause death or grievous bodily harm unless the person believes on reasonable grounds that it is necessary for the selfpreservation of the person or the preservation of any one under that person's protection from death or grievous bodily harm.

(4) A peace officer, and every person lawfully assisting the peace officer, is justified in using force that is intended or is likely to cause death or grievous bodily harm to a person to be arrested, if

- (a) the peace officer is proceeding lawfully to arrest, with or without warrant, the person to be arrested;

- (b) the offence for which the person is to be arrested is one for which that person may be arrested without warrant;

- (c) the person to be arrested takes flight to avoid arrest;

- (d) the peace officer or other person using the force believes on reasonable grounds that the force is necessary for the purpose of protecting the peace officer, the person lawfully assisting the peace officer or any other person from imminent or future death or grievous bodily harm; and

- (e) the flight cannot be prevented by reasonable means in a less violent manner. 


\section{Appendix L}

\section{Manipulation Check Questions for Study 2}

1. Where did the incident take place?

a) at a recreational centre parking lot

b) at a church parking lot

c) at a convenience store parking lot

d) at a mall parking lot

2. What did the suspect have on him that concerned the police?
a) a comb
b) a gun
c) a knife
d) a cell phone

3. Why were the police called?

a) a woman said she was threatened and the guy was waiting for her outside

b) a girlfriend called because her boyfriend threatened her in public

c) a man was loitering outside of the convenience store

d) a guy started a fight

4. In the transcript, did the expert witness say:

a) There was no expert in my transcript

b) That police do not receive enough training

c) That police can suffer perceptual distortions, like memory loss, in use of force encounters

d) That police need to report their use of force behaviour immediately following an incident

5. Were there differences between the defendant's testimony and what his body-worn camera footage showed?

a) Yes

b) No, there were no differences between the defendant's testimony and his body-worn camera footage 


\section{Appendix M}

\section{Jury Questionnaire for Study 2}

INSTRUCTIONS: Please respond to the following items with regards to the seconddegree murder charge against the defendant.

1. How do you find the defendant, James Mitchell?

GUILTY

\section{NOT GUILTY}

2. Please provide a reason for your verdict:

3. To what degree do you feel Officer James Mitchell is guilty? Chose a number between 1 to 10 where 1 equals not guilty at all and 10 completely guilty.

4. Second degree murder is punishable for a 25-year custodial sentence. However, the accused may be eligible for parole between 10 and 25 years of that sentence. If it were up to you, when would you consider the defendant to be eligible for parole, at the minimum of 10 years or maximum punishment of no parole up to 25 years? Please choose which range, if any, you think that defendant should serve in custody before being eligible for parole. What (if any) punishment do you believe the defendant deserves?

$\begin{array}{lllllllllll}\longleftrightarrow 0 & 1 & 2 & 3 & 4 & 5 & 6 & 7 & 8 & 9 & 10\end{array}$

No punishment

Maximum punishment

5. How credible is the defendant, Officer Mitchell?

\begin{tabular}{lllllll}
\hline 1 & 2 & 3 & 4 & 5 & 6 & 7
\end{tabular}

Not at all credible somewhat credible extremely credible

6. How persuasive is the defendant, Officer Mitchell's, testimony?

$\begin{array}{ccrcccc}41 & 2 & 3 & 4 & 5 & 6 & 7 \\ \text { Not at all persuasive } & & \text { somewhat persuasive } & & \text { extremely persuasive }\end{array}$

7. How credible is the Crown attorney?

$\begin{array}{llllllll}\longrightarrow 1 & 2 & 3 & 4 & 5 & 6 & 7\end{array}$


Not at all credible

somewhat credible

extremely credible

8. How persuasive is the Crown attorney?

\begin{tabular}{lllllll}
\hline 1 & 2 & 3 & 4 & 5 & 6 & 7
\end{tabular}

Not at all persuasive somewhat persuasive extremely persuasive

9. How credible is the Defence attorney?

\begin{tabular}{lllllll}
\hline 1 & 2 & 3 & 4 & 5 & 6 & 7
\end{tabular}

Not at all credible somewhat credible

extremely credible

10. How persuasive is the Defence attorney?

\begin{tabular}{lllllll}
\hline 1 & 2 & 3 & 4 & 5 & 6 & 7
\end{tabular}

Not at all persuasive somewhat persuasive extremely persuasive

11. How credible is the witness, Steve Coleman, the customer at the convenience store?

\begin{tabular}{lllllll}
\hline 1 & 2 & 3 & 4 & 5 & 6
\end{tabular}

Not at all credible somewhat credible extremely credible

12. How persuasive is the witness, Steve Coleman, the customer at the convenience store?

\begin{tabular}{lllllll}
\hline 1 & 2 & 3 & 4 & 5 & 6 & 7
\end{tabular}

Not at all persuasive somewhat persuasive extremely persuasive

13. How credible is the witness, Eric Lalonde, the man working in the store?

\begin{tabular}{lllllll}
\hline 1 & 2 & 3 & 4 & 5 & 6 & 7
\end{tabular}

Not at all credible somewhat credible extremely credible

14. How persuasive is the witness, Eric Lalonde, the man working in the store?

$\begin{array}{lrrrrrr}4 & 2 & 3 & 4 & 5 & 6 & 7 \\ & \text { Not at all persuasive } & \text { somewhat persuasive } & \text { extremely persuasive }\end{array}$


15. How credible is the witness, Officer Duford, the other police officer at the scene?

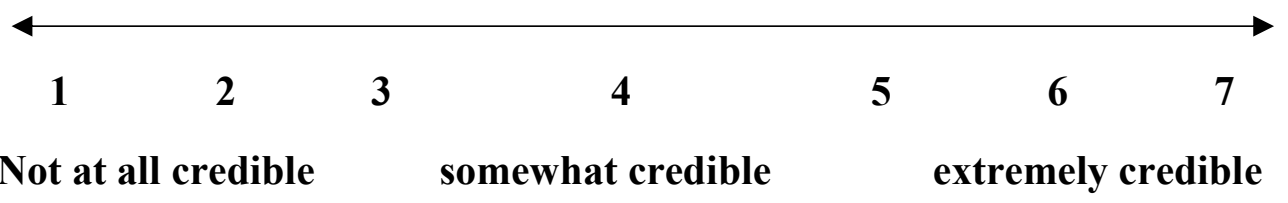

16. How persuasive is the witness, Officer Duford, the other police officer at the scene?

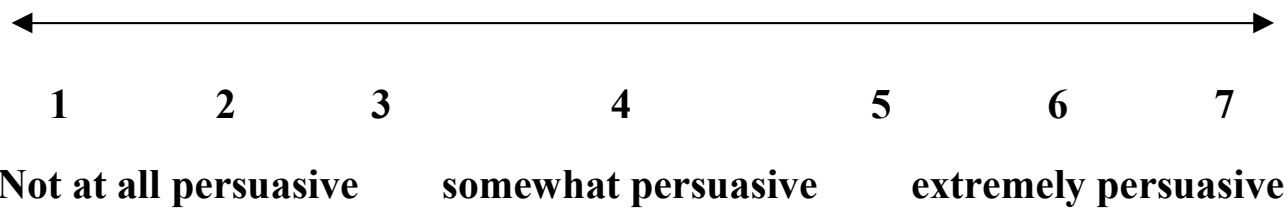

Note: Only those who receive the manipulation of expert testimony in Study 2 will be asked to provide ratings on the following two questions (17 and 18):

17. How credible is Dr. Carl Hudson, the expert witness, who provided information regarding processing and memory issues wen having to act in a dangerous situation?

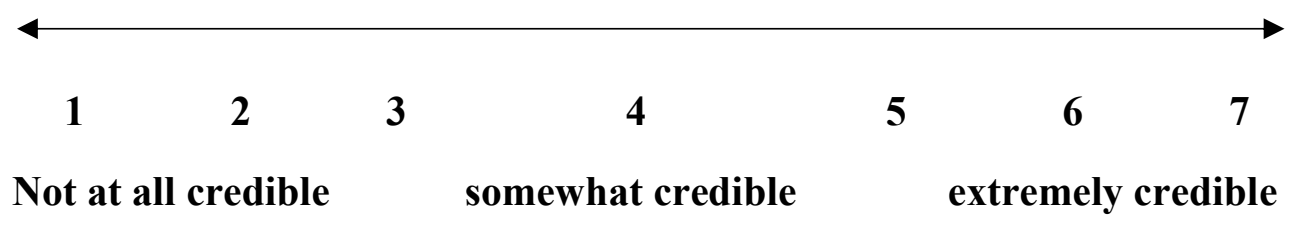

18. How persuasive is Dr. Carl Hudson, the expert witness, who provided information regarding processing and memory issues wen having to act in a dangerous situation?

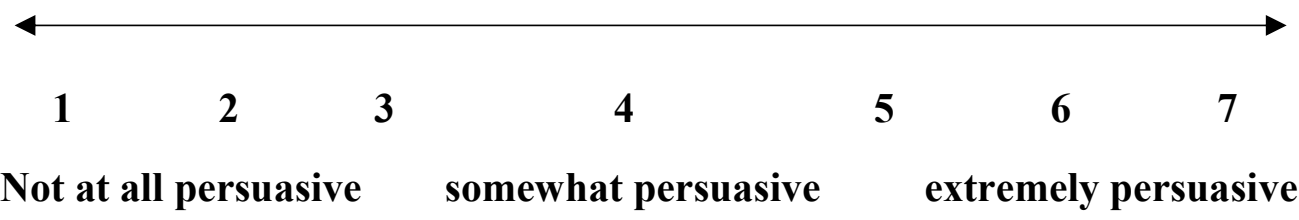


19. How important was the body-worn video evidence to your verdict decision?

\begin{tabular}{ccccccc}
\hline & & & & & \\
1 & 2 & 3 & 4 & 5 & 7
\end{tabular}




\section{Appendix N}

\section{Debriefing Form}

\section{Police Use of Force and Jury Decision-making}

Thank you for your participation in the present study: To Shoot or not to Shoot:

Decision-making in Police Use of Force Trials. To reiterate, the purpose of this study was to engage community members in a examination of their decision-making when an officer is accused in a criminal trial case regarding a use of force incident.

Background on the video: Although the trial is fictitious, the video was from a real police use of force incident. The incident occurred in Roy, Utah. The suspect died of the gun shot wounds and the officer was not charged in the incident. The internal review cleared the shooting as justified. If watching the video made you feel distressed or uncomfortable, and you would like to speak to someone about your thoughts, please feel free to contact Carleton University Health and Counseling Services at 613-520-6674 (http://www.carleton.ca/health/) or the Distress Centre of Ottawa and Region at 613-2383311 (http://www.dcottawa.on.ca).

Research personnel: The following people are involved in this research project and may be contacted at any time: Holly Ellingwood (Doctoral Student, Principal Investigator, HollyEllingwood@cmail.carleton.ca, Lab 613-520-1728), or Dr. Craig Bennell (Faculty Advisor, Craig.Bennell@carleton.ca, 613-520-2600, ext. 1769).

Concerns: If you have any ethical concerns with the study, please contact Dr. Andy Adler, Chair, Carleton University Research Ethics Board-B (by phone at 613-520-2600 ext. 4085 or via email at ethics@carleton.ca).

Thank you for your time.

This research has been cleared by Carleton University Research Ethics Board-B (Clearance \# 108721). 


\section{Appendix O}

\section{Opinions about BWC Use and Ethnicity}

Table 13

Opinions about BWC Use by Ethnicity

\begin{tabular}{|c|c|c|c|c|}
\hline \multirow[b]{2}{*}{ Question } & \multicolumn{2}{|c|}{ Mean (SD) } & \multirow{2}{*}{$\begin{array}{l}\text { Hedges' } \\
\mathrm{g}\end{array}$} & \multirow[b]{2}{*}{$95 \%$ CI } \\
\hline & White & $\begin{array}{l}\text { Non- } \\
\text { White }\end{array}$ & & \\
\hline $\begin{array}{l}\text { How concerned are you with being video- } \\
\text { recorded (including surreptitiously) by other } \\
\text { people?* }\end{array}$ & $2.90(1.85)$ & $3.32(2.16)$ & -0.22 & $-.57, .13$ \\
\hline $\begin{array}{l}\text { How concerned are you with police officers } \\
\text { wearing a device that would video-record } \\
\text { their conduct while performing their duties } \\
\text { in public?* }\end{array}$ & $2.63(1.93)$ & $3.05(1.92)$ & -0.22 & $-.57, .13$ \\
\hline $\begin{array}{l}\text { Police officers wearing a body-worn camera } \\
\text { would improve officer behaviour while on } \\
\text { duty }\end{array}$ & $2.59(1.40)$ & $2.55(1.41)$ & 0.03 & $-.32, .38$ \\
\hline $\begin{array}{l}\text { Police officers wearing a body-worn camera } \\
\text { would improve citizen behaviour while on } \\
\text { duty }\end{array}$ & $3.10(1.47)$ & $2.66(1.48)$ & 0.3 & $-.05, .65$ \\
\hline BWC recordings should be kept for... & $4.79(2.13)$ & $4.63(2.25)$ & 0.07 & $-.27, .42$ \\
\hline $\begin{array}{l}\text { If police wore body-worn cameras, officers } \\
\text { would be safer }\end{array}$ & $3.14(1.46)$ & $3.24(1.42)$ & -0.07 & $-.42, .28$ \\
\hline $\begin{array}{l}\text { Police should alert people before they record } \\
\text { them with a body-worn camera }\end{array}$ & $3.44(1.80)$ & $2.84(1.59)$ & 0.34 & $-.01, .69$ \\
\hline $\begin{array}{l}\text { Body-worn cameras should be recording at } \\
\text { all times when police are on duty }\end{array}$ & $2.83(1.56)$ & $2.66(1.48)$ & 0.11 & $-.24, .46$ \\
\hline $\begin{array}{l}\text { Body-worn cameras should only record } \\
\text { when police are approaching a possible } \\
\text { incident/potential suspect }\end{array}$ & $3.88(1.95)$ & $3.53(1.81)$ & 0.18 & $-.17, .53$ \\
\hline $\begin{array}{l}\text { Officers should be able to control when a } \\
\text { body-worn camera records }\end{array}$ & $4.82(1.90)$ & $4.11(1.74)$ & $.38 *$ & $.03, .73$ \\
\hline $\begin{array}{l}\text { The use of body-worn cameras by police } \\
\text { will make police more accountable for any } \\
\text { misconduct }\end{array}$ & $2.26(1.25)$ & $2.42(1.43)$ & -0.13 & $-.48, .22$ \\
\hline
\end{tabular}


Opinions about BWC Use by Ethnicity (continued)

\begin{tabular}{|c|c|c|c|c|}
\hline \multirow[b]{2}{*}{ Question } & \multicolumn{2}{|c|}{ Mean (SD) } & \multirow[b]{2}{*}{$\begin{array}{l}\text { Hedges' } \\
\quad \mathrm{g}\end{array}$} & \multirow[b]{2}{*}{$95 \%$ CI } \\
\hline & White & $\begin{array}{l}\text { Non- } \\
\text { White }\end{array}$ & & \\
\hline $\begin{array}{l}\text { The use of body-worn cameras by police } \\
\text { will reduce false misconduct reports against } \\
\text { the police by the public }\end{array}$ & $2.35(1.29)$ & $2.42(1.41)$ & -0.05 & $-.40, .30$ \\
\hline $\begin{array}{l}\text { The use of body-worn cameras by police } \\
\text { will improve investigations by providing } \\
\text { much needed evidence (i.e., caught in the act } \\
\text { on video) }\end{array}$ & $2.11(1.08)$ & $2.24(1.28)$ & -0.12 & $-.47, .23$ \\
\hline $\begin{array}{l}\text { The use of body-worn cameras by police } \\
\text { violates my right to privacy }\end{array}$ & $4.52(1.67)$ & $4.26(1.54)$ & 0.16 & $-.19, .50$ \\
\hline $\begin{array}{l}\text { The use of body-worn cameras by police } \\
\text { will increase public trust in the police }\end{array}$ & $3.04(1.45)$ & $2.82(1.16)$ & 0.16 & $-.19, .51$ \\
\hline $\begin{array}{l}\text { I would be willing to pay slightly higher } \\
\text { taxes to ensure my local police service is } \\
\text { equipped with body-worn cameras }\end{array}$ & $3.98(1.79)$ & $3.97(1.95)$ & 0.01 & $-.34, .35$ \\
\hline $\begin{array}{l}\text { A photograph tells the truth by providing an } \\
\text { image }\end{array}$ & $3.32(1.51)$ & $3.11(1.64)$ & 0.14 & $-.21, .49$ \\
\hline $\begin{array}{l}\text { A video recording tells the truth about the } \\
\text { recorded event }\end{array}$ & $2.64(1.25)$ & $2.66(1.23)$ & -0.02 & $-.36, .33$ \\
\hline $\begin{array}{l}\text { A photograph can be altered/manipulated } \\
\text { after the photo has been taken }\end{array}$ & $2.17(1.26)$ & $2.32(1.28)$ & -0.12 & $-.47, .23$ \\
\hline $\begin{array}{l}\text { A video can be altered/manipulated after the } \\
\text { video was recorded }\end{array}$ & $2.68(1.41)$ & $2.39(1.13)$ & 0.21 & $-.14, .56$ \\
\hline $\begin{array}{l}\text { In court, I would view a video recording } \\
\text { from a police officer (via a body-worn } \\
\text { camera) as more credible than a video } \\
\text { recording from a bystander (via a cell phone } \\
\text { or handheld camera) }\end{array}$ & $3.65(1.48)$ & $3.50(1.16)$ & 0.11 & $-.24, .45$ \\
\hline $\begin{array}{l}\text { In court, I would view video evidence of a } \\
\text { potential crime presented by the prosecution } \\
\text { as more credible than video evidence } \\
\text { presented by the defence (the lawyer } \\
\text { representing the accused)? }\end{array}$ & $4.03(1.25)$ & $3.50(1.18)$ & $.43^{*}$ & $.08, .78$ \\
\hline
\end{tabular}


Opinions about BWC Use by Ethnicity (continued)

\begin{tabular}{|c|c|c|c|c|}
\hline \multirow[b]{2}{*}{ Question } & \multicolumn{2}{|c|}{ Mean (SD) } & \multirow[b]{2}{*}{$\begin{array}{l}\text { Hedges' } \\
\text { g }\end{array}$} & \multirow[b]{2}{*}{$95 \% \mathrm{CI}$} \\
\hline & White & $\begin{array}{l}\text { Non- } \\
\text { White }\end{array}$ & & \\
\hline $\begin{array}{l}\text { In court, I would view video evidence of a } \\
\text { potential crime introduced by the judge to be } \\
\text { more credible than video evidence presented } \\
\text { by the prosecution or the defence }\end{array}$ & $3.87(1.27)$ & $3.45(1.13)$ & 0.34 & $-.01, .69$ \\
\hline $\begin{array}{l}\text { A photograph of an incident gives a more } \\
\text { accurate account than eyewitness testimony } \\
\text { of the same incident }\end{array}$ & $3.15(1.39)$ & $2.95(1.27)$ & 0.15 & $-.20, .50$ \\
\hline $\begin{array}{l}\text { A video of an incident from a police issued } \\
\text { body-worn camera gives a more accurate } \\
\text { account than eyewitness testimony of the } \\
\text { same incident }\end{array}$ & $2.61(1.24)$ & $2.68(1.04)$ & -0.06 & $-.41, .29$ \\
\hline $\begin{array}{l}\text { Video produced from body-worn cameras is } \\
\text { consistently of very high visual quality. }\end{array}$ & $3.55(1.27)$ & $3.24(1.03)$ & 0.26 & $-.09, .61$ \\
\hline $\begin{array}{l}\text { Stress of a use of force event can cause } \\
\text { problems with respect to an officer's } \\
\text { memory of the event? }\end{array}$ & $2.81(1.14)$ & $2.55(1.06)$ & 0.23 & $-.12, .58$ \\
\hline $\begin{array}{l}\text { Expert witnesses for the defence are only } \\
\text { hired guns that are there to help get accused } \\
\text { acquitted, even when the evidence suggests } \\
\text { they may be guilty }\end{array}$ & $3.80(1.43)$ & $3.45(1.39)$ & 0.25 & $-.10, .60$ \\
\hline $\begin{array}{l}\text { Experts hired by the Defence or Prosecution } \\
\text { only report what the side that hired them } \\
\text { wants to hear }\end{array}$ & $3.21(1.32)$ & $3.55(1.50)$ & -0.03 & $-.38, .32$ \\
\hline
\end{tabular}

Note. Bold denotes significant above effect size cut-off for Hedges'g; * denotes confidence intervals that are significant as they do not include zero; $M=$ mean; $S D=$ standard deviation; $C I=$ confidence interval; * used a scale from 1 (not at all concerned) to 7 (extremely concerned); responses were given on 7-point Likert scales where 1 = strongly agree, $4=$ neutral, and $7=$ strongly disagree 


\section{Appendix P}

\section{Opinions about BWC Use and Sex}

Table 14

Opinions about BWC Use by Sex

\begin{tabular}{|c|c|c|c|c|}
\hline \multirow{2}{*}{ Question } & \multicolumn{2}{|c|}{ Mean (SD) by Sex } & \multirow{2}{*}{$\begin{array}{l}\text { Hedges' } \\
\text { g }\end{array}$} & \multirow{2}{*}{$95 \% \mathrm{CI}$} \\
\hline & Male & Female & & \\
\hline $\begin{array}{l}\text { How concerned are you with being video- } \\
\text { recorded (including surreptitiously) by other } \\
\text { people?* }\end{array}$ & $3.08(1.97)$ & $2.88(1.86)$ & -0.11 & $-.37, .16$ \\
\hline $\begin{array}{l}\text { How concerned are you with police officers } \\
\text { wearing a device that would video-record } \\
\text { their conduct while performing their duties } \\
\text { in public?*}\end{array}$ & $2.91(2.01)$ & $2.53(1.85)$ & -0.2 & $-.46, .06$ \\
\hline $\begin{array}{l}\text { Police officers wearing a body-worn camera } \\
\text { would improve officer behaviour while on } \\
\text { duty }\end{array}$ & $2.70(1.51)$ & $2.50(1.31)$ & -0.14 & $-.40,-.12$ \\
\hline $\begin{array}{l}\text { Police officers wearing a body-worn camera } \\
\text { would improve citizen behaviour while on } \\
\text { duty }\end{array}$ & $3.10(1.55)$ & $2.98(1.42)$ & -0.08 & $-.34, .18$ \\
\hline BWC recordings should be kept for... & $4.74(2.15)$ & $4.78(2.15)$ & 0.02 & $-.24, .28$ \\
\hline $\begin{array}{l}\text { If police wore body-worn cameras, officers } \\
\text { would be safer }\end{array}$ & $3.24(1.56)$ & $3.09(1.36)$ & -0.1 & $-.36, .16$ \\
\hline $\begin{array}{l}\text { Police should alert people before they record } \\
\text { them with a body-worn camera }\end{array}$ & $3.21(1.75)$ & $3.44(1.80)$ & 0.13 & $-.13, .39$ \\
\hline $\begin{array}{l}\text { Body-worn cameras should be recording at } \\
\text { all times when police are on duty }\end{array}$ & $2.69(1.67)$ & $2.88(1.45)$ & 0.12 & $-.14, .38$ \\
\hline $\begin{array}{l}\text { Body-worn cameras should only record } \\
\text { when police are approaching a possible } \\
\text { incident/potential suspect }\end{array}$ & $3.98(1.95)$ & $3.69(1.91)$ & -0.15 & $-.41, .11$ \\
\hline $\begin{array}{l}\text { Officers should be able to control when a } \\
\text { body-worn camera records }\end{array}$ & $4.83(1.88)$ & $4.60(1.89)$ & -0.12 & $-.38, .14$ \\
\hline $\begin{array}{l}\text { The use of body-worn cameras by police } \\
\text { will make police more accountable for any } \\
\text { misconduct }\end{array}$ & $2.29(1.26)$ & $2.29(1.29)$ & 0 & $-.26, .26$ \\
\hline
\end{tabular}


Opinions about BWC Use by Sex (continued)

\begin{tabular}{|c|c|c|c|c|}
\hline \multirow{2}{*}{ Question } & \multicolumn{2}{|c|}{ Mean (SD) by Sex } & \multirow{2}{*}{$\begin{array}{l}\text { Hedges' } \\
\text { g }\end{array}$} & \multirow{2}{*}{ 95\% CI } \\
\hline & Male & Female & & \\
\hline $\begin{array}{l}\text { The use of body-worn cameras by police } \\
\text { will reduce false misconduct reports against } \\
\text { the police by the public }\end{array}$ & $2.39(1.31)$ & $2.35(1.32)$ & -0.03 & $-.29, .23$ \\
\hline $\begin{array}{l}\text { The use of body-worn cameras by police } \\
\text { will improve investigations by providing } \\
\text { much needed evidence (i.e., caught in the act } \\
\text { on video) }\end{array}$ & $2.26(1.18)$ & $2.03(1.05)$ & -0.21 & $-.47, .05$ \\
\hline $\begin{array}{l}\text { The use of body-worn cameras by police } \\
\text { violates my right to privacy }\end{array}$ & $4.44(1.76)$ & $4.51(1.56)$ & 0.04 & $-.22, .30$ \\
\hline $\begin{array}{l}\text { The use of body-worn cameras by police } \\
\text { will increase public trust in the police }\end{array}$ & $2.89(1.48)$ & $3.09(1.35)$ & 0.14 & $-.12, .40$ \\
\hline $\begin{array}{l}\text { I would be willing to pay slightly higher } \\
\text { taxes to ensure my local police service is } \\
\text { equipped with body-worn cameras }\end{array}$ & $4.00(1.83)$ & $3.67(1.80)$ & -0.18 & $-.44, .08$ \\
\hline $\begin{array}{l}\text { A photograph tells the truth by providing an } \\
\text { image }\end{array}$ & $3.30(1.50)$ & $3.27(1.57)$ & -0.02 & $-.28, .24$ \\
\hline $\begin{array}{l}\text { A video recording tells the truth about the } \\
\text { recorded event }\end{array}$ & $2.75(1.34)$ & $2.55(1.17)$ & -0.16 & $-.42, .01$ \\
\hline $\begin{array}{l}\text { A photograph can be altered/manipulated } \\
\text { after the photo has been taken }\end{array}$ & $2.17(1.20)$ & $2.21(1.31)$ & 0.03 & $-.23, .29$ \\
\hline $\begin{array}{l}\text { A video can be altered/manipulated after the } \\
\text { video was recorded }\end{array}$ & $2.61(1.37)$ & $2.65(1.37)$ & 0.03 & $-.23, .29$ \\
\hline $\begin{array}{l}\text { In court, I would view a video recording } \\
\text { from a police officer (via a body-worn } \\
\text { camera) as more credible than a video } \\
\text { recording from a bystander (via a cell phone } \\
\text { or handheld camera) }\end{array}$ & $3.57(1.50)$ & $3.67(1.37)$ & 0.07 & $-.19, .33$ \\
\hline $\begin{array}{l}\text { In court, I would view video evidence of a } \\
\text { potential crime presented by the prosecution } \\
\text { as more credible than video evidence } \\
\text { presented by the defence (the lawyer } \\
\text { representing the accused)? }\end{array}$ & $3.80(1.34)$ & $4.05(1.17)$ & 0.2 & $-.06, .46$ \\
\hline $\begin{array}{l}\text { In court, I would view video evidence of a } \\
\text { potential crime introduced by the judge to be } \\
\text { more credible than video evidence presented } \\
\text { by the prosecution or the defence }\end{array}$ & $3.64(1.38)$ & $3.93(1.13)$ & 0.23 & $-.03, .49$ \\
\hline
\end{tabular}


Opinions about BWC Use by Sex (continued)

\begin{tabular}{|c|c|c|c|c|}
\hline \multirow{2}{*}{ Question } & \multicolumn{2}{|c|}{ Mean (SD) by Sex } & \multirow{2}{*}{ Hedges'g } & \multirow{2}{*}{$95 \% \mathrm{CI}$} \\
\hline & Male & Female & & \\
\hline $\begin{array}{l}\text { A photograph of an incident gives a more } \\
\text { accurate account than eyewitness testimony } \\
\text { of the same incident }\end{array}$ & $3.05(1.40)$ & $3.17(1.35)$ & 0.09 & $-.17, .35$ \\
\hline $\begin{array}{l}\text { A video of an incident from a police issued } \\
\text { body-worn camera gives a more accurate } \\
\text { account than eyewitness testimony of the } \\
\text { same incident }\end{array}$ & $2.64(1.25)$ & $2.60(1.18)$ & -0.03 & $-.29, .23$ \\
\hline $\begin{array}{l}\text { Video produced from body-worn cameras is } \\
\text { consistently of very high visual quality. }\end{array}$ & $3.43(1.31)$ & $3.55(1.10)$ & 0.1 & $-.16, .36$ \\
\hline $\begin{array}{l}\text { Stress of a use of force event can cause } \\
\text { problems with respect to an officer's } \\
\text { memory of the event? }\end{array}$ & $2.78(1.24)$ & $2.76(1.04)$ & -0.02 & $-.28, .24$ \\
\hline $\begin{array}{l}\text { Expert witnesses for the defence are only } \\
\text { hired guns that are there to help get accused } \\
\text { acquitted, even when the evidence suggests } \\
\text { they may be guilty }\end{array}$ & $3.47(1.47)$ & $3.96(1.35)$ & $.35 *$ & $.09, .61$ \\
\hline $\begin{array}{l}\text { Experts hired by the Defence or Prosecution } \\
\text { only report what the side that hired them } \\
\text { wants to hear }\end{array}$ & $3.35(1.32)$ & $3.64(1.36)$ & 0.22 & $-.05, .48$ \\
\hline
\end{tabular}

Note. $N_{\text {male }}=101, N_{\text {female }}=129$. Bold denotes significant above effect size cut-off for Hedges'g; * denotes confidence intervals that are significant as they do not include zero; $M=$ mean; $S D=$ standard deviation; $C I=$ confidence interval; * used a scale from 1 (not at all concerned) to 7 (extremely concerned); responses were given on 7-point Likert scales where $1=$ strongly agree, $4=$ neutral, and $7=$ strongly disagree 


\section{Appendix Q}

\section{Opinions about BWC Use and Age}

Table 15

Opinions about BWC Use - Regressions for Age

\begin{tabular}{|c|c|c|c|c|}
\hline Question & $b$ & $t$ & $p$ & $95 \%$ CI \\
\hline $\begin{array}{l}\text { How concerned are you with being video-recorded } \\
\text { (including surreptitiously) by other people?* }\end{array}$ & -.03 & -3.50 & .001 & $-.05,-.01$ \\
\hline 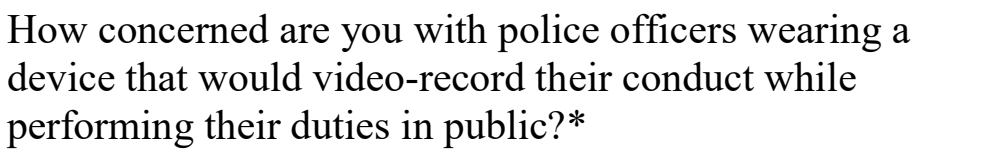 & -.03 & -2.87 & .005 & $-.04,-.01$ \\
\hline $\begin{array}{l}\text { Police officers wearing a body-worn camera would } \\
\text { improve officer behaviour while on duty }\end{array}$ & -.01 & -2.28 & .023 & $-.03,-.00$ \\
\hline $\begin{array}{l}\text { Police officers wearing a body-worn camera would } \\
\text { improve citizen behaviour while on duty }\end{array}$ & -.01 & -1.68 & .095 & $-.02,-.00$ \\
\hline BWC recordings should be kept for... & -.01 & -.74 & .463 & $-.03, .01$ \\
\hline If police wore body-worn cameras, officers would be safer & -.00 & -.62 & .535 & $-.02, .01$ \\
\hline $\begin{array}{l}\text { Police should alert people before they record them with a } \\
\text { body-worn camera }\end{array}$ & .02 & 2.75 & .007 & $.01, .04$ \\
\hline $\begin{array}{l}\text { Body-worn cameras should be recording at all times when } \\
\text { police are on duty }\end{array}$ & .00 & .63 & .532 & $-.01, .02$ \\
\hline $\begin{array}{l}\text { Body-worn cameras should only record when police are } \\
\text { approaching a possible incident/potential suspect }\end{array}$ & -.02 & -1.81 & .072 & $-.03, .00$ \\
\hline $\begin{array}{l}\text { Officers should be able to control when a body-worn } \\
\text { camera records }\end{array}$ & -.01 & -.67 & .503 & $-.02, .01$ \\
\hline $\begin{array}{l}\text { The use of body-worn cameras by police will make police } \\
\text { more accountable for any misconduct }\end{array}$ & -.01 & -1.11 & .269 & $-.02, .01$ \\
\hline $\begin{array}{l}\text { The use of body-worn cameras by police will reduce false } \\
\text { misconduct reports against the police by the public }\end{array}$ & -.01 & -1.54 & .126 & $-.02, .00$ \\
\hline $\begin{array}{l}\text { The use of body-worn cameras by police will improve } \\
\text { investigations by providing much needed evidence (i.e., } \\
\text { caught in the act on video) }\end{array}$ & -.01 & -2.70 & .007 & $-.02,-.00$ \\
\hline $\begin{array}{l}\text { The use of body-worn cameras by police violates my right } \\
\text { to privacy }\end{array}$ & .03 & 3.75 & $<.001$ & $.01, .04$ \\
\hline $\begin{array}{l}\text { The use of body-worn cameras by police will increase } \\
\text { public trust in the police }\end{array}$ & .00 & -.05 & .962 & $-.01, .01$ \\
\hline
\end{tabular}


Opinions about BWC Use - Regressions for Age (continued)

\begin{tabular}{|c|c|c|c|c|}
\hline Question & $\boldsymbol{b}$ & $t$ & $p$ & $95 \% \mathrm{CI}$ \\
\hline $\begin{array}{l}\text { I would be willing to pay slightly higher taxes to ensure } \\
\text { my local police service is equipped with body-worn } \\
\text { cameras }\end{array}$ & -.01 & -.71 & .477 & $-.02, .01$ \\
\hline A photograph tells the truth by providing an image & -.00 & -.61 & .541 & $-.02, .01$ \\
\hline A video recording tells the truth about the recorded event & .00 & .27 & .787 & $-.01, .01$ \\
\hline $\begin{array}{l}\text { A photograph can be altered/manipulated after the photo } \\
\text { has been taken }\end{array}$ & .01 & 1.97 & .05 & $.00, .02$ \\
\hline $\begin{array}{l}\text { A video can be altered/manipulated after the video was } \\
\text { recorded }\end{array}$ & .01 & .90 & .370 & $-.01, .02$ \\
\hline $\begin{array}{l}\text { In court, I would view a video recording from a police } \\
\text { officer (via a body-worn camera) as more credible than a } \\
\text { video recording from a bystander (via a cell phone or } \\
\text { handheld camera) }\end{array}$ & -.01 & -1.00 & .321 & $-.02, .01$ \\
\hline $\begin{array}{l}\text { In court, I would view video evidence of a potential crime } \\
\text { presented by the prosecution as more credible than video } \\
\text { evidence presented by the defence (the lawyer representing } \\
\text { the accused)? }\end{array}$ & .01 & 1.39 & .167 & $-.01, .02$ \\
\hline $\begin{array}{l}\text { In court, I would view video evidence of a potential crime } \\
\text { introduced by the judge to be more credible than video } \\
\text { evidence presented by the prosecution or the defence }\end{array}$ & .01 & 1.63 & .104 & $-.00, .02$ \\
\hline $\begin{array}{l}\text { A photograph of an incident gives a more accurate account } \\
\text { than eyewitness testimony of the same incident }\end{array}$ & -.01 & -1.69 & .093 & $-.02, .00$ \\
\hline $\begin{array}{l}\text { A video of an incident from a police issued body-worn } \\
\text { camera gives a more accurate account than eyewitness } \\
\text { testimony of the same incident }\end{array}$ & -.01 & -1.69 & .094 & $-.02, .00$ \\
\hline $\begin{array}{l}\text { Video produced from body-worn cameras is consistently } \\
\text { of very high visual quality. }\end{array}$ & .01 & 1.67 & .097 & $-.01, .02$ \\
\hline $\begin{array}{l}\text { Stress of a use of force event can cause problems with } \\
\text { respect to an officer's memory of the event? }\end{array}$ & .00 & .03 & .980 & $-.01, .01$ \\
\hline $\begin{array}{l}\text { Expert witnesses for the defence are only hired guns that } \\
\text { are there to help get accused acquitted, even when the } \\
\text { evidence suggests they may be guilty }\end{array}$ & -.01 & -1.74 & .083 & $-.02, .00$ \\
\hline $\begin{array}{l}\text { Experts hired by the Defence or Prosecution only report } \\
\text { what the side that hired them wants to hear }\end{array}$ & -.01 & -.81 & .416 & $-.02, .01$ \\
\hline
\end{tabular}

Note. Bold denotes statistically significant results of $p<.05 . B=$ regression coefficient; $t$

=t-test; $p$ = probability; $C I=$ confidence interval; * used a scale from 1 (not at all 
concerned) to 7 (extremely concerned); responses used a 7-point Likert scale where $1=$ strongly agree to $7=$ strongly disagree 
Table 16

Opinions about BWC Use - Significant Results for Age and Nominal Regressions of Responses

\begin{tabular}{|c|c|c|c|c|c|c|}
\hline Question & Answer & Wald & $b$ & OR & $p$ & 95\% CIs \\
\hline $\begin{array}{l}\text { An officer testifies in a use of force } \\
\text { court case that he was standing beside } \\
\text { a bush, but a video of the incident } \\
\text { shows it was a mailbox. Would your } \\
\text { tendency be to view this officer as } \\
\text { dishonest, mistaken or not sure? }\end{array}$ & $\begin{array}{l}\text { dishonest } \\
\text { vs. not sure } \\
\text { dishonest } \\
\text { vs. mistaken }\end{array}$ & 15.75 & .05 & 1.05 & .000 & $1.03-1.08$ \\
\hline $\begin{array}{l}\text { An officer testifies in a use of force } \\
\text { court case that the suspect was } \\
\text { lunging at him with a bat, but the } \\
\text { video shows the suspect was walking } \\
\text { with a bat. Would your tendency be to } \\
\text { view this officer as dishonest, } \\
\text { mistaken or not sure? }\end{array}$ & $\begin{array}{l}\text { dishonest } \\
\text { vs. not sure }\end{array}$ & 2.59 & .02 & 1.02 & .108 & $1.00,1.04$ \\
\hline \multirow{2}{*}{$\begin{array}{l}\text { Can a camera capture depth } \\
\text { perception? }\end{array}$} & no vs. yes & 3.53 & -.02 & .98 & .060 & $.95,1.00$ \\
\hline & $\begin{array}{l}\text { no vs. } \\
\text { don't know }\end{array}$ & .59 & .01 & 1.01 & .441 & $.99,1.03$ \\
\hline \multirow[t]{2}{*}{ Can a video capture depth perception? } & no vs. yes & .42 & .01 & 1.01 & .516 & $.98,1.04$ \\
\hline & $\begin{array}{l}\text { no vs. } \\
\text { don't know }\end{array}$ & 4.77 & .04 & 1.04 & .029 & $1.00-1.07$ \\
\hline \multirow{2}{*}{$\begin{array}{l}\text { Can a camera capture a scene in poor } \\
\text { lighting or darkness better than the } \\
\text { human eye can see? }\end{array}$} & no vs. yes & .35 & -.01 & 1.00 & .56 & $.97,1.02$ \\
\hline & $\begin{array}{l}\text { no vs. } \\
\text { don't know }\end{array}$ & 1.84 & .02 & 1.02 & .18 & $1.00,1.04$ \\
\hline \multirow{2}{*}{$\begin{array}{l}\text { Can a video recorder record a scene in } \\
\text { poor lighting or darkness better than } \\
\text { the human eye can see? }\end{array}$} & no vs. yes & .58 & .01 & 1.01 & .448 & $.99,1.03$ \\
\hline & $\begin{array}{l}\text { no vs. } \\
\text { don't know }\end{array}$ & 2.76 & .02 & 1.02 & .097 & $1.00,1.04$ \\
\hline \multirow{2}{*}{$\begin{array}{l}\text { Can a video recorder record a scene as } \\
\text { fast as the human visual system can } \\
\text { process that scene? }\end{array}$} & no vs. yes & 2.26 & .02 & 1.02 & .133 & $.99,1.05$ \\
\hline & $\begin{array}{l}\text { no vs. } \\
\text { don't know }\end{array}$ & 1.53 & .02 & 1.02 & .217 & $.99,1.04$ \\
\hline $\begin{array}{l}\text { Can a video recorder pick up on subtle } \\
\text { threat cues (for example, tensing of a }\end{array}$ & no vs. yes & .07 & .00 & 1.00 & .792 & $.98,1.03$ \\
\hline $\begin{array}{l}\text { suspect's body, flash of metal), the } \\
\text { same as the human visual system can? }\end{array}$ & $\begin{array}{l}\text { no vs. } \\
\text { don't know }\end{array}$ & .35 & .01 & 1.01 & .555 & $.99,1.03$ \\
\hline
\end{tabular}

Note. Bold denotes statistically significant findings $p<.05 . B=$ regression coefficient; $O R=$ odds ratio; $p=$ probability; $C I=$ confidence interval 
Table 17

Opinions about BWC Use - Odds Ratio

\begin{tabular}{lccccc}
\hline Question & Wald & $\boldsymbol{b}$ & OR & $\boldsymbol{p}$ & $\mathbf{9 5 \%}$ CIs \\
\hline $\begin{array}{l}\text { During an incident where a police officer had to use } \\
\text { force on a suspect, the officer said they turned on }\end{array}$ & .64 & .01 & 1.01 & .422 & $1.00,1.03$ \\
their body-worn camera, but it did not record. If you & & & & & \\
$\begin{array}{l}\text { were to hear this explanation in a court case } \\
\text { involving allegations of excessive use of force by the } \\
\text { police officer, would your tendency be to view this } \\
\text { officer as dishonest, mistaken or other? }\end{array}$ & & & & & \\
\hline
\end{tabular}

Note. The third response selection "Other" proved to be invalid due to people answering dishonest or mistaken when specifying why they chose other, making this response redundant and inaccurate as it could represent an interpretation of either dishonest or mistaken. Therefore, the "Other" selection was removed and a binary logistic regression was run for the above question responses of dishonest or telling the truth (mistaken). $B=$ regression coefficient; $O R=$ odds ratio; $p=$ probability; $C I=$ confidence interval 


\section{Appendix R}

\section{PL Subscale Results}

Table 18

Predicting effects of police legitimacy subscales on verdict-Summary of logistic regression

\begin{tabular}{lccccc}
\hline \multicolumn{1}{c}{ Predictor } & Wald & b & $\boldsymbol{p}$ & OR & $\mathbf{9 5 \%}$ CI \\
\hline PL Lawfulness & 5.869 & -.352 & .015 & .703 & $.53, .94$ \\
PL Procedural Fairness & 5.750 & -.397 & .016 & .672 & $.49, .93$ \\
PL Distributive Fairness & .198 & -.061 & .941 & .941 & $.72,1.23$ \\
PL Police Effectiveness & .559 & -.073 & .930 & .930 & $.77,1.13$ \\
& & & & & \\
\hline $\begin{array}{l}\text { P = regression coefficient, } p=\text { probability, OR }=\text { odds ratio, CI= confidence interval, } \\
P L=\text { Police Legitimacy scale }\end{array}$
\end{tabular}

Table 19

Predicting effects of police legitimacy subscales and need for cognition on severity of punishment - Summary of regression

\begin{tabular}{lccccc}
\hline Predictor & $\mathbf{b}$ & $\mathbf{S E}$ & $\boldsymbol{\beta}$ & $\boldsymbol{p}$ & $\mathbf{9 5 \%} \mathbf{C I}$ \\
\hline PL Lawfulness & -.400 & .138 & -.185 & .004 & $-.67,-.13$ \\
PL Procedural Fairness & -.313 & .161 & -.145 & .052 & $-.63, .00$ \\
PL Distributive Fairness & .065 & .139 & .030 & .642 & $-.21, .34$ \\
PL Police Effectiveness & -.086 & .099 & -.039 & .385 & $-.28, .11$ \\
& & & & & \\
\hline $\begin{array}{l}b=\text { regression coefficient, SE = standard error, } \beta=\text { standardized correlation coefficient, } \\
p=\text { probability, CI = confidence interval, } P L=\text { Police Legitimacy scale }\end{array}$
\end{tabular}


Table 20

Predicting effects of police legitimacy subscales and need for cognition on defendant credibility - Summary of regression

\begin{tabular}{lccccc}
\hline Predictor & $\mathbf{b}$ & $\mathbf{S E}$ & $\boldsymbol{\beta}$ & $\boldsymbol{p}$ & $\mathbf{9 5 \%}$ CI \\
\hline PL Lawfulness & .182 & .076 & .131 & .017 & $.03, .33$ \\
PL Procedural Fairness & .220 & .087 & .158 & .011 & $.05, .39$ \\
PL Distributive Fairness & .222 & .075 & .160 & .003 & $.08, .37$ \\
PL Police Effectiveness & -.021 & .052 & -.015 & .688 & $-.12, .08$ \\
& & & & & \\
\hline $\begin{array}{l}b=\text { regression coefficient, SE = standard error, } \beta=\text { standardized correlation coefficient, } \\
p=\text { probability, CI = confidence interval, PL }=\text { Police Legitimacy scale }\end{array}$
\end{tabular}

Table 21

Predicting effects of police legitimacy subscales and need for cognition on defendant persuasiveness - Summary of regression

\begin{tabular}{lccccc}
\hline Predictor & b & SE & $\boldsymbol{\beta}$ & $\boldsymbol{p}$ & $\mathbf{9 5 \%}$ CI \\
\hline PL Lawfulness & .123 & .080 & .088 & .126 & $-.03, .28$ \\
PL Procedural Fairness & .241 & .091 & .173 & .008 & $.06, .42$ \\
PL Distributive Fairness & .058 & .078 & .042 & .459 & $-.10, .21$ \\
PL Police Effectiveness & .077 & .055 & .055 & .158 & $-.03, .19$
\end{tabular}

$b=$ regression coefficient, $S E=$ standard error, $\beta=$ standardized correlation coefficient, $p=$ probability, $C I=$ confidence interval, $P L=$ Police Legitimacy scale, $N C$ = Need for Cognition Short Form scale 